\title{
SUSTAINABLE FINANCE
}

PROGRAMME

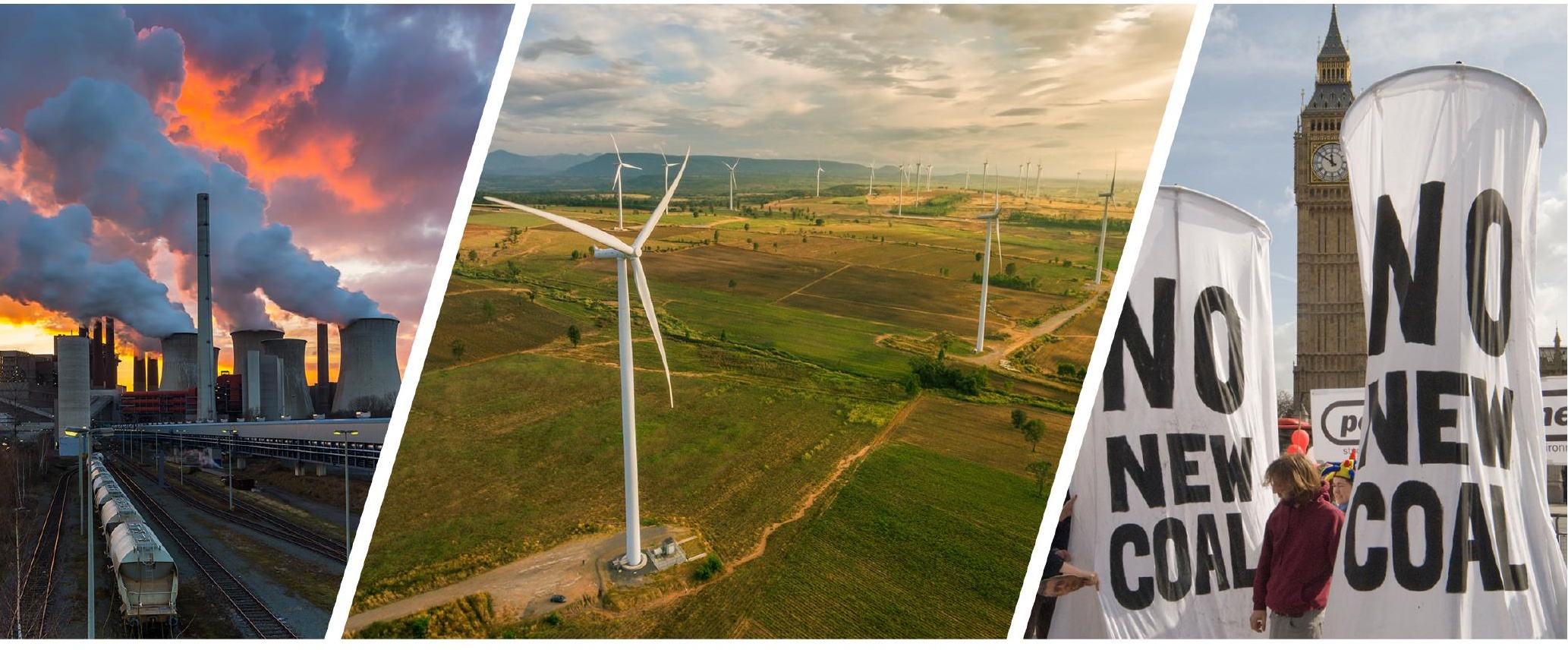

The fate of European coal-fired power stations planned in the mid-2000s: Insights for policymakers, companies, and investors considering new coal Working Paper August 2017

Authors: Ben Caldecott | Daniel J. Tulloch | Geraldine Bouveret | Alex Pfeiffer | Lucas Kruitwagen | Jeremy McDaniels | Gerard Dericks 


\section{About the Sustainable Finance Programme}

The Sustainable Finance Programme at the University of Oxford Smith School of Enterprise and the Environment (the "Oxford Smith School") aims to be the world's leading centre for research and teaching on sustainable finance and investment. The Programme was established in 2012 to understand the requirements, challenges, and opportunities associated with a reallocation of capital towards investments aligned with global environmental sustainability.

We research environment-related risk and opportunity across different sectors, geographies, and asset classes; how such factors are emerging and how they positively or negatively affect asset values; how such factors might be interrelated or correlated; their materiality (in terms of scale, impact, timing, and likelihood); who will be affected; and what affected groups can do to pre-emptively manage risk. We have conducted pioneering research on stranded assets and remain the only academic institution conducting work in a significant and coordinated way on the topic.

The production of high-quality research on the materiality of environment-related factors is a necessary, though insufficient, condition for these factors to be successfully integrated into decision-making. Consequently, we develop the data, analytics, frameworks, and models required to enable the integration of this information. We have particular expertise in asset-level data, spatial analysis, scenarios, and stress tests, and also focus on how information is presented and used.

We also research barriers to the adoption of practices related to sustainable finance and investment. This includes the role of policy, regulation, governance, incentives, behaviours, and norms in shaping investment decisions and capital allocation.

The Programme is based in a world leading university with a global reach and reputation. We work with leading practitioners from across the investment chain (including actuaries, asset owners, asset managers, accountants, banks, data providers, investment consultants, lawyers, ratings agencies, stock exchanges), with firms and their management, and with experts from a wide range of related subject areas (including finance, economics, management, geography, anthropology, climate science, law, area studies, psychology) within the University of Oxford and beyond. 


\section{Global Advisory Council}

The Global Sustainable Finance Advisory Council has been created to guide our work and is chaired by Professor Gordon L. Clark, Director of the Oxford Smith School. It also provides a high-level forum for work on sustainable finance and stranded assets to be co-ordinated internationally. Members currently include:

Jane Ambachtsheer, Partner and Global Head of Responsible Investment, Mercer Investment Rob Bailey, Research Director, Energy, Environment and Resources, Chatham House Vicki Bakhshi, Head of Governance \& Sustainable Investment, BMO Global Asset Management (EMEA) Morgan Bazilian, Affiliate Professor, The Royal Institute of Technology of Sweden

David Blood, Co-Founder and Senior Partner, Generation IM

Yvo de Boer, President, Sustainability Challenge Foundation

Susan Burns, Founder and CEO, Global Footprint Network

James Cameron, Chairman, Overseas Development Institute

Diana Fox Carney, Pi Capital

Mike Clark, Institute and Faculty of Actuaries

Rowan Douglas, Head, Capital Science and Policy Practice, Willis Towers Watson

Professor Robert Eccles, Visiting Professor of Management Practice, Saïd Business School, University of Oxford Emily Farnworth, Head of Climate Initiatives, World Economic Forum

Jessica Fries, Executive Chairman, The Prince's Accounting for Sustainability Project (A4S)

Ben Goldsmith, CEO, Menhaden Capital

Kristin Halvorsen, Director, Center for International Climate and Environmental Research (CICERO) and former Norwegian Minister of Finance

Connie Hedegaard, Chair, KR Foundation, and former European Commissioner for Climate Action

Thomas Heller, Chairman of the Board and Founder, Climate Policy Initiative

Anthony Hobley, CEO, Carbon Tracker Initiative

Christina Hood, Head of Unit, Environment and Climate Change, International Energy Agency

Andrew Howard, Head of Sustainable Research, Schroder Investment Management

Catherine Howarth, CEO, ShareAction

Zoe Knight, Head, Climate Change Centre of Excellence, HSBC

Bernice Lee, Executive Director, Hoffmann Centre for the Sustainable Resource Economy, Chatham House

Bob Litterman, Senior Partner and Chairman of Risk Committee, Kepos Capital

Mindy Lubber, President, Ceres

Nick Mabey, CEO, E3G

Richard Mattison, CEO, Trucost

Stephanie Pfeifer, CEO, Institutional Investors Group on Climate Change

Fiona Reynolds, Managing Director, UN Principles for Responsible Investment

Nick Robins, Co-Director, UNEP Inquiry into a Sustainable Financial System

Paul Simpson, CEO, Carbon Disclosure Project

Andrew Steer, President and CEO, World Resources Institute

James Thornton, CEO, ClientEarth

Simon Upton, Director, Environment Directorate, OECD

Steve Waygood, Chief Responsible Investment Officer, Aviva Investors

Peter Wheeler, Executive Vice President, The Nature Conservancy (TNC)

Michael Wilkins, Managing Director, Infrastructure Finance Ratings, Standard \& Poor's

Baroness Bryony Worthington, Executive Director Europe, Environmental Defense Fund

Professor Wang Yao, Director General, International Institute of Green Finance, Central University of Finance and Economics 


\section{About the Authors}

Ben Caldecott is Director of the Sustainable Finance Programme. He is concurrently an Adviser to The Prince of Wales's Accounting for Sustainability Project, an Academic Visitor at the Bank of England, and a Visiting Scholar at Stanford University.

Daniel J. Tulloch is an Honorary Research Associate in the Sustainable Finance Programme and was previously a Postdoctoral Research Associate there. Daniel holds a Ph.D. in Finance from the University of Otago, New Zealand. He also holds an M.Sc. in International Accounting and Financial Management from the University of East Anglia, Norwich.

Geraldine Bouveret is a Postdoctoral Research Associate in the Sustainable Finance Programme. Geraldine holds a Ph.D. in Mathematics (specialising in Financial Mathematics) from Imperial College London. She also holds a Master Degree in Finance from ESSEC Business School and a Master Degree in Mathematics from Université Paris Dauphine and ENSAE ParisTech.

Alexander Pfeiffer is a Research Assistant in the Sustainable Finance Programme and a D.Phil. Student in the University of Oxford School of Geography and the Environment. He holds a M.Sc. in Business Administration and Management from the University of Mannheim in Germany. Prior to his D.Phil., he worked between 2011-14 for McKinsey \& Company, Inc. in Germany and has further work experience from occupations at KPMG and UBS Investment Bank.

Lucas Kruitwagen is a Research Assistant in the Sustainable Finance Programme and a D.Phil. Student in the University of Oxford School of Geography and the Environment. He is also a Visiting Researcher at Imperial College London's Centre for Environmental Policy. He holds an MSc (Distinction) from Imperial College London and a B.Eng. from McGill University where he was a Loran Scholar.

Jeremy McDaniels is a Senior Analyst at the UNEP Inquiry into the Design of a Sustainable Financial System. He is a former Research Assistant in the Sustainable Finance Programme. He is a graduate of Oxford's M.Sc. in Environmental Change and Management (Distinction), and holds a B.A. from the University of British Columbia.

Gerard Dericks is a Postdoctoral Research Associate in the Sustainable Finance Programme. Prior to joining the Oxford Smith School, he was an analyst at Property Market Analysis LLP and research consultant for Policy Exchange in London. He holds a Ph.D. and M.Sc. from the London School of Economics and a B.A. from Ritsumeikan University.

\section{Acknowledgements}

We would like to thank the European Climate Foundation for providing a grant to support this research and the reviewers for their feedback.

\section{Working Paper Series}

This Working Paper is intended to stimulate discussion within the research community and among users of research. The views expressed in this paper represent those of the author(s) and do not necessarily represent those of the host institutions or funders.

\section{University of Oxford Disclaimer}

The Chancellor, Masters, and Scholars of the University of Oxford make no representations and provide no warranties in relation to any aspect of this publication, including regarding the advisability of investing in any particular company or investment fund or other vehicle. While we have obtained information believed to be reliable, neither the University, nor any of its employees, students, or appointees, shall be liable for any claims or 
losses of any nature in connection with information contained in this document, including but not limited to, lost profits or punitive or consequential damages. 


\section{Table of Contents}

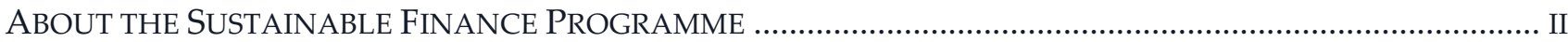

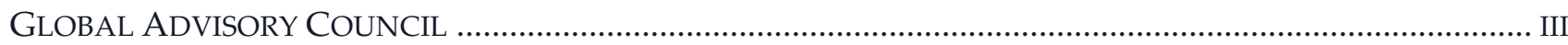

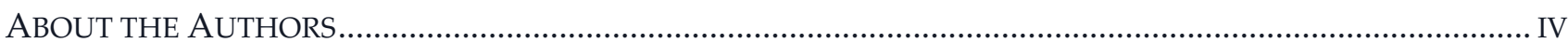

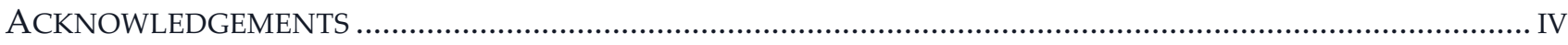

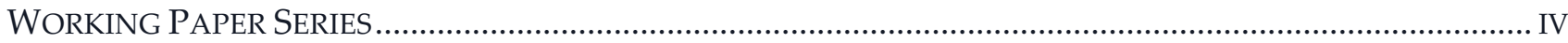

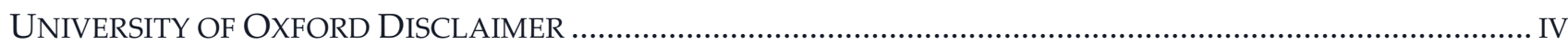

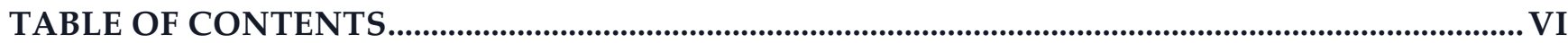

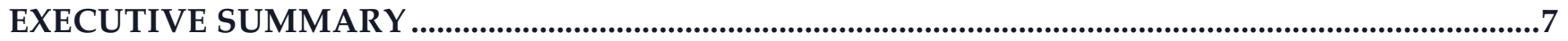

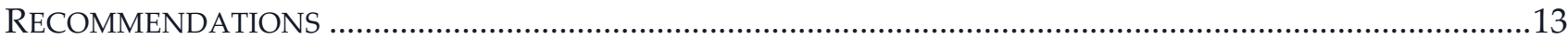

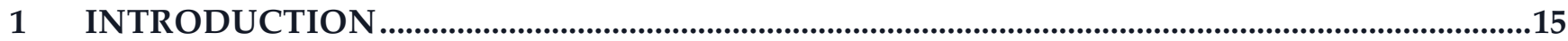

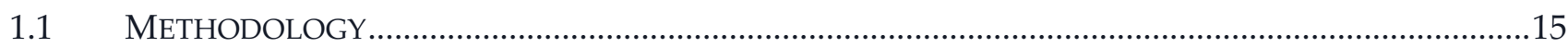

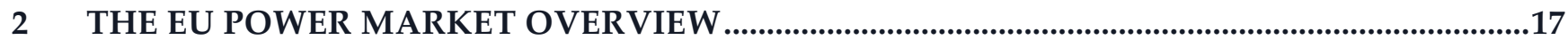

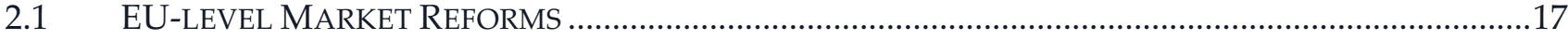

2.2 WHOLESALE POWER MARKETS: THE ENERGY-ONLY MARKET …...............................................19

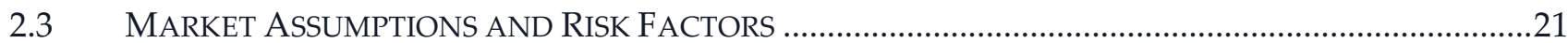

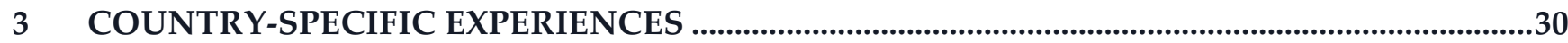

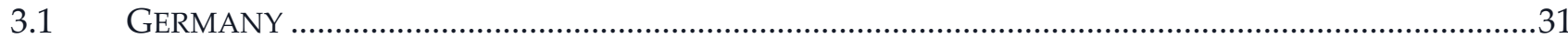

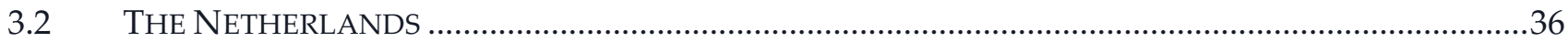

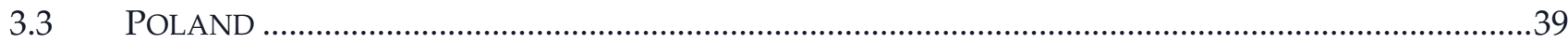

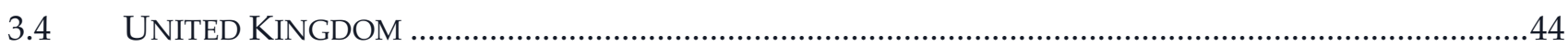

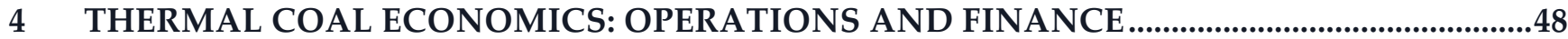

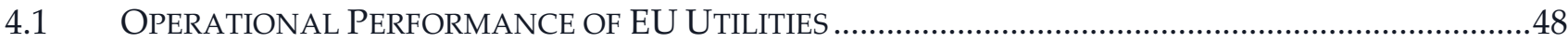

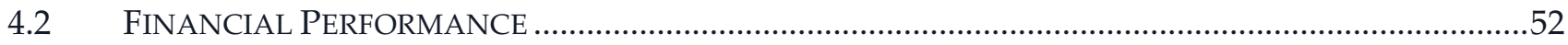

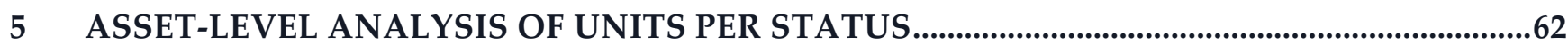

5.1 STEAM CONDITIONS - COAL-FIRED GENERATING TECHNOLOGIES .............................................62

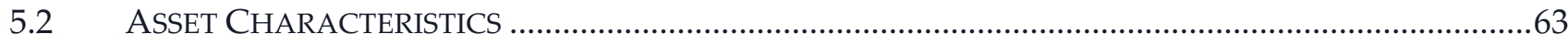

6 GOING FORWARD: UTILITIES' PROSPECTS AND RESPONSES ...........................................68

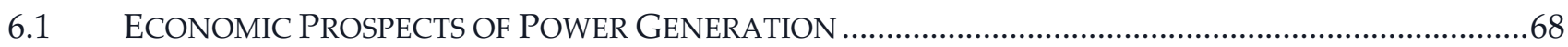

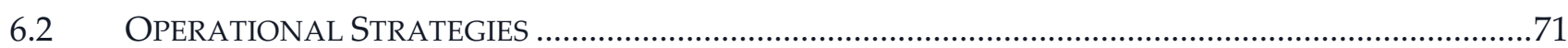

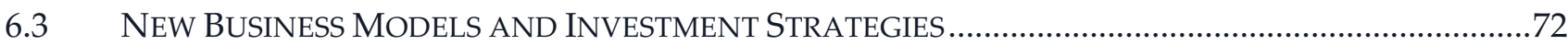

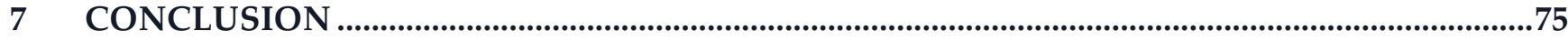

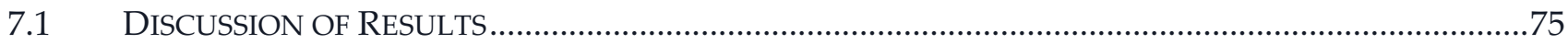

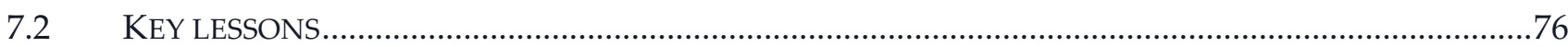

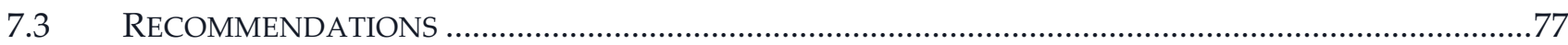

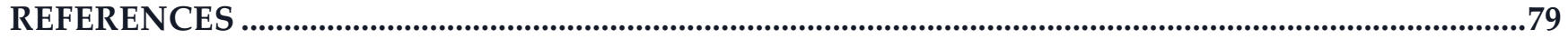




\section{Executive Summary}

Between 2005 and 2008 EU utilities were determined to embark on a major coal-plant construction programme. They announced plans to build $49 \mathrm{GW}$ of new coal-fired power capacity, about $6.3 \%$ of total EU installed generating capacity. The majority of proposed coal plants were located in Germany ( $>20 \mathrm{GW})$, the United Kingdom (>7 GW), the Netherlands ( $>4 \mathrm{GW})$, and Poland $(>3 \mathrm{GW})$.

Yet post-2008, only $10.5 \mathrm{GW}$ of this planned capacity became operational, $37.8 \mathrm{GW}(77 \%)$ was cancelled, and there remains 1.1 GW still in planning unlikely to ever be built. The capacity that was built has suffered from significant write-downs (see figures below) and has weighed down the balance sheets of conventional utilities, contributing to the sector's general malaise and financial underperformance. The significant financial, human, and organisational capital wasted taking forward so many coal projects through the development process was also a major distraction for utilities just as the European power system entered an unprecedented period of technology, policy and market innovation.

There are a number of important questions that stem from this: why did the majority of plant proposals not go ahead; what makes the projects that did proceed different; what challenges are these new plants likely to face now and in the future; and to what extent are the projects that did succeed likely to become stranded generation assets? The results are relevant not just to understanding the fate of the remaining coal-fired power stations in Europe, but also the future of those currently planned or being built in other countries. This working paper examines each of these questions in turn.

\section{EU 2005-08 Planned Coal Plant Status ${ }^{1}$}

\begin{tabular}{|c|c|c|c|c|c|}
\hline & $\begin{array}{c}\text { Planned } \\
\text { (MW) }\end{array}$ & $\begin{array}{c}\text { Operational } \\
\text { (MW) }\end{array}$ & $\begin{array}{c}\text { Outstanding } \\
(\mathbf{M W})\end{array}$ & $\begin{array}{c}\text { Cancelled } \\
(\mathbf{M W})\end{array}$ & $\begin{array}{c}\text { Cancelled Rate } \\
(\%)\end{array}$ \\
\hline Germany & 20,352 & 4,922 & 1,100 & 14,330 & $70 \%$ \\
\hline Netherlands & 4,470 & 3,470 & 0 & 1,000 & $22 \%$ \\
\hline Poland & 3,408 & 858 & 0 & 2,550 & $75 \%$ \\
\hline United Kingdom & 7,090 & 0 & 0 & 7,090 & $100 \%$ \\
\hline Other EU (14 states) & 14,109 & 1,260 & 0 & 12,849 & $91 \%$ \\
\hline Total & $\mathbf{4 9 , 4 2 9}$ & $\mathbf{1 0 , 5 1 0}$ & $\mathbf{1 , 1 0 0}$ & $\mathbf{3 7 , 8 1 9}$ & $\mathbf{7 7 \%}$ \\
\hline
\end{tabular}

\section{Which Plants Were Built and Why Others Were Cancelled}

Of the 65 coal-fired power plants planned between 2005-08, only 11 made it to market. Much of the built coal-fired power plants occurred in Germany, Poland, and the Netherlands. In Germany and Poland, coal-fired power generation retained competitiveness against gas-fired generation, despite coal being the emission intensive of the two fuels. Further, both countries had ample domestic coal reserves which could contribute to national energy security. Six of the built plants were located directly adjacent to local coal mines. Countries with large indigenous coal reserves, particularly lignite, were more likely to ultimately build coal capacity. The Netherlands is an exception, but has large volumes of coal that pass through its Rotterdam port.

The political environment of all three countries (Germany, Poland, and the Netherlands) was conducive to building additional coal-fired power assets. We find that much of the coal-fired capacity which made it to market

1 Platts WEPP Database: Q4 2007, Q2 2016, European Climate Foundation database. 
was considered 'clean coal'; especially in the Netherlands, which previously positioned itself as a nation which only built 'clean coal'. The five new German and three new Dutch plants only burn less polluting bituminous coal. In addition, all the coal plants that were not cancelled utilised more efficient supercritical or ultra-supercritical generation technologies. By contrast, of the 53 coal plants that were cancelled, at least 11 had planned to use subcritical technology. ${ }^{2}$ Among those 11 subcritical plants 3 were in the UK. Poland ended up building only a single coal-fired plant, which burned lignite: a more polluting and $\mathrm{CO}_{2}$-intensive type of coal. Therefore, it appears that plants which were bigger, from larger companies, and which were using less polluting fuel, and more efficient technology with pollution controls were the most likely to be built. This pushed up average capital costs, implying higher sunk costs.

\section{Optimism Bias in Investment Decisions}

In the 2005 to 2008 period, market conditions appeared favourable for expanding coal-fired generation. The EU experienced increasing GDP growth (which was historically associated with increased energy demand) and increases in forecasted electricity demand. Furthermore, forecasts predicted a relative decline in the price of coal, suggesting that the fuel costs of coal-fired power generation would be lower in the future. Utilities also had positive growth forecasts and access to relatively cheap debt, which encouraged capacity expansion.

The cumulative impact of these factors increased the likelihood of optimism bias, which encouraged many power utilities to propose an expansion of the coal-fired fleet. The expansion of coal was preferable as it was a 'trialled and tested' technology in the EU, and some EU member states had ample coal-reserves to exploit.

Instead, the post-2008 period was defined by a decoupling of GDP and energy demand, lower electricity demand than forecast, and electricity overcapacity due to the over expansion of various generating technologies. Moreover, the expansion of renewable capacity depressed wholesale electricity prices and resulted in the underutilisation of existing coal-fired capacity. With such a dramatic shift in the operating environment, the vast majority of planned coal-fired projects were cancelled. For some, the net present value of finalising and bringing these assets online to operate them for several years still seemed higher than the net present value of cancelling the projects in their current state and absorbing the sunk costs. Hence, mainly highly efficient (and co-generating) capacity went online, adding to the overcapacities in the European system.

\footnotetext{
2 Data on combustion technologies is available for 45 of the 65 plants.
} 


\section{EU Realised and Forecast Electricity Generation, 2000-20403}

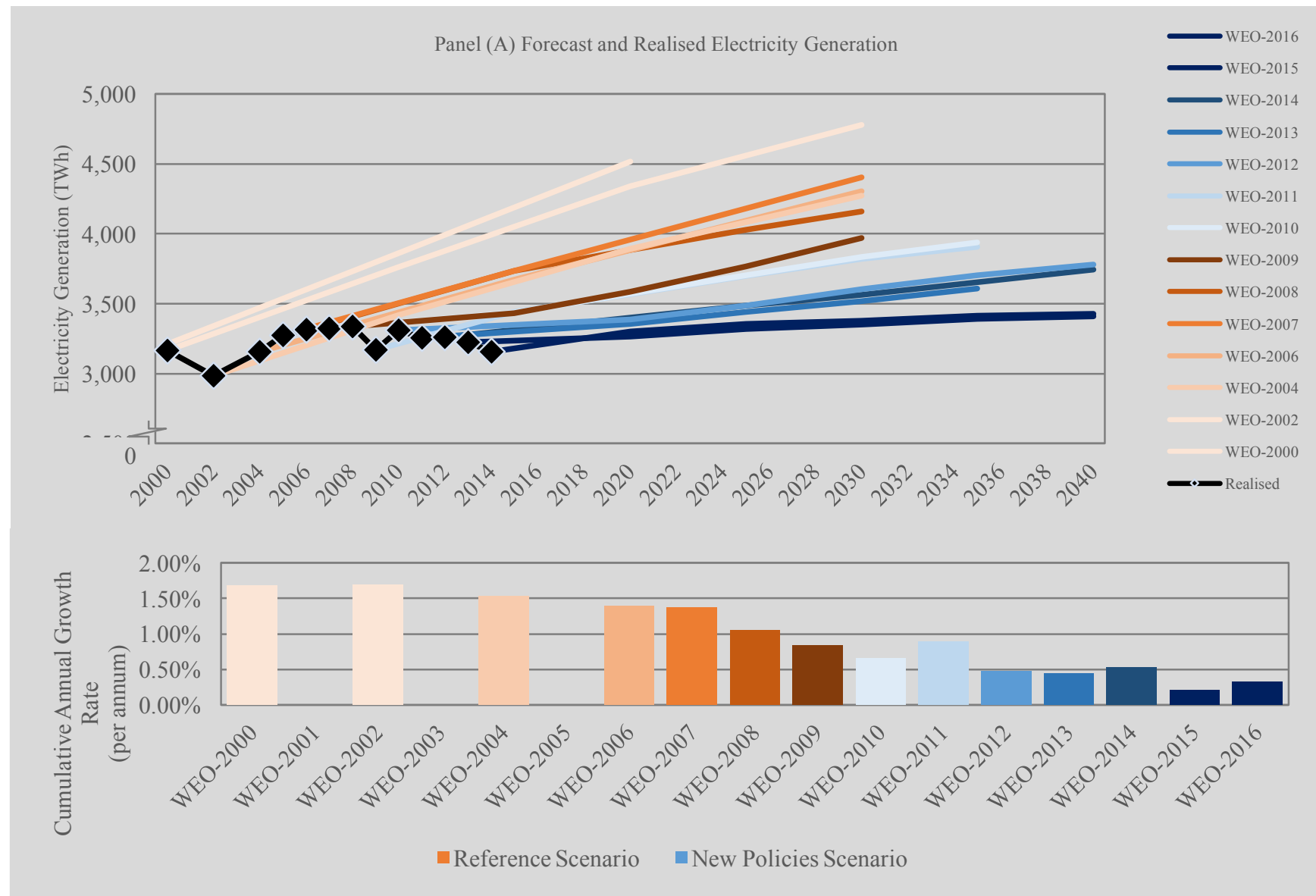

Panel (A) illustrates the realised and forecast electricity generation extracted from 2000-2016 annual IEA's World Energy Outlook (WEO) reports. Data is extracted for the European Union. The black line with markets illustrates the realised electricity generation, extracted from WEO reports. The coloured lines represent the forecast electricity generation. IEA presents 'Reference Scenario' forecasts as the core scenario between 2000 and 2009, illustrated with orange lines. IEA presents 'New Policies Scenarios' forecasts as the core scenario from 2010 onwards, illustrated with blue lines. Cumulative Annual Growth Rate in Panel B is calculated as the slope between the WEO realised capacity (or nearest capacity forecast where applicable) and furthest WEO capacity forecast.

${ }^{3}$ IEA World Energy Outlook. 


\section{EU Realised and Forecast Capacity, 2000-20404}

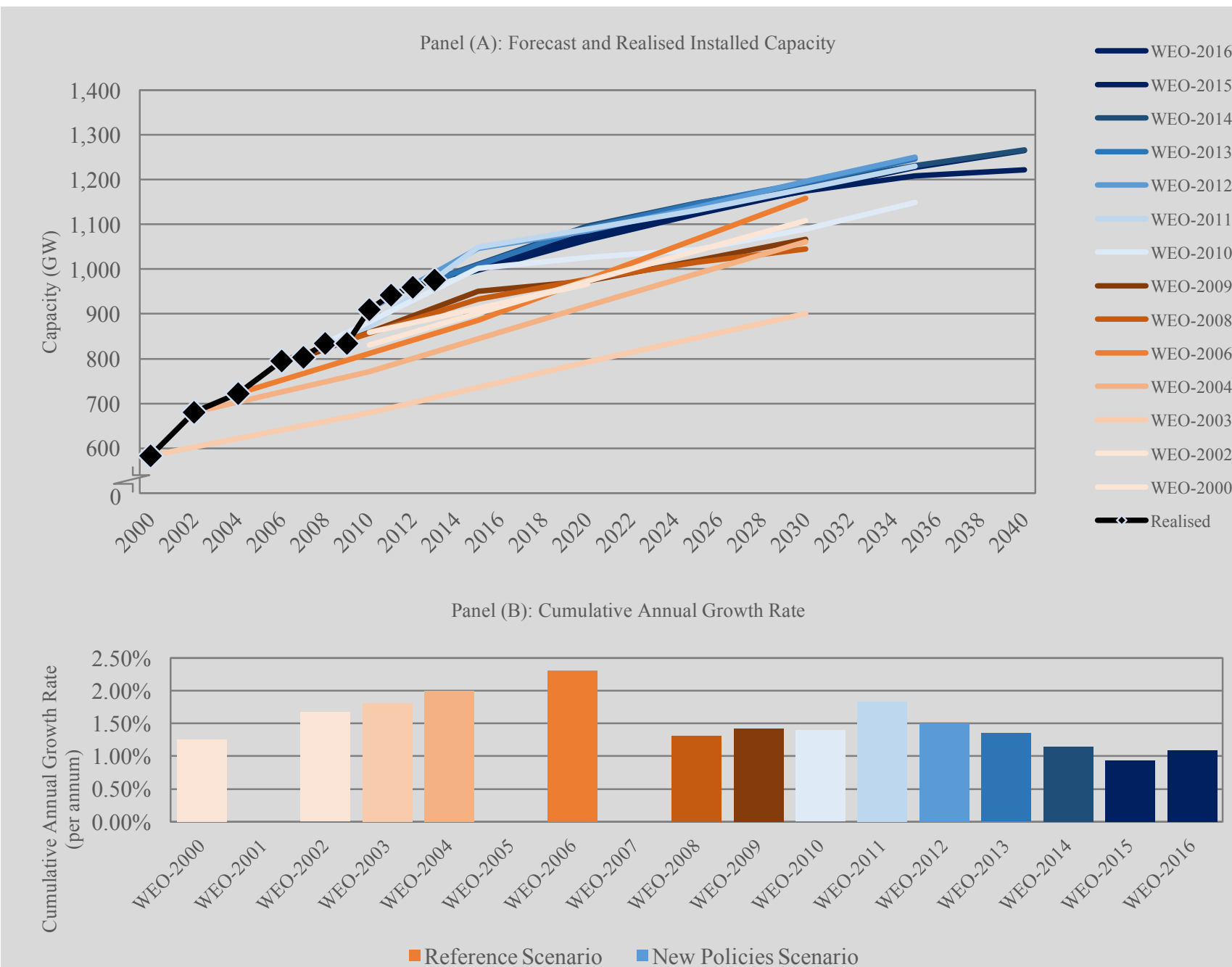

This figure illustrates the realised and forecast capacity extracted from annual IEA's World Energy Outlook (WEO) reports between 2000 and 2015. Data is extracted for the European Union. IEA reports 'Reference Scenario' as the core scenario between 2000 and 2009, illustrated in Orange. IEA reports 'New Policies Scenarios' as the core scenario from 2010 onwards, illustrated in Blue. Realised data is extracted from WEO reports. Cumulative Annual Growth Rate is calculated as the slope between the WEO realised capacity (or nearest capacity forecast where applicable) and furthest WEO capacity forecast.

The table below presents a list of the major European utilities, and both their operating and planned (and under construction) coal-fired capacity. The data shows that many of the firms planned to build additional coal-fired capacity. However, by mid-2016 seven companies reduced their coal capacity, only six companies increased their coal capacity, and one remained unchanged. The following section examines the financial performance of these 14 major European utilities.

\footnotetext{
4 IEA World Energy Outlook.
} 


\section{Coal Capacity and Market Value for Sample Firms ${ }^{5}$}

\begin{tabular}{|c|c|c|c|c|c|c|c|c|}
\hline \multirow[b]{2}{*}{$\begin{array}{l}\text { Unit } \\
\text { (MW) }\end{array}$} & \multicolumn{2}{|c|}{2007} & \multicolumn{2}{|c|}{2016} & \multirow{2}{*}{$\begin{array}{l}\% \text { Change in } \\
\text { Operation } \\
\text { capacity }\end{array}$} & \multicolumn{2}{|c|}{$\begin{array}{c}\text { Market Capitalisation } \\
(€ \text { million }) \\
\end{array}$} & \multirow{2}{*}{$\begin{array}{l}\% \text { Change in } \\
\text { Market } \\
\text { Capitalisation }\end{array}$} \\
\hline & Operating & $\begin{array}{l}\text { Planned \& } \\
\text { Under } \\
\text { Construction }\end{array}$ & Operating & $\begin{array}{l}\text { Planned \& } \\
\text { Under } \\
\text { Construction }\end{array}$ & & Dec 2007 & Dec 2015 & \\
\hline CEZ & 6,510 & 1,980 & 6,224 & $\mathrm{~N} / \mathrm{A}$ & $-4.4 \%$ & 30,135 & 8,782 & $-70.9 \%$ \\
\hline EDF & 9,324 & N/A & 7,920 & N/A & $-15.1 \%$ & 148,465 & 25,227 & $-83.0 \%$ \\
\hline EDP & 1,250 & 800 & 1,250 & $\mathrm{~N} / \mathrm{A}$ & $0.0 \%$ & 16,288 & 12,069 & $-25.9 \%$ \\
\hline ENEL & 6,536 & 750 & 8,193 & $\mathrm{~N} / \mathrm{A}$ & $25.4 \%$ & 50,297 & 36,598 & $-27.2 \%$ \\
\hline EnBW & 2,727 & 912 & 3,175 & $\mathrm{~N} / \mathrm{A}$ & $16.4 \%$ & 14,699 & 5,746 & $-60.9 \%$ \\
\hline E.ON & 14,000 & 7,570 & 4,302 & $\mathrm{~N} / \mathrm{A}$ & $-69.3 \%$ & 93,335 & 17,419 & $-81.3 \%$ \\
\hline Fortum & 1,629 & $\mathrm{~N} / \mathrm{A}$ & 1,309 & $\mathrm{~N} / \mathrm{A}$ & $-19.6 \%$ & 27,486 & 12,366 & $-55.0 \%$ \\
\hline $\begin{array}{l}\text { GDF } \\
\text { Suez }\end{array}$ & N/A & N/A & 2,375 & N/A & & 0 & 39,024 & $\mathrm{~N} / \mathrm{A}$ \\
\hline Iberdrola & 1,225 & $\mathrm{~N} / \mathrm{A}$ & 498 & $\mathrm{~N} / \mathrm{A}$ & $-59.3 \%$ & 51,935 & 41,062 & $-20.9 \%$ \\
\hline PGE & $\mathrm{N} / \mathrm{A}$ & $\mathrm{N} / \mathrm{A}$ & 10,260 & 878 & & 0 & 5,577 & N/A \\
\hline RWE & 17,004 & 7,240 & 16,121 & 1,100 & $-5.2 \%$ & 53,682 & 7,095 & $-86.8 \%$ \\
\hline Tauron & $\mathrm{N} / \mathrm{A}$ & $\mathrm{N} / \mathrm{A}$ & 5,300 & 900 & & 0 & 1,177 & N/A \\
\hline Vattenfall & 12,026 & 2,840 & 13,505 & $\mathrm{~N} / \mathrm{A}$ & $12.3 \%$ & 0 & 0 & $\mathrm{~N} / \mathrm{A}$ \\
\hline Verbund & 1,003 & $\mathrm{~N} / \mathrm{A}$ & 598 & $\mathrm{~N} / \mathrm{A}$ & $-40.4 \%$ & 14,757 & 4,120 & $-72.1 \%$ \\
\hline Total: & 73,234 & 22,092 & 81,030 & 2,878 & $10.6 \%$ & 30,135 & 8,782 & $-70.9 \%$ \\
\hline
\end{tabular}

The next figure shows that between 2000 and 2007 the market capitalisation of our sample group witnessed a 2.6fold increase from $€ 149 \mathrm{bn}$ to $€ 501 \mathrm{bn}$. The sector's market capitalisation peaked in 2007 at around half a trillion euros. In 2008, the GFC resulted in a decline in market capitalisation of between $-37 \%$ and $-51 \%$. The energy sector has never truly recovered from the loss, and has continued to decline over the subsequent years to around $€ 216 \mathrm{bn}$; $-57 \%$ lower than its peak value.

The pre-2008 period witnessed policy intervention and company mergers. Indeed, European legislators demonstrated, through the three packages of liberalisation, their willingness to enforce compliance with singlemarket mandates. ${ }^{6}$ Concerns over increased competition due to liberalisation and unbundling of generation from transmission and distribution encouraged utility companies to seek dominant market positions in multiple countries. Further, the removal of national barriers also encouraged a wave of synergistic merger and acquisition activity to either expand across borders to gain economies of scale, or allow domestic suppliers to defend against predatory foreign competitors. ${ }^{7}$ High profits in the early 2000 s gave utility companies strong cash positions leading up to 2008. ${ }^{8}$ Simultaneously, a downward revision of organic growth, from 2 to $1.6 \%$, provided an incentive for utilities to fund growth using debt, which had a marginal cost of only $2.4 \%$ after tax. ${ }^{9}$

\footnotetext{
5 S\&P Capital IQ, WEPP Q4 2007 \& Q2 2016.

${ }^{6}$ George Parker, Sarah Laitner, and Thomas Catan, “Lights out? How Europe Is Trying to Fix a Power Failure," Financial Times, 2006.

7 Tulloch and Caldecott, "Current and Future Challenges Facing the European Union's Energy System."

8 Ed Crooks and Mark Mulligan, "Two Hot Trends Coming Together," Financial Times, 2006.

9 "Europe's Coming Merger Boom," The Economist, 2005.
} 


\section{Group Market Capitalisation and Median Market Capitalisation Growth, 2000-201510}

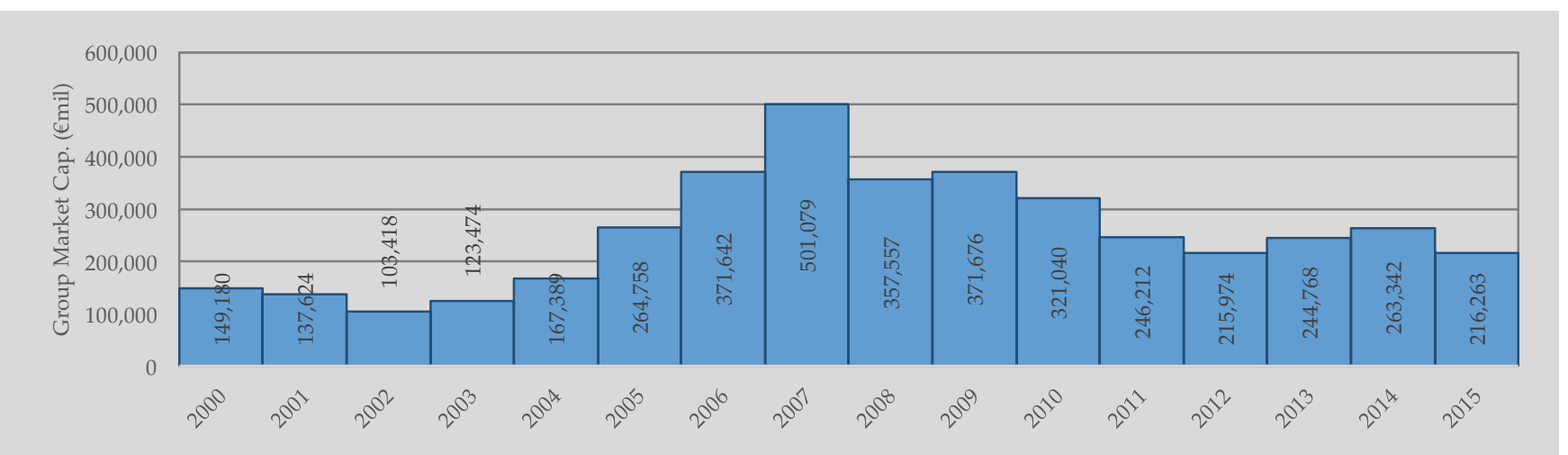

This figure illustrates the sum of annual market capitalisations, in euros, across the 14 sample firms.

The next figure shows that utilities rapidly expanded in size, as measured in total assets. The increasing amounts of debt on the balance sheet imply that the sector is exposed to increasing financial risk. The increase in debt means that utilities magnify both gains and losses. However, the return on capital has trended below the long-term cost of capital, destroying value for shareholders. ${ }^{11}$

\section{Book Value of Energy Utilities, 2000-2015 12}

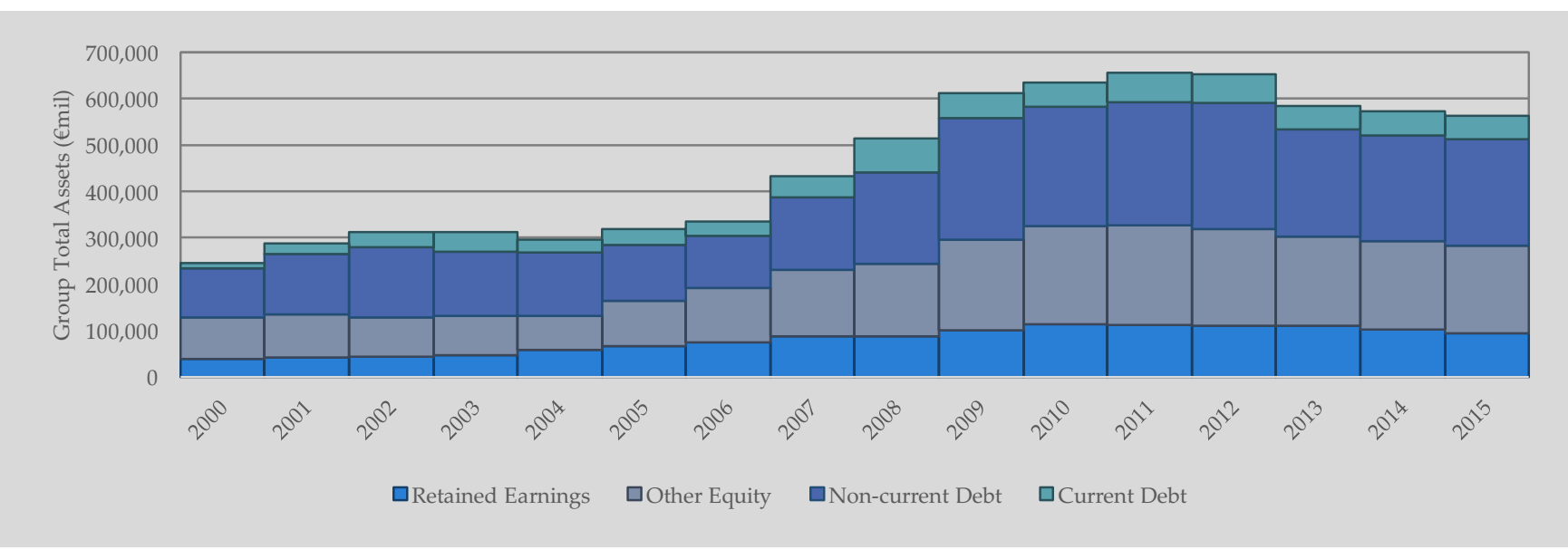

This figure illustrates the group's total assets between 2000 and 2015. To calculate total assets, we aggregate the group's total equity and total debt.

The next figure illustrates the group's asset write-down and impairment of goodwill between 2000 and 2015. Between 2000 and 2009, the group's asset write-down typically remains low, at around €1.1bn per annum. In 201012 , there is a more than six-fold increase in write-downs, to around $€ 6.9$ bn per annum. Plot (A) shows that major asset write-downs of $€ 20$ bn per annum occur from 2013 onwards. Plot (B) also shows a relatively similar pattern for impairment of goodwill.

Both Plots (A) and (B) highlight the utility industry's recognition of the reduced value of their impaired assets, and a fundamental change in the operating environment. Specifically, the carrying value and recoverable amount

10 S\&P Capital IQ.

11 FTI-CL Energy, "Towards the Target Model 2.0: Policy Recommendations for a Sustainable EU Power Market Design."

12 S\&P Capital IQ. 
from the generating asset themselves are perceived to be significantly lower. Put simply, merchant operations and the assets used to generate power are viewed as less profitable in the long term.

\section{Group Asset Write-down and Impairment of Goodwill ${ }^{13}$}

(A) Asset Write-downs

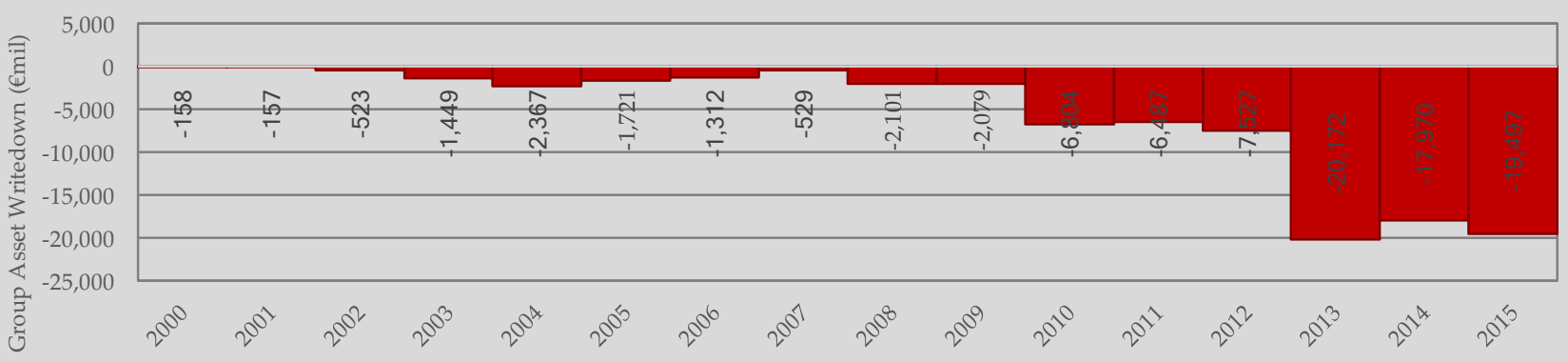

(B) Impairment of Goodwill

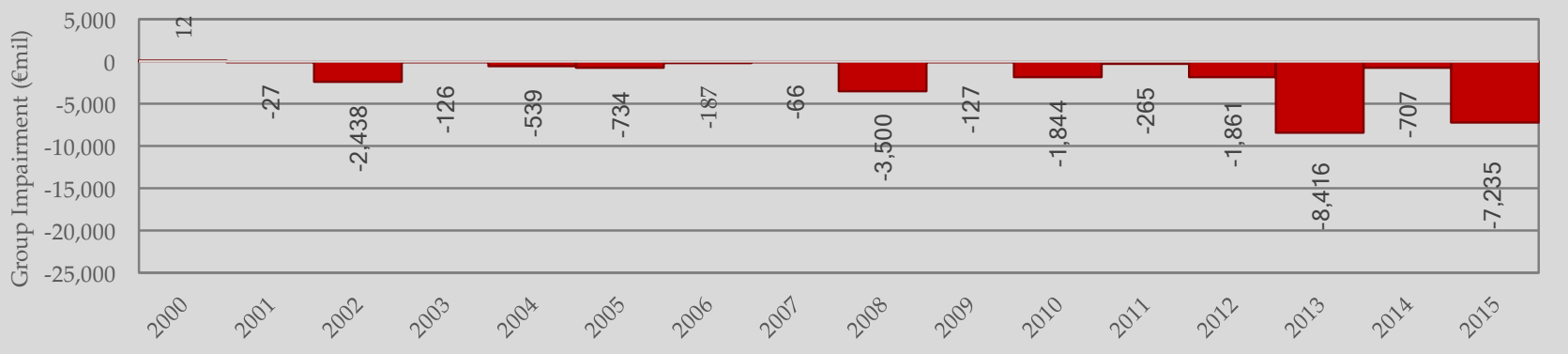

\section{Recommendations}

European utilities completely misjudged the prospects for new coal-fired generation and have since paid a significant price for this mistake. The subsequent write-downs, underperformance, and reductions to balance sheet capacity still weigh down the sector. Had more coal-fired plants reached completion, the negative impacts on the companies would have been even more significant. Utility executives may have anti-coal protestors to thank for successfully campaigning to reduce or stop expansions in some countries such as the UK - a small saving grace.

The implications for utilities and utility investors in jurisdictions where coal expansions are being considered are clear: in a sector experiencing significant technology, policy, and market innovation, optimism biases at a company-level and in terms of both company-level and sector-wide forecasting, are likely to yield significant stranded assets. These have long term implications for companies and their ability to successfully navigate the transition observed in power markets internationally. Utilities and utility investors considering new coal should guard against these optimism biases and consider them carefully.

In Europe, the end of coal-fired generation is certain, even if the exact timeline of the phase-out is uncertain. Further premature closures of coal assets and 'forced' mothballing will occur. However, the extent to which this will take place is very country specific and depends on regulations, market mechanisms, and technological advances.

\footnotetext{
13 S\&P Capital IQ.
} 
Through our analysis, we have identified a range of practical solutions for coal-fired utilities to minimise the risk of stranded coal-fired generation assets in the short- to medium-term. These can be universally applied:

1) Adapt current operations to the new environment by switching fuels (e.g. to biomass), or implementing a two-shift system to increase flexibility for large generators.

2) Analyse which plants within generation fleets can be decommissioned or mothballed and plan fewer conventional capacity investments. The former will give clarity and transparency to the options available to management if power prices continue to decline.

3) Consider and map out conflicts of interest between conventional power division and renewables, T\&D and energy services. If these are difficult to reconcile at a group level consider splitting, spinning off, or creating clearer divisional splits within the company.

4) Explore ways of leveraging the current asset base and proximity to end clients in developing new business models which could bring value to the business and the grid in times of higher price volatility. New demand-side management technologies, electric vehicle deployment, storage, and distributed energy to name a few are not only disruptive to the current energy architecture but also opportune to both incumbents and new market entrants.

5) Undertake an analysis of relevant disclosures to assess exposure to the long-term trends affecting the sector. This would ultimately minimise asset stranding and value destruction.

European policymakers will have to design the best ways to accelerate the phase-out of coal in order to secure power sector decarbonisation. We recommend that they: ${ }^{14}$

6) Reform the EU ETS to address the chronic oversupply of carbon credits. Prices on the EU ETS should reflect the negative impact of coal and foster a switch away from using coal in the electricity mix.

7) Introduce emission performance standards.

8) Continue to strengthen the National Emissions Ceiling (NEC) Directive and the IED to align existing emissions with the ones displayed in the best available techniques reference document (BREF). Application of the best available techniques should be enforced to achieve the 7th Environment Action Programme's objectives.

Looking beyond Europe, we also strongly recommend that policymakers internationally:

9) End the public financing of coal projects, prevent the lifetime extension of coal power stations and move financial support towards the development of alternative technologies and energy savings.

10) Conduct structural market transformations to incentivise private investment in low carbon technologies.

11) Build new capacity in low carbon technologies to replace legacy conventional generation assets at the appropriate rate.

12) Recognise that some existing and new-built conventional generating technologies will require early decommissioning in the transition to a low-carbon energy grid.

14 Our set of recommendations is in line with the ones stated in the 2014 WWF report, "Europe's Dirty 30": http://www.wwf.de/fileadmin/fm-wwf/Publikationen-PDF/Studie-Dirty-Thirty-2014.pdf. 


\section{Introduction}

The principle aim of this report is to conduct a comprehensive analysis of the growth of coal-fired power generation in EU member states between 2005 and 2008. In 2005, total installed capacity in the EU stood at 777 GW, and EU utilities were about to embark on a major coal-plant construction programme. EU utilities announced plans to build an additional $49 \mathrm{GW}$ of new coal-fired power capacity, about $6.3 \%$ of total EU installed capacity. The majority of proposed coal installations were to be located in Germany $(>20 \mathrm{GW})$, the United Kingdom $(>7$ GW), the Netherlands (>4 GW), and Poland (>3 GW).

The decision to install new coal-fired generation was made for various reasons. Many of these countries had significant coal reserves and coal-fired electricity was the cheapest form of power in many regions. The use of coal in power generation was also viewed as being of strategic importance, both in terms of heightened concerns over energy security and the need to maintain competitive electricity prices. Simultaneously, positive market conditions with high wholesale electricity prices made the 2005 to 2008 period among the most profitable years for merchant electricity generation. Utilities also entered a period of major sector liberalisation, with positive growth forecasts and relatively cheap debt providing ample incentives to expand operations, build new capacity, or execute a series of mergers and acquisitions to take an ever-increasing market share of electricity generation.

Against these opportunities, coal-fired power generation met several significant challenges post-2008 which rapidly discouraged investment. A series of policy interventions increased operational and investment risk in the European electricity market. ${ }^{15}$ Reducing emissions from the energy sector is fundamental to addressing risks of anthropogenic climate change, requiring deep decarbonisation of the energy system and a fundamental shift in infrastructure. ${ }^{16}$ This in turn involves addressing the largest source of emissions in electricity generation: coalbased electricity production.

Beyond increased regulation, the electricity industry was met with deteriorating market conditions, changing public opinion, as well as a build-up of significant overcapacity in many markets (the UK being a notable exception). The latter challenges dramatically impacted the business models of vertically integrated electricity utilities in Europe, which relied heavily on thermal generation - including hard coal - and lignite-fuelled power plants.

As a result, new coal-fired capacity became much less attractive. Post-2008, only $10.5 \mathrm{GW}$ of the $49 \mathrm{GW}$ of planned coal capacity became operational, $1 \mathrm{GW}$ was still 'delayed' as of 2016, and nearly $38 \mathrm{GW}$ of planned capacity was eventually cancelled. The projects that did not proceed were cancelled or postponed for a variety of reasons, and there are a number of important questions that stem from this: what were these reasons and why did the majority of plant proposals not go ahead; what makes the projects that did proceed different; what challenges are these new plants likely to face now and in the future; and to what extent are the projects that did succeed likely to become stranded generation assets? The results are relevant not just to understanding the fate of the remaining coal-fired power stations in Europe, but also the future of those currently planned or being built in other countries.

\subsection{Methodology}

To answer these questions, this report is divided into six sections. Section 2 provides an overview of the panEuropean power industry. The section begins by outlining the broad policy changes in the power sector, which include major liberalisation and decarbonisation objectives. The legislation of interest has been extracted from Europa - the central law archive for the European Union. Next, the section outlines literature regarding the EU's

\footnotetext{
${ }^{15}$ Daniel J Tulloch, Ivan Diaz-Rainey, and I.M. Premachandra, “The Impact of Liberalization and Environmental Policy on the Financial Returns of European Energy Utilities," The Energy Journal 38, no. 2 (2017): 77-106, doi:http:/ /dx.doi.org/10.5547/01956574.38.2.dtul.

16 Nature Energy, "A World in Transition," Nature Energy 1 (January 2016): 1.
} 
broad market framework for valuing electricity, considering the various interactions between generating technologies. Third, the section outlines major assumptions regarding market conditions which guided power investment decisions. We closely examine financial reports, statements, announcements, and disclosures from utilities between 2000 and present to see what assumptions were guiding utilities' investment decisions. This is complemented by a review of analysis from investment houses and consultancies over the same period. We delineate the analysis into three periods: pre-2005, the 2005 to 2008 period, and the post-2008 period.

Section 3 examines country-level nuances and seeks to understand why some EU member states proceeded with building coal-fired capacity, while others cancelled all projects. Section 3 focuses on four country-level case studies. We identify three countries which planned, and ultimately built the largest quantities of coal-fired capacity. These three countries are Germany, the Netherlands, and Poland. Collectively, these three countries built $88 \%(9.25 \mathrm{GW})$ of all new coal-fired capacity in the EU. In addition, we contrast the experience of these three countries against that of the UK. The UK planned $7 \mathrm{GW}$ of coal-fired capacity over the same period, among the largest plans in the EU, but ultimately cancelled all projects. For each country, we present an overview of market conditions, energy policy, the expansion of coal, and the impact of new plants on energy policy.

Section 4 examines the operational and financial performance of the EU's coal-fired power fleet. The section uses a sample of the EU's largest 14 energy utilities, as measured by market capitalisation. The section utilises a combination of data from Eurostat, 17 Platt's World Electric Power Producers (WEPP), and data from Standard and Poor's Capital IQ. First, Section 4 outlines the changing generation mix of the EU power industry between 2000 and present, including: (1) gross electricity generated by technology type, (2) installed capacity, and (3) utilisation rates of various technologies. Second, Section 4 provides an analysis of financial performance of the sample, including: (1) change in market and book value of the sample, (2) changes in profitability, and (3) measurement of stranded assets. The section ends with the implications of the information above.

Section 5 examines the characteristics of units which were operational, retired, planned, cancelled, and under construction. The analysis is delineated across the three periods of interest (pre-2005, 2005 to 2008, and post-2008). The section analyses various types of coal-fired units and the associated capital costs, operational and maintenance costs, size of units, and efficiency of the technology. The section draws a conclusion on patterns of both successful and unsuccessful coal-fired technologies in the EU.

Section 6 examines the prospects of the EU power industry and potential responses to changing market conditions using a range of technical reports, academic papers, and company reports. First, Section 6 presents an overview of: (1) the growth outlook of the industry, (2) changing resource landscapes, (3) carbon markets and climate policy, (4) support for renewables, and (5) future policy and regulation, including capacity remuneration mechanisms. Second, Section 6 presents operational strategies that utilities have implemented to adapt to the new business environment. Third, the section examines new business models and investment strategies which present potential future avenues for operations in the EU power industry.

Section 7 concludes the report by drawing together the various facets of the analyses.

17 The statistical office of the European Union. 


\section{The EU Power Market Overview}

This section highlights policy changes in the power sector, outlines the literature on the EU's market framework for valuing electricity, as well as the major assumptions on market conditions which guided power investment decisions.

\subsection{EU-level Market Reforms}

Traditionally, European energy supply was based on national and regional markets, where vertically integrated utilities could produce, transmit, and distribute energy to nearby consumers with natural, regional monopolies. In such a system, the supply of electricity was a relatively simple operation. Each power plant generated electricity and supplied it to local energy consumers through their transmission lines. The plant's major operating expenditure (OPEX) was the price of the underlying fuel. The cost of the commodity determined the cost of electricity, and suppliers charged a premium for energy supply. The OPEX model allowed investments to be written off against annual profits.

Since 1996, the European power industry has undergone a series of major regulatory changes with the objective of increasing competition and creating a single internal energy market for the EU. The European Commission determined that the supply-side (generator) operations could be competitive and removed national barriers to create an international market where utilities could compete on price, services, and market share. This induced competition was designed to expose the inefficiencies in operations and gradually phase out the inefficient power plants through competition.

The current electricity market design assumed OPEX technologies (such as coal-, gas- and oil-fired generators) or hydro plants would supply the bulk of services. ${ }^{18}$ The different types of generators also had defined roles in the energy system: large units (usually coal) supplied long-term baseload power, while flexible units (usually gas) supplied peak demand. Massive support for Renewable Energy Source (RES) generation was unanticipated and thus the current market paradigm was designed to induce competition between OPEX technologies.

\subsubsection{Sector Liberalisation}

To liberalise the energy sector and induce competition, the European Commission introduced three major reform initiatives known as the 'three packages'. ${ }^{19}$ The first package of liberalisation for the power industry ${ }^{20}$ in 1996 was the first attempt to remove national barriers in the EU. The package only resulted in minor liberalisation and competition as only high-volume commercial consumers could switch suppliers. ${ }^{21} \mathrm{~A}$ lack of clear rules on electricity transmission resulted in some vertically integrated companies continuing to possess monopolies over transmission lines. As a result, there was relatively little competition in the EU power industry, however the EU industry saw some benefits from increased efficiency, price reductions, higher standards of service, and increased competitiveness. ${ }^{22}$

The second package 22 of liberalisation in 2003 attempted to create a level playing field by reducing the risk of market dominance. The second package allowed consumers to freely choose suppliers and for suppliers to deliver

\footnotetext{
18 M Ahlstrom et al., "The Evolution of the Market: Designing a Market for High Levels of Variable Generation," Power and Energy Magazine, IEEE, 2015, doi:10.1109/MPE.2015.2458755.

${ }^{19}$ For a full discussion of the three packages, please see Chapter 2 of Daniel James Tulloch, "The Impact of Risk Factors and Regulatory Change in the Returns of European Energy Utilities" (University of Otago, 2016).

${ }^{20}$ Directive 1996/92/EC

21 Per Ove Eikeland, “The Third Internal Energy Market Package: New Power Relations among Member States, EU Institutions and Non-State Actors?," JCMS: Journal of Common Market Studies 49, no. 2 (2011): 243-63, doi:10.1111/j.14685965.2010.02140.x.

22 Directive 2003/54/EC
} 
their power across the EU. Non-household and household consumers could freely choose their power suppliers from 2004 and 2007, respectively. Further, an open market was established through regulated access to grids. ${ }^{23}$ Thus, EU utilities saw an opportunity to rapidly expand across borders. The following period saw a large amount of planned generating capacity and many synergistic mergers and acquisitions. The rapid growth in utilities occurred for two reasons: first, to expand operations and take an increasingly larger market share; and second, to defend domestic markets against large international competition. The period immediately following the second package of liberalisation provided ample opportunities for utilities to plan large amounts of coal capacity.

The third package of liberalisation, ${ }^{24}$ published in 2009, was designed to address the unachieved liberalisation objectives of the second package - mainly the lack of effective unbundling of transmission system operators from generators. At the time, more than two-thirds of the European generation market share was owned by eight large utilities, ${ }^{25}$ and unfair access to transmission grids still prevailed. ${ }^{26}$ As a result, the third package required full vertical unbundling by separating ownership between transmission and generation companies.

\subsubsection{Sector Decarbonisation}

The power system is also perceived as an industry which can contribute to decarbonising the economy, with relatively less behavioural and structural changes. ${ }^{27}$ Beyond sector liberalisation, a second theme that has gained prominence in recent years is the 'greening' of energy supply. The Large Combustion Plant (LCP) directive ${ }^{28}$ of 2001 aimed to control the emissions from pollutants, particles, and ozone precursors. This legislation immediately applied to all new builds, and affected existing capacity from 2008. Following the LCP directive, the 2008 Integration Pollution Prevention and Control (IPPC) Directive set emission limit values across a variety of industrial activities, including combustion installations. ${ }^{29}$ The IPPC Directive set even stricter emission limit values for typical emissions from coal-fired generation, including $\mathrm{SO}_{2}, \mathrm{NOx}$, and dust. As a result of the latter, many coal-fired power plants saw stricter emission standards implemented and many more required additional pollution control technologies to be installed to remain compliant with regulation.

In 2009, the EU enacted legislation aimed to boost renewable energy use by $20 \%$, reduce greenhouse gas emissions by $20 \%$, and achieve a $20 \%$ increase in energy efficiency by 2020 , commonly referred to as the '20-20-20' targets. The main method by which this was to be achieved was through regulation, prescribing processes, products and activities which are congruent with the overall emission reduction objectives. In 2014, these objectives were revised as the 40-27-27 targets: (1) a reduction of greenhouse gas emissions of at least $40 \%$ relative to 1990 levels, (2) at least $27 \%$ share for renewable energy, and (3) at least $27 \%$ improvement in energy efficiency. Increasing the proportion of coal-fired technology may be incompatible with a low-carbon energy system. While some coal-fired plants can meet current standards, eventually they may be phased-out by regulatory reforms and stricter standards in the future.

In addition to regulation, conventional thermal generators also faced a threat from the increased penetration of RES generating technology. Over the last two decades, the electricity industry has rapidly shifted towards

23 Tooraj Jamasb and Michael Pollitt, "Electricity Market Reform in the European Union: Review of Progress toward Liberalization \& Integration," The Energy Journal 26 (2005): 11-41, doi:10.2307/23297005; Eikeland, "The Third Internal Energy Market Package: New Power Relations among Member States, EU Institutions and Non-State Actors?"

24 Directive 2009/72/EC, Regulation (EC) No 714/2009, and Regulation (EC) No 713/2009.

25 Jamasb and Pollitt, "Electricity Market Reform in the European Union: Review of Progress toward Liberalization \& Integration."

${ }^{26}$ ACER, "Annual Report on the Results of Monitoring the Internal Electricity and Natural Gas Markets in 2012" (Brussels: Agency for the Cooperation of Energy Regulators, 2013).

27 David M. Newbery, “Towards a Green Energy Economy? The EU Energy Union's Transition to a Low-Carbon Zero Subsidy Electricity System - Lessons from the UK's Electricity Market Reform," Applied Energy, 2016,

doi:10.1016/j.apenergy.2016.01.046.

28 2001/80/EC

${ }^{29}$ Directive 2008/1/EC 
predominantly high fixed-cost capital expenditure (CAPEX) technologies, such as renewables, with near-zero marginal cost. This rapid expansion of CAPEX technology is partly due to a range of EU and member state policy incentives aimed at reducing emissions. As intimated above, the rapid deployment of RES technology was mostly unanticipated. Current market mechanisms to value electricity are designed to induce competition between OPEX technologies with varying operating cost. The following section outlines how the broad method of valuing electricity in the EU, the energy-only market, often results in renewables outbidding all thermal generation technology.

\subsection{Wholesale Power Markets: the Energy-Only Market}

The energy-only market represents the traditional basis for wholesale electricity trading in the EU, where generators are paid for dispatched electricity and market forces determine value. Electricity generators can be ranked on their short-run marginal cost (SRMC), which is the marginal cost of producing an extra increment $(\mathrm{MWh})$ of energy. ${ }^{30}$ In the energy-only market, generators offer into the market and are remunerated at the market clearing price. ${ }^{31}$ The supply curve obtained is known as a merit-order curve. All bids below the clearing price are in merit, while bids above the clearing price are out of merit. The marginal generator (the last dispatched) sets the price for other market participants. ${ }^{32}$ Figure 1 shows that the low SRMC of RES and nuclear energy technology means these generators can sometimes out-bid all gas- and coal-fired generation regardless of energy demand. ${ }^{33}$ Relatively expensive fuels, such as coal and gas, are only brought online when demand and clearing prices increase to a sufficient level to remunerate operations.

\footnotetext{
30 Jenny Riesz and Michael Milligan, “Designing Electricity Markets for a High Penetration of Variable Renewables," Wiley Interdisciplinary Reviews: Energy and Environment 4, no. 3 (2015): 279-89, doi:10.1002/wene.137.

31 Ahlstrom et al., "The Evolution of the Market: Designing a Market for High Levels of Variable Generation."

32 Riesz and Milligan, "Designing Electricity Markets for a High Penetration of Variable Renewables."

${ }^{33}$ Richard Green and Nicholas Vasilakos, "Market Behaviour with Large Amounts of Intermittent Generation," Energy Policy 38, no. 7 (July 2010): 3211-20, doi:http:/ / dx.doi.org/10.1016/j.enpol.2009.07.038.
} 
Figure 1: The Merit Order Curve 34

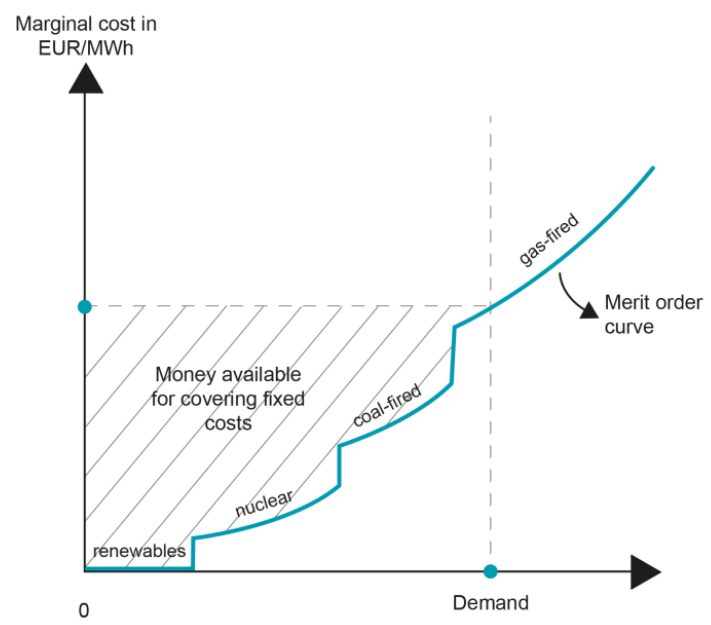

The deployment of renewables not only displaces generation by fossil-fuelled incumbents, but also reduces wholesale electricity costs in what is called market 'cannibalisation'. ${ }^{35}$ Because renewable generation has negligible marginal costs, increasing penetration of renewables decreases average wholesale electricity prices by pulling prices closer to zero for increasing periods of time. This effect reduces revenues for not only market incumbents, but also for the renewable generators themselves. Lower wholesale prices leave incumbents unable to recoup the necessary return on thermal investments through merchant generation without additional payments beyond the energy market. ${ }^{36}$ This inability to recoup investment places expensive generators at increased risk of asset stranding, as revenues trend below cost of capital and destroy value. ${ }^{37}$ Beyond lower wholesale electricity prices, the increased penetration of RES in the electricity industry has been documented to have a variety of impacts on the sector, including: reduced utilisation factors of incumbent generators, ${ }^{38}$ keeping retail prices high due to tariffs to support subsidies, ${ }^{39}$ and exacerbation of the oversupply of generating capacity. ${ }^{40}$ There are concerns that, even without subsidies, the low SRMCs of RES generators will result in their full dispatch in normal conditions. ${ }^{41}$

As electricity cannot be economically stored, energy supply and demand must be balanced at all times. Gas turbines and internal combustion engines, which burn natural gas or oil, have fast start-up times and are able to quickly ramp up operations during periods of low RES supply. In contrast, coal-fired generators are relatively inflexible, are designed for high-volume operations and have lengthy start-up times which range from hours to days. Further, these large generators have minimum loads, the lowest level a plant can operate at without

34 Benedict De Meulemeester, “Capacity Payments: Expensive Solution for a Non-Existing Problem," EnergyPost.eu, 2014.

35 Lion Hirth, "The Market Value of Variable Renewables," 2013, doi:10.1016/j.eneco.2013.02.004.Previous; Pilita Clark,

"Renewable Energy Sector Runs the Risk of Overpowering the Market," Financial Times, 2015.

36 Ben Caldecott and Jeremy McDaniels, "Stranded Generation Assets: Implications for European Capacity Mechanisms, Energy Markets and Climate Policy," Stranded Assets Programme, SSEE, University of Oxford, 2014, 1-62; David Newbery, “Missing Money and Missing Markets: Reliability, Capacity Auctions and Interconnectors," Energy Policy, 2015,

doi:10.1016/j.enpol.2015.10.028; David Robinson, "The Scissors Effect - How Structural Trends and Government Intervention Are Damaging the Major European Electricity Companies and Affecting Consumers," The Oxford Institute for Energy Studies Paper EL, no. 14 (2015): 1-37.

37 FTI-CL Energy, “Towards the Target Model 2.0: Policy Recommendations for a Sustainable EU Power Market Design" (Paris: FTI-CL Energy, 2015).

38 Sylvia Pfeifer, "Utilities Grapple with Renewables Surge," Financial Times, 2013.

39 Jeevan Vasagar, “Germany Cautions on Impact of Renewables," Financial Times, 2014.

40 Pfeifer, "Utilities Grapple with Renewables Surge."

41 Riesz and Milligan, "Designing Electricity Markets for a High Penetration of Variable Renewables." 
completely shutting down, of approximately $50-70 \%$ of the unit's capacity and find it difficult and costly to scale back operations..$^{42}$ As a result, coal-fired generators are at risk of becoming stranded due to their inability to compete with RES on both price and flexibility in the energy only market.

\subsection{Market Assumptions and Risk Factors}

In this section, we examine the assumptions and risk factors which underpinned investment decisions for thermal power generation in the EU between 2000 and present. Sections 2.3.1 to 2.3.4 outline a variety of structural and temporary challenges faced by the electricity industry over this period. In particular, we group the assumptions and risk factors into four themes: 1) Gross Domestic Product (GDP) and energy demand, 2) installed capacity, 3) commodity markets, and 4) a low-carbon future.

The methodology for this section is a review of public and private sector sources to outline projections of future market conditions. Among the sources most widely used for energy markets is the annual World Energy Outlook (WEO) report produced by the International Energy Agency (IEA). Annually, the IEA provides analysis of trends in energy supply and demand, and the impact of various factors on energy security and economic development. The projections are based on a set of central assumptions. However, these assumptions have undergone a major structural shift based on changing opinion regarding the impact of new policies and regulation on the power industry. This change in assumptions reflects a fundamental shift in the power industry.

Prior to 2010, the IEA based all future projections on the set of policies from the mid-point of the year of publication. These projections are often called the 'Reference Scenario'. From 2010 onwards, the IEA modified the scenario assumptions to integrate the significant policy advances made at that time. ${ }^{43}$ More precisely, the projections begin to account for the broad commitments and policies that have been announced by countries to both reduce greenhouse gas emissions and phase out fossil-energy subsidies. The latter scenario is therefore named New Policies Scenario. The New Policies Scenario considers broad policy commitments even if the measures to implement these commitments have not yet been identified. There is a clear structural break in both market assumptions and outlook from the pre-2010 Reference Scenario and the post-2010 New Policies Scenario. Comparing both the New Policies Scenario and the Current Policies Scenario over time allows us to quantify the shift in market outlook as a result of policies in the power market. The first change in market condition relates to the change in GDP and total energy consumption.

\subsubsection{Decoupling of GDP and Energy Demand}

Energy demand has been linked to economic growth as wealth effects and increased business activity result in greater electricity consumption. ${ }^{44}$ This relationship represented one of the most important assumptions for investors in the pre-2008 period. A survey of IEA WEO since 2000 shows bullish beliefs with respect to short- and medium-term energy demand growth in the EU.

This belief stemmed from the assumption that electricity demand growth was inexorably linked to GDP growth, and GDP growth was unlikely to be significantly curtailed. ${ }^{45}$ Some utilities also assumed that economic growth, and hence also electricity demand growth, would continue to grow as it did in previous years and remain high

42 Green and Vasilakos, "Market Behaviour with Large Amounts of Intermittent Generation"; Riesz and Milligan, "Designing Electricity Markets for a High Penetration of Variable Renewables."

43 International Energy Agency (IEA), “World Energy Outlook 2010,” 2010.

44 Alice Shiu and Pun-Lee Lam, "Electricity Consumption and Economic Growth in China," Energy Policy 32, no. 1 (2004): 4754, doi:10.1016/S0301-4215(02)00250-1; Paresh Kumar Narayan and Arti Prasad, "Electricity Consumption-real GDP Causality Nexus: Evidence from a Bootstrapped Causality Test for 30 OECD Countries," Energy Policy 36, no. 2 (February 2008): 910-18, doi:http:/ / dx.doi.org/10.1016/j.enpol.2007.10.017; Paresh Kumar Narayan and Russell Smyth, "Multivariate Granger Causality between Electricity Consumption, Exports and GDP: Evidence from a Panel of Middle Eastern Countries," Energy Policy 37, no. 1 (2009): 229-36, doi:10.1016/j.enpol.2008.08.020.

45 RWE, “Annual Report” (Essen, 2007). 
for the foreseeable future. ${ }^{46}$ Real world data showed growth in electricity consumption had a positive relationship with real GDP growth between 2000 and 2007 (see Figure 2). In October 2008, the IMF World Economic Outlook projected real EU GDP growth of $1.7 \%$ in 2008 and $0.6 \%$ in 2009.47

However, the global financial crisis (GFC) of 2007-09 was truly a 'black swan' event - a highly impactful event which ex-ante analysis scarcely anticipated. Following the GFC, EU electricity demand fell for the first time since 1992. Figure 2 shows that the GDP and electricity demand relationship were both near zero in 2008, and began to decouple by moving in opposite directions. ${ }^{48}$ In 2009, both GDP and electricity consumption fell by more than $4 \%$. Although demand reversed much of this loss in 2009, these gains have been eroded in subsequent years due to the loss of manufacturing production ${ }^{49}$ and increased energy efficiency - particularly in home appliances and lighting. 50 The GFC represented a major structural break, which significantly shifted the assumptions and risk factors driving investment decisions in the EU energy utility sector. In the following years, particularly post-2010, the relationship between GDP and electricity demand began to deviate further. The breakdown of the relationship can occur for various reasons: the economic slowdown as a result of the GFC, increased energy efficiency in generating technology and appliances, and also changes in economic cycles which previously decoupled GDP from electricity growth in the US in the early 1980s. Regardless, GDP is losing its role in forecasting future electricity consumption.

\section{Figure 2: Real GDP and Electricity Consumption Growth ${ }^{51,52}$}

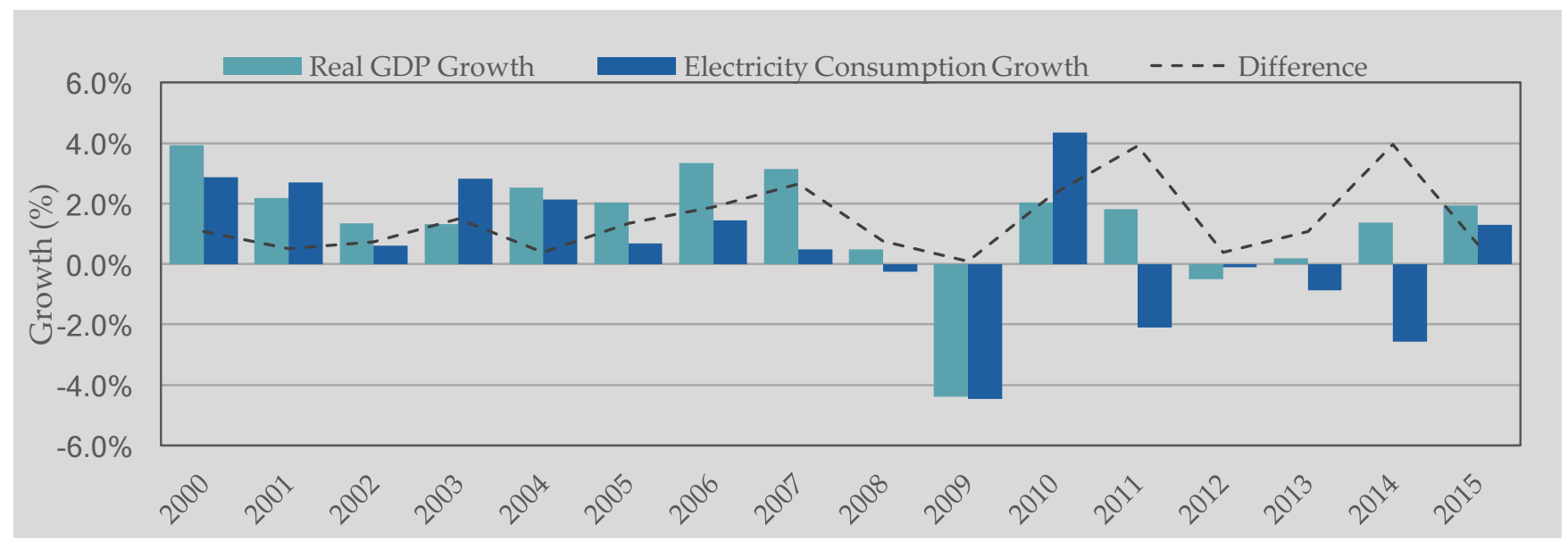

Simultaneously, the industry saw a major shift in market sentiment regarding future outlook. We surveyed the annual IEA WEO reports between 2000 and 2016 to gauge the projected outlook for each publication year. For each WEO report, we extracted the EU's realised and forecast electricity generation and capacity for the central scenario. Figure 3 shows the realised and forecast data between 2000 and 2040. We delineate the reports into those that use the 'Reference Scenario' (orange lines), and those that use the 'New Policies Scenario' (blue lines).

First, Panel (A) of Figure 3 shows that forecast electricity generation is expected to continue growing in the EU. In 2000 , electricity generation was expected to grow by approximately $1.7 \%$ per annum. For the most part, estimates

\footnotetext{
46 E.ON, “Annual Report,” 2007.

47 International Monetary Fund, “World Economic Outlook, October 2008," World Economic and Financial Surveys, 2008. 48 European Commission, "Energy Economic Developments: Investment Perspectives in Electricity Markets," Report, vol. 8014 (Luxembourg: Publications office of the European Union, 2015), doi:10.2765/48569; Robinson, “The Scissors Effect How Structural Trends and Government Intervention Are Damaging the Major European Electricity Companies and Affecting Consumers."

49 Andrew Sentance, "Services Rescue UK Economy from Worsening Downturn," The Telegraph, April 2016.

50 Simon Evans, "A Detailed Look at Why UK Homes Are Using Less Energy," Carbon Brief, June 2014.

51 BP plc, "BP Statistical Review of World Energy 2016," 2016.

52 "Real GDP Growth Rate - Volume," Eurostat, 2016.
} 
of future electricity generation were higher than the generation realised, suggesting optimism bias in future demand, although realised electricity demand exceeded forecasts for 2004-08. The current policies scenario, used until 2009, forecast increasing energy demand and profitable times ahead. This provided an incentive for utilities to monopolise on excess demand and contributed to plans to expand the EU's power generation fleet.

The global financial crisis reduced energy demand very suddenly; it was also the first time realised energy demand fell below forecasts. In 2009-10, the IEA remained optimistic that energy demand would recover. But in 2010, the IEA also switched to the New Policies Scenario, which dramatically downgraded future energy demand in the face of policies designed to reduce emissions from the power industry. By 2015, growth in electricity generation effectively flatlines close to zero. A combination of the GFC and change in assumptions has implications beyond coal-fired power. It suggests that future energy demand has begun to stagnate and will not see the growth forecast in earlier years.

\section{Figure 3: Realised and Forecast Electricity Generation, 2000-204053}

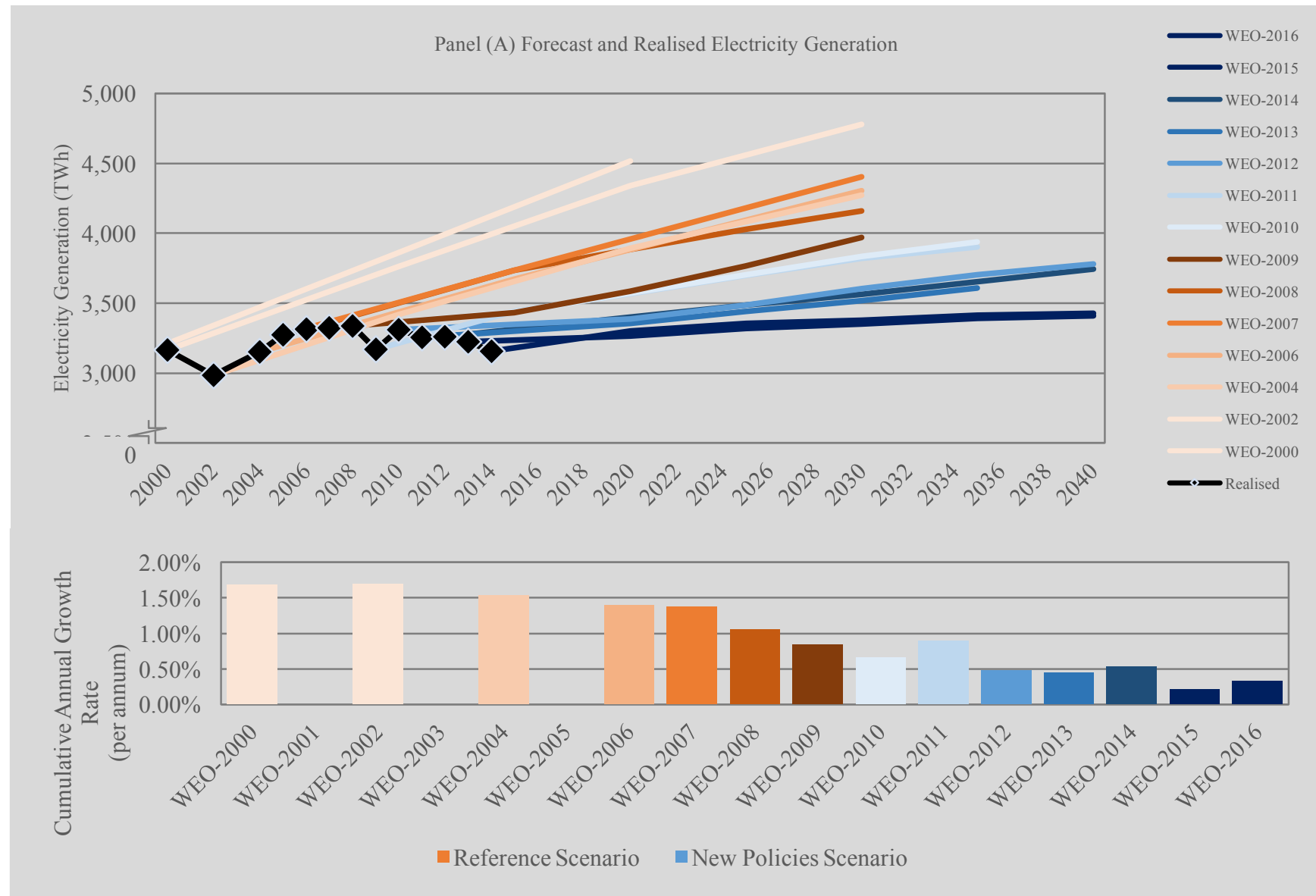

Panel (A) illustrates the realised and forecast electricity generation extracted from 2000-2016 annual IEA's World Energy Outlook (WEO) reports. Data is extracted for the European Union. The black line with markets illustrates the realised electricity generation, extracted from WEO reports. The coloured lines represent the forecast electricity generation. IEA presents 'Reference Scenario' forecasts as the core scenario between 2000 and 2009, illustrated with orange lines. IEA presents 'New Policies Scenarios' forecasts as the core scenario from 2010 onwards, illustrated with blue lines. Cumulative Annual Growth Rate in Panel B is calculated as the slope between the WEO realised capacity (or nearest capacity forecast where applicable) and furthest WEO capacity forecast.

\footnotetext{
53 IEA World Energy Outlook.
} 


\subsubsection{Installed Capacity}

In addition to forecasting energy generation, the IEA also forecast installed capacity growth in the short- and medium-term (see

Figure 4). Generally, the IEA forecast increasing capacity between 2000 and 2016 . However, the realised capacity exceeded year-on-year projections during the entire period examined. As capacity grew, so did the forecasts. In 2000 , installed capacity was forecast to grow by $1.26 \%$ per annum. By 2006 , this forecast had risen to $2.31 \%$ per annum. In reality, the realised growth in capacity was almost double, at 3.8\% per annum between 2000 and 2014. This increase in capacity suggested that the EU was not only replacing existing capacity, but also actively extending its generation fleet - despite forecasts of electricity demand beginning to decline.

Figure 4: Realised and Forecast Capacity, 2000-204054

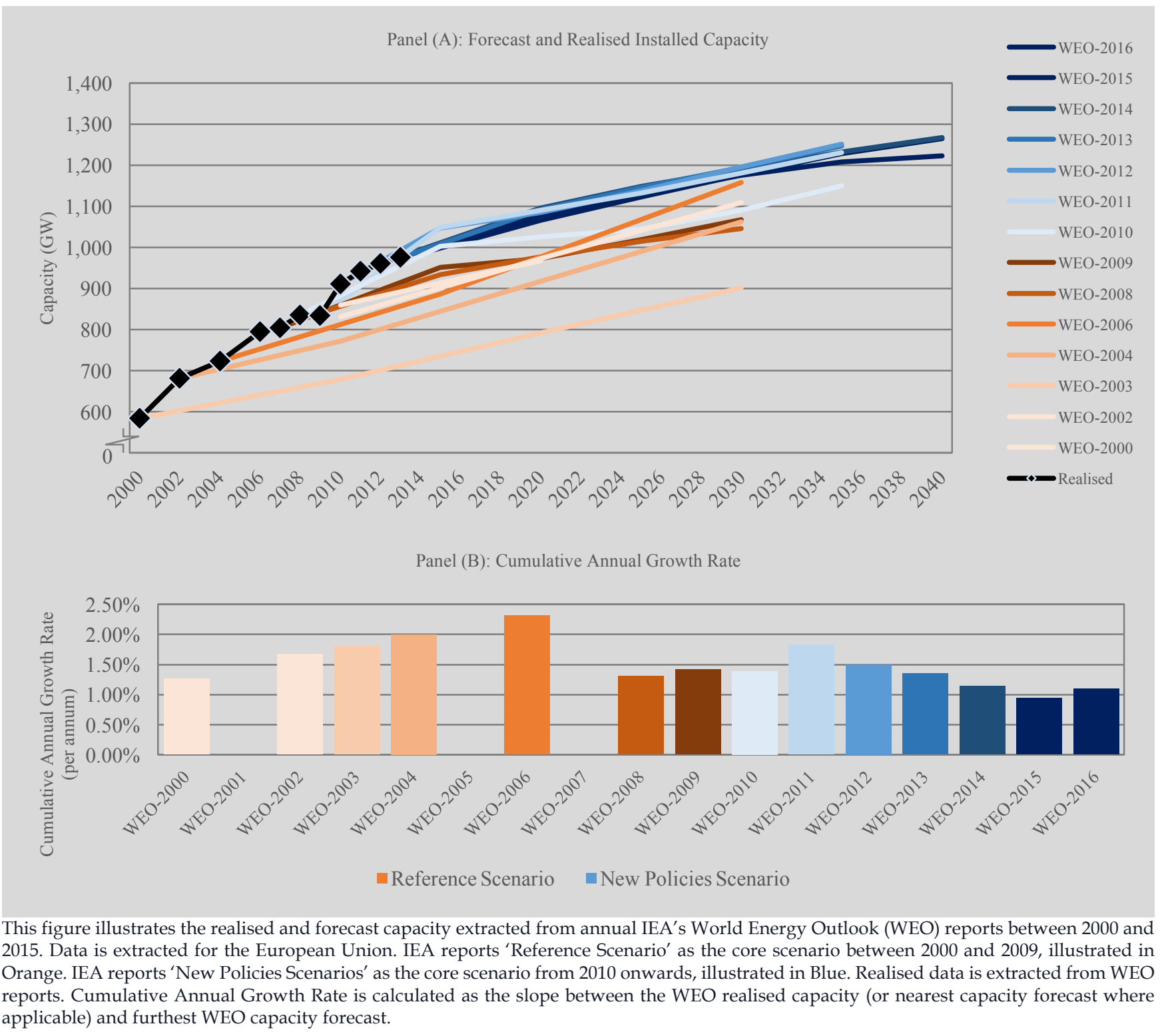

54 IEA World Energy Outlook. 
Unlike electricity generation forecasts, the GFC had little impact on capacity in the short and medium term. The forecast capacity growth in $2008(1.31 \%)$ and $2009(1.42 \%)$ were lower than the $2.31 \%$ forecast in 2006. Nonetheless, 2009 saw a large increase in realised capacity. The lack of impact is likely due to the lengthy project lead-times for capacity investments, and the various EU policy incentives to support RES capacity deployment. Between 2008 and 2016, forecasts of installed capacity ranged from $0.93 \%$ to $1.83 \%$ per annum. These estimates remain high, despite taking into account new policies in the central scenario. The results imply that the EU will continue to expand its power fleet, despite potential overcapacity. As noted previously, overcapacity and reduced operating hours are potentially damaging for coal-fired power plants, which require a high turnover to remain profitable. Alternatively, a fall in the underlying price of fuel increases the profitability of OPEX technologies.

\subsubsection{Commodity Markets}

The following section examines the evolution of commodity prices in the EU between 2000 and 2015. Figure 5 shows the change in global coal, global oil, and European natural gas prices. The three variables are the standard commodities reported in the World Bank's Global Commodity Markets reports. For each year, we extract the realised commodity price at year-end and the forecast price in the short- and medium-term; between now and 2025.

Across all commodities, the realised prices show increasing prices up until 2008. The price of coal nearly tripled between 2000 and 2008, from $\$ 34 / \mathrm{mt}$ to over $\$ 100 / \mathrm{mt}$. This relative price increase was greater than that of oil $(\$ 30 / \mathrm{bbl}$ to $\$ 74 / \mathrm{bbl})$ and natural gas $(\$ 4 / \mathrm{mmBtu} \$ 11 / \mathrm{mmBtu})$ over the same period. However, while oil and natural gas saw steady growth over the period, coal experienced a brief decline in price during the 2004-07 period. During this window, coal was the relatively cheap fuel in power generation and thus would have been economically attractive for power generators in the absence of a substantial carbon price.

As late as the 2007 forecasts, the general assumption was that global commodity prices were above fundamentals and were expected to fall towards their long-term prices. By 2015, coal was expected to decline to between $\$ 27 / \mathrm{mt}$ and $\$ 39 / \mathrm{mt}$ (-27 to $-39 \%$ ), oil was expected to fall between $\$ 17 / \mathrm{bbl}$ and $\$ 35 / \mathrm{bbl}$ (-22 to $-46 \%$ ), and natural gas was expected to fall between $\$ 2.4 / \mathrm{mmBtu}$ and $\$ 5 / \mathrm{mmBtu}(-23$ to $-47 \%)$. The GFC represents a significant structural break in these estimates. Following the GFC, both realised and forecast commodity prices remained higher than pre-2008 levels.

European utilities acknowledged rising commodity prices earlier than those external to the industry. Pre-2008, utilities 55 assumed that commodity prices would remain high for many years which would also impact wholesale electricity prices. These estimates stemmed from moderate oil demand growth and diminishing oil supply growth. ${ }^{56}$ Geopolitical tensions with Russia were expected to put upwards pressure on oil and gas prices. ${ }^{57}$ Utilities, such as RWE, expected arbitrage between oil, coal, and gas markets to keep prices high in all three markets. ${ }^{58}$ High commodity prices in all three markets would mean expensive fuel contracts for power generators, keeping wholesale electricity prices high.

Conflicts between Russian gas suppliers and the Ukrainian government began in 2006, when contract negotiations broke down and Russia cut off Ukrainian gas supplies. ${ }^{59}$ Gazprom threatened to halt gas supplies again in 2007 and disputes continued through 2009.60 These Russian-Ukraine gas disputes began to spill over into the wider European energy system and threatened natural gas supplies in numerous European countries. The uncertainty

\footnotetext{
55 RWE, “Annual Report”; E.ON, “Annual Report.”

56 International Energy Agency (IEA), “Oil Market Report 2006,” 2006.

57 Peggy Hollinger, "Gazprom Threat Adds to Fear on EU Supply," Financial Times, 2006.

58 RWE, "Annual Report."

${ }^{59}$ Hollinger, "Gazprom Threat Adds to Fear on EU Supply."

${ }^{60}$ Harvey Morris, "Ukraine 'Confident' of Gas Flow to the EU," Financial Times, 2009.
} 
over Ukraine's gas supply caused price spikes in European gas prices and increased long-term concerns over prices and security of supply.

At the same time, technological advances in horizontal drilling and hydraulic fracturing led to a massive boom in recoverable gas and oil in the United States and fundamentally changed global commodities markets. As American utility companies rushed to take advantage of inexpensive gas, American legislators took the opportunity to put further environmental controls on unabated coal-fired power stations, rapidly reducing American demand for coal. As a result, US coal companies began exporting more and more coal, leading to an oversupply of coal in international markets and a drop in global coal prices. ${ }^{61}$ As global coal prices fell, cheap coal became an attractive fuel in power generation for EU utilities. As European utilities adopted more coal-fired power, the price for natural gas in Europe began to decline.

Figure 5: Forecast and Realised Coal, Oil and Natural Gas Prices, 2000-202562

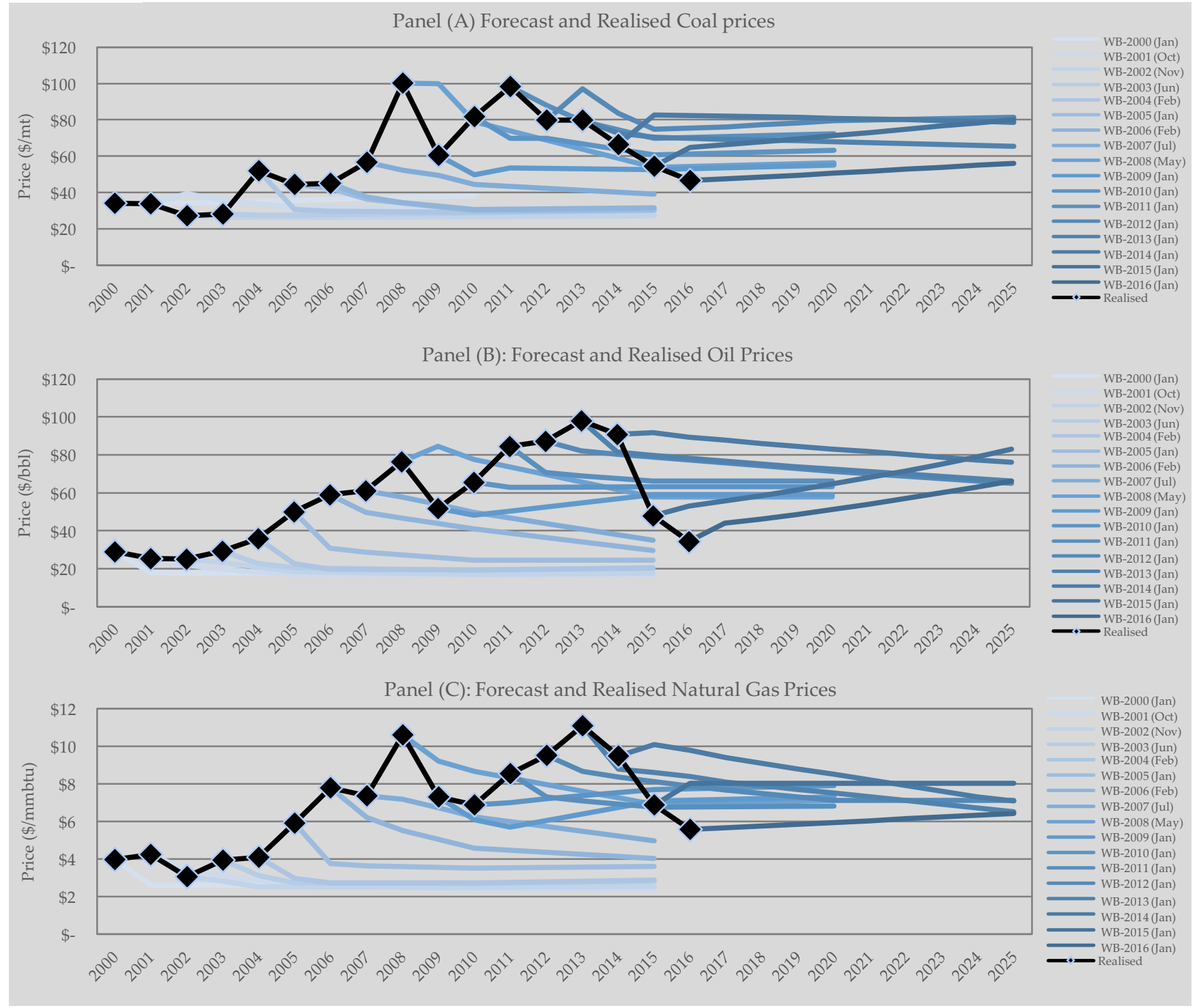

61 Sylvia Pfeifer, “Cost Advantage Fuels Demand for Coal," Financial Times, 2012.

62 World Bank's Global Commodity Markets reports 
The black line presents the realised price of the commodity. The blue lines illustrate the forecast price in the short- to medium-term from each report. The date in the legend represents the month the forecast was made. The number of published reports varied across years, thus we selected the earliest report.

The sudden prospect of domestic gas resources in the EU, and the shift in commodity prices, were also effective in diminishing Russian resource aggression which had dominated policy concerns from 2005 to $2009 .{ }^{63}$ Many countries in the EU began exploring their own options for shale gas recovery. ${ }^{64}$ Policy and public attitudes towards domestic EU shale gas development varied, with full bans in some countries (e.g. France, Bulgaria, Netherlands, Germany, Scotland, Wales) and moderate support in others (e.g. Denmark, England, and Poland). ${ }^{65}$ Ultimately, a combination of stronger environmental controls, property rights, difficult geology, and labour and equipment capacity would all prevent the rise of shale gas in the EU, and the industry never reached commercial production. 66 ConocoPhillips, the last international oil company exploring for shale gas in Poland, announced it would be ceasing operations in Poland in 2015.67

\subsubsection{A Low-Carbon Energy Future}

\section{Carbon Pricing}

To address a major pillar of climate policy in the EU, the Emissions Trading Scheme (EU ETS) was introduced in 2005 as a market-based mechanism to reduce emissions. The cap and trade system set a maximum amount of total greenhouse gasses which would be emitted by all participants in the EU ETS, and the cap reduced in size each year. Initially, during Phase I, carbon allowances were 'grandfathered' to utilities to address potential international competition and harmonisation issues; but if a utility required more credits, they must purchase them from willing sellers. The EU ETS was not without challenges. During the period of grandfathering, high market prices for carbon meant utilities could sell these 'free gifts' for windfall profits. In 2006, carbon prices peaked at over $€ 30 /$ ton, in part due to water stress and concerns for hydro and nuclear power capacity. 68 Speculation regarding the proportion of emissions allowance which would be auctioned in Phase II of the ETS also raised the price of carbon allowances. ${ }^{69}$

Despite entering the ETS second phase, the economic slowdown post-GFC substantially reduced demand for emissions allowances. Substantial uncertainty also marred the second phase of the EU ETS as member states were not forthcoming with how many emissions certificates would be auctioned rather than allocated. ${ }^{70}$ However, as Phase II continued and Phase III began, it became clear that a substantial surplus of emissions certificates existed and the price became less and less consequential to carbon-intensive generators. ${ }^{71}$ An over-supply of allowances caused the price of emissions to drop substantially. ${ }^{72}$

As coal-fired power generation typically has twice the emissions of gas-fired generation, the EU ETS was intended to shift investment away from coal by increasing the relative cost of operations. However, the low carbon price observed in the EU ETS resulted in coal-fired power generation retaining competitiveness due to a lack of penalty for carbon emissions.

\footnotetext{
63 Paul Betts, “Gas Glut That Risks Spoiling Russia's Power Games,” Financial Times, 2009.

${ }^{64}$ Gideon Rachman, "Shale Gas Will Change the World," Financial Times, 2010.

65 Sylvia Pfeifer, Pilita Clark, and Ed Crooks, "Critics Try to Stifle Shale Gas Revolution,” Financial Times, 2011; Tara Patel,

"Fracking in Europe," Bloomberg, 2015.

66 Paul Stevens, "Shale Gas in the United Kingdom," 2013.

67 Agnieszka Barteczko, “Conoco the Last Global Oil Firm to Quit Polish Shale Gas," Reuters, 2015.

68 Fiona Harvey, "Carbon Permits Reach Record Prices," Financial Times, 2006.

69 Fiona Harvey, "Power Groups in the Dark over Auction Plan," Financial Times, 2007.

70 Ibid.

71 Pilita Clark, Joshua Chaffin, and Javier Blas, "EU Carbon Prices Crash to Record Low," Financial Times, 2013.

72 Ibid.
} 


\section{The Growth in Renewables}

While recognising the need for renewable power generation, major utilities did not see the deployment of renewables as a threat to large conventional generation. Utilities instead anticipated the deployment of gas, nuclear, and clean coal generation to decarbonise the grid, supported by material and increasing carbon prices. ${ }^{73}$ In reality, incumbents were surprised by the rapid deployment of RES over the past decade. As noted previously, installed capacity in the EU continually exceeded forecast growth. The majority of this growth has come from new onshore wind and solar PV installations, ${ }^{74}$ and the deployment of renewables also continued in the period following the global financial crisis. ${ }^{75}$

A variety of factors contributed to the rapid deployment of RES generation. The first factor is the rapidly falling cost of energy from solar and wind sources. The average levelised cost of energy (LCOE) for onshore wind fell from around \$93/MWh in 2009 to around $\$ 72 /$ MWh by end of 2015. ${ }^{76,77,78}$ The LCOE for onshore wind could, as an estimate, decline to around $\$ 53 /$ MWh by 2025.79 The average LCOE for solar fell from $\$ 306 / \mathrm{MWh}$ in 2009 to around $\$ 130 / \mathrm{MWh}$ in $2015.80,81,82$ The LCOE of solar could, as an estimate, decline further to around $\$ 55 / \mathrm{MWh}$ by 2025.83 As a result of their falling costs, wind and solar PV capacity grew from approximately $13 \mathrm{GW}$ in 2000 to over $235 \mathrm{GW}$ in 2015 - a compound annual growth rate of $21 \% .{ }^{84}$ By 2040, the average LCOE global for solar $\mathrm{PV}$ is expected to be $\$ 40 / \mathrm{MWh}$ and approximately $\$ 47 / \mathrm{MWh}$ for onshore wind, ${ }^{85,86}$ making them increasingly competitive against conventional thermal generation.

The deployment of renewables was also incentivised by a range of policy incentives. In particular, many EU countries implemented feed-in tariff programmes for renewables generators, net-metering programmes, capital grants, investment or sales tax credits, and public institution tendering programmes. ${ }^{87}$ These subsidies sheltered RES from risk exposure in the wholesale electricity market, ensuring attractive returns for investors to encourage investment in the technology. As such, a wider range of investors have been attracted to the industry and the deployment of RES has dramatically increased in the EU.

\section{The Stagnation of Nuclear and CCS}

The growth of renewables contrasts starkly with the stagnations of nuclear generation and the lack of carbon capture and storage (CCS) equipped power generation. Prior to the post-GFC drop in electricity, emissions, and commodity prices, nuclear was favoured as a low-carbon generating option. ${ }^{8} 8$

\footnotetext{
73 Financial Times, “Nuclear Pays Its Way," Financial Times, 2006; Mike Farley, "Generation Gap and Clean Coal's Vital Role," Financial Times, 2007.

74 European Environment Agency, "Renewable Energy in Europe 2016: Recent Growth and Knock-on Effects" (Copenhagen, 2016).

75 Pilita Clark, “Europe Sees Surge in Clean Power," Financial Times, 2012.

76 “BNEF New Energy Outlook," 2016, doi:10.1017/CBO9781107415324.004.

77 Joseph Salvatore, "World Energy Perspective - Cost of Energy Technologies," World Energy Council, 2013, doi:ISBN: 9780 946121304.

78 IRENA, "The Power to Change: Solar and Wind Cost Reduction Potential to 2025" (Bonn, Germany, 2016).

79 IRENA, "The Power to Change: Solar and Wind Cost Reduction Potential to 2025" (Bonn, Germany, 2016).

80 “BNEF New Energy Outlook," 2016, doi:10.1017/CBO9781107415324.004.

81 Joseph Salvatore, “World Energy Perspective - Cost of Energy Technologies,” World Energy Council, 2013, doi:ISBN: 9780 946121304.

82 IRENA, “The Power to Change: Solar and Wind Cost Reduction Potential to 2025" (Bonn, Germany, 2016).

83 IRENA, "The Power to Change: Solar and Wind Cost Reduction Potential to 2025."

84 BP plc, "BP Statistical Review of World Energy 2016."

85 “BNEF New Energy Outlook," 2016, doi:10.1017/CBO9781107415324.004.

86 Joseph Salvatore, "World Energy Perspective - Cost of Energy Technologies," World Energy Council, 2013, doi:ISBN: 9780 946121304.

87 Janet L. Sawin et al., “REN21 2016 Global Status Report,” 2016.

88 Financial Times, "Nuclear Pays Its Way."
} 
Despite an earlier nuclear 'revival', ${ }^{89}$ the Fukushima accident in March 2011 caused a large shift in public opinion away from nuclear power. Countries, most notably Germany, accelerated phase-out plans for nuclear generation, responding to widespread public demand. ${ }^{90}$ Nuclear ambitions across the continent were substantially dampened, leaving utilities uncertain as to whether nuclear generation would receive future policy support. ${ }^{11}$ The stagnation of nuclear leaves a clear role for large capacity generators to supply baseload capacity for extended periods of time: a role for which coal-fired generation is the most apt.

In contrast, new generators are in planning or construction stage in some EU member states, including: Bulgaria, Finland, France, Poland, Romania, Slovakia, and the UK. ${ }^{92}$ EU member states Belgium, Spain, Finland, and Sweden have already been successful in adding nuclear capacity by upgrading existing reactors. ${ }^{93}$ For these member states, coal is likely to directly compete with nuclear for baseload capacity, thus plans for coal-fired capacity will be smaller, if at all.

Thermal generation with CCS also failed to achieve meaningful deployment, as not a single CCS project was successful in receiving funding under the EEPR or the first phase of the NER300. ${ }^{94}$ This left CCS projects largely unfunded by the EU until July 2014 when the results of the second phase of the NER and funding were announced. Overall, 21 power plant CCS projects in the EU have been cancelled or put on hold. ${ }^{95}$ The single CCS project receiving funding, the UK's Whiterose Project, was again thrust into uncertainty when the UK government rescinded its own funding of CCS. ${ }^{96}$ Targeted policy support for CCS has also diminished as electricity prices have fallen and massive build-outs of wind and solar capacity have demonstrated the promise of renewables as a lowcarbon generating option. In many regards, renewables seem to have won the favour of policymakers by demonstrating reliable delivery and constantly reducing costs.

\footnotetext{
89 Rebecca Bream and Joshua Chaffin, “European Nuclear Industry in Grips of Revival,” Financial Times, 2009.

90 Gerrit Weismann, “Nuclear Phaseout: Germany Faces 'Herculean' Task to Move to Renewables,” Financial Times, 2011.

91 Sylvia Pfeifer, "Fukushima Fallout: Renaissance in Nuclear Power Generation Now a Long Way off," Financial Times, 2011.

92 Wna, "Plans for New Nuclear Reactors Worldwide," World Nuclear Association, 2013.

93 Ibid.

94 Monica Lupion and Howard J. Herzog, “NER300: Lessons Learnt in Attempting to Secure CCS Projects in Europe," International Journal of Greenhouse Gas Control 19, no. 2013 (2013): 19-25, doi:10.1016/j.ijggc.2013.08.009; Global CCS Institute, "Moving CCS Forward in Europe," 2013.

${ }_{95} \mathrm{MiT}$, "Cancelled and Inactive Projects," Carbon Capture $\mathcal{E}$ Sequestration $\mathcal{E}$ MiT, n.d.

96 House of Commons Energy and Climate Change Committee, "The Future of CCS in the UK," 2016.
} 


\section{Country-specific Experiences}

The planned expansion of coal in the EU was asymmetric across time and member states. Table 1 shows that 18 member states planned 49.4 GW of new coal-fired capacity between 2005 and 2008. Of this, $35.3 \mathrm{GW}(71 \%)$ of the planned coal capacity was concentrated in Germany (20.4 GW), the Netherlands (4.5 GW), Poland (3.4 GW) and the United Kingdom (7.1 GW).

Despite large plans, much of this capacity never made it to market. By 2016, only $10.5 \mathrm{GW}$ of the planned capacity became operational and $37.8 \mathrm{GW}(77 \%)$ was ultimately cancelled. While Germany has a remaining $1.1 \mathrm{GW}$ of outstanding capacity in the planning phase; it is uncertain whether this capacity will ultimately be built. Only five countries did not cancel all their projects. This section therefore focuses on the three countries which brought the largest proportion of coal-fired generation online. This includes: Germany (4.9 GW), the Netherlands (3.5 GW), and Poland $(0.9 \mathrm{GW})$. We contrast their experience against that of the United Kingdom, which was a major user of coal-fired generation but did not build a single one of its seven planned plants.

\section{Table 1: EU 2005-08 Planned Coal Plant Status ${ }^{97}$}

\begin{tabular}{|c|c|c|c|c|c|}
\hline & $\begin{array}{c}\text { Planned } \\
(\mathbf{M W})\end{array}$ & $\begin{array}{c}\text { Operational } \\
(\mathbf{M W})\end{array}$ & $\begin{array}{c}\text { Outstanding } \\
(\mathbf{M W})\end{array}$ & $\begin{array}{c}\text { Cancelled } \\
(\mathbf{M W})\end{array}$ & $\begin{array}{c}\text { Cancelled Rate } \\
(\%)\end{array}$ \\
\hline Germany & 20,352 & 4,922 & 1,100 & 14,330 & $70 \%$ \\
\hline Netherlands & 4,470 & 3,470 & 0 & 1,000 & $22 \%$ \\
\hline Poland & 3,408 & 858 & 0 & 2,550 & $75 \%$ \\
\hline United Kingdom & 7,090 & 0 & 0 & 7,090 & $100 \%$ \\
\hline Other EU (14 states) & 14,109 & 1,260 & 0 & 12,849 & $91 \%$ \\
\hline Total & $\mathbf{4 9 , 4 2 9}$ & $\mathbf{1 0 , 5 1 0}$ & $\mathbf{1 , 1 0 0}$ & $\mathbf{3 7 , 8 1 9}$ & $\mathbf{7 7 \%}$ \\
\hline
\end{tabular}

Figure 6 shows the location of all planned and operational coal plants in the EU, and their proximity to coal reserves. Of the 65 coal plants planned between 2005-08, plants have been completed in Germany (5), Netherlands (3), Poland (1), the Czech Republic (1), and Slovenia (1). Many of these planned coal-fired plants occur in member states which have significant hard coal or lignite reserves. There are two observations with respect to the plants which became operational. First, much of the planned capacity tended to occur in countries with significant lignite or hard coal reserves. The plants that became operational also tended to occur in countries with large lignite reserves - a form of coal which is used exclusively in electricity production. Of these countries, only the Netherlands has no natural coal reserves. However, considerable quantities of coal do move through its port of Rotterdam, a major European transport hub and the location of two of its three completed plants. Second, 6 of the 11 operational plants are located directly adjacent to a local mine, whereas 35 of the $53(66 \%)$ cancelled plants are not. The implications of these observations are that member states with access to plentiful coal reserves are more likely to plan capacity, and the capacity is more likely to become operational. Of course, there are many additional factors beyond the resource landscape which affect the uptake of coal-fired generation. The following sections examine the underlying market conditions that facilitated or hindered the expansion of coal at the member state level.

97 Platts WEPP Database: Q4 2007, Q2 2016, European Climate Foundation database. 


\section{Figure 6: EU 2005-08 Planned Coal Plant Present Status and Coal Deposits ${ }^{98}$}

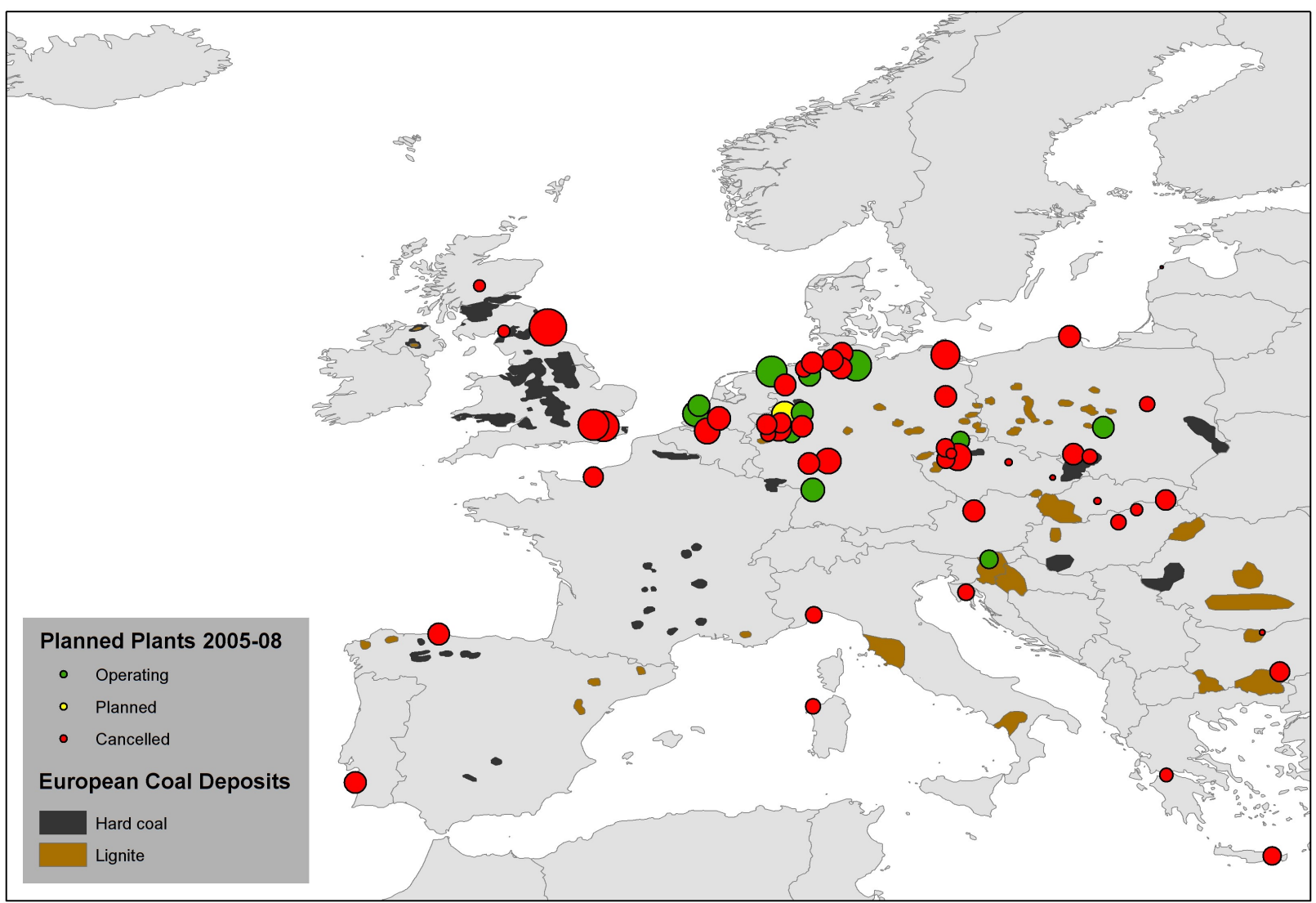

\subsection{Germany}

\subsubsection{Power Market Overview}

Germany is the largest power market in Europe, with total net electricity generation of $571.8 \mathrm{TWh}$ (excluding pumped storage), and total consumption by final consumers of 487.5 TWh in 2014.99,100 Generation is dominated by four vertically integrated companies (Vattenfall, EnBW, RWE, and E.ON). Generation market concentration declined significantly in recent years as decentralised generation proliferated. The cumulative market share of the Big Four utilities was $67 \%$ of generation in 2014, a 6-percentage point decline relative to $2010 .{ }^{101}$ In addition to these Big Four, distribution and supply markets consist of nearly 900 small public firms (Stadtwerke). ${ }^{102}$ The market is also characterised by high levels of interconnection to neighbouring countries, and a net positive export

98 Platts WEPP Database: Q4 2007, Q2 2016; European coal deposits data from various sources compiled by Oxford Smith School.

99 The Federal Network Agency, "Report: Monitoring Report 2015," 2015.

100 For the purposes of this case study production, consumption, and market share values refer to the Germany-Austria integrated market, which shares a price zone for wholesale trading and is not constrained by transmission bottlenecks at any network connections. Germany does not share price zones or contiguous markets with any of its other neighbouring countries.

101 Ibid.

102 A key driver for divergent market share profiles in generation and supply segments was divestment of upstream infrastructure by state and municipal level governments to generate revenues. Of the Big Four, EnBW is the only utility with a majority of its shares still under state control. 
balance to countries such as the Netherlands and Poland. Exports have increased in recent years and reached a net trade balance of 34.5 TWh in 2014.

The German generation mix and generation output profile has changed in recent years, with the increasing penetration of renewable sources (see Figure 7). This has also led to steadily declining wholesale market prices in Germany over the past couple of years as the increasing share of zero marginal cost renewables generation results in overcapacity of low marginal cost baseload generation (including coal-fired plants).

Figure 7: Gross Electricity Generation Profile for Germany, 1990-2014103

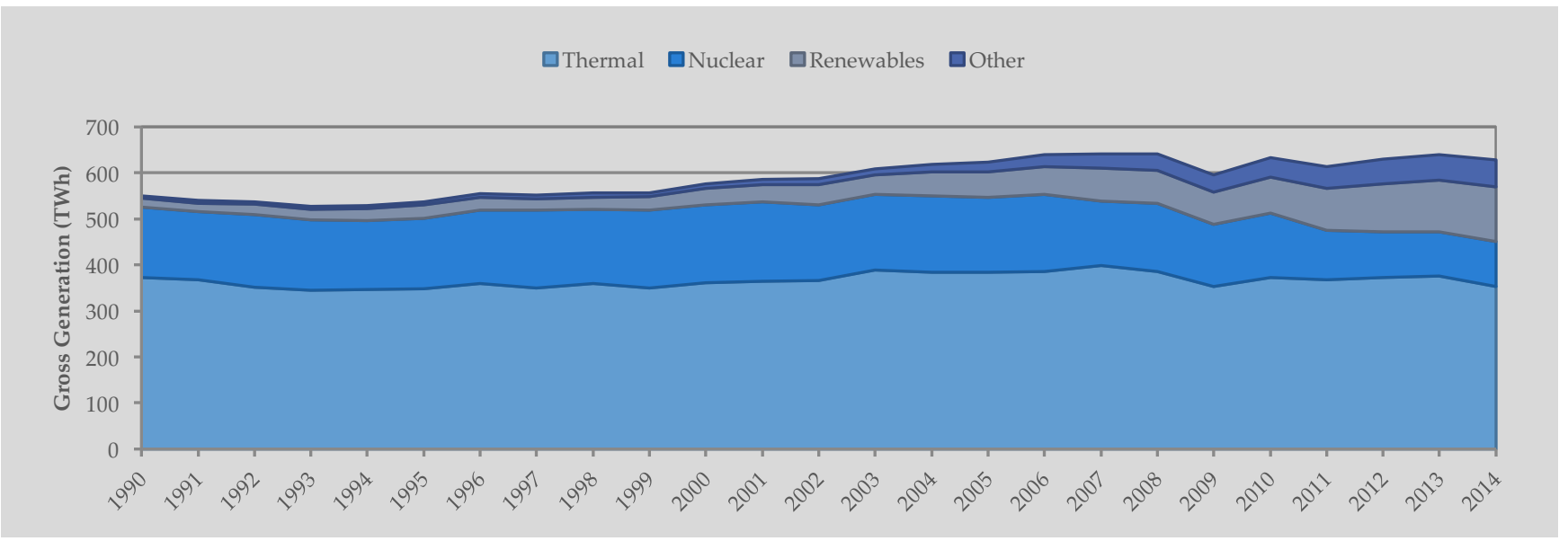

\subsubsection{Energy Policy Context}

The German energy policy landscape has evolved significantly in recent years with the implementation of the Energiewende policy reforms, including the closure of nuclear energy capacity (see

Table 2). The policy reforms outline the targets in greenhouse gas emissions and the proportion of renewables in final energy consumption between now and 2050. The dramatic reductions in emissions pose threats to coal's role in future electricity generation.

Table 2: $\mathrm{CO}_{2}$ Reduction, Renewable, and Efficiency Targets of the German 'Energiewende' (2013, 2014)104

\begin{tabular}{|c|c|c|c|c|c|c|}
\hline & 2013 & 2014 & 2020 & 2030 & 2040 & 2050 \\
\hline \multicolumn{7}{|c|}{ Greenhouse gas emissions } \\
\hline Greenhouse gas emissions (compared to 1990) & $-22.6 \%$ & $-27 \%$ & Min $-40 \%$ & Min $-55 \%$ & Min $-70 \%$ & $\begin{array}{l}\text { Min }-80 \\
\text { to }-95 \%\end{array}$ \\
\hline \multicolumn{7}{|c|}{ Increase in share of renewable energy in final energy consumption } \\
\hline Share in gross final energy consumption & $12 \%$ & $13.5 \%$ & $18 \%$ & $30 \%$ & $45 \%$ & $60 \%$ \\
\hline Share in gross power consumption & $25.3 \%$ & $27.4 \%$ & Min 35\% & $\begin{array}{c}\text { Min } 50 \% \\
(2025: 40-45 \%)\end{array}$ & $\begin{array}{c}\text { Min } 65 \% \\
(2035: 55-60 \%)\end{array}$ & Min $80 \%$ \\
\hline Share & $9.1 \%$ & $12 \%$ & $14 \%$ & NA & NA & NA \\
\hline Share in transport sector & $5.5 \%$ & $5.6 \%$ & NA & NA & NA & NA \\
\hline
\end{tabular}

103 Eurostat, "Database - Eurostat," 2016.

104 Monitoring report (2015). 
Despite these standards, Germany has vast reserves and resources of hard coal (2.5bn tonnes reserves, 83bn tonnes of known resources) and lignite (40.4bn tonnes reserves, 36.5bn tonnes known resources). ${ }^{105}$ Under current economic and technological conditions many lignite mines are still profitable in Germany - even without subsidies - but hard coal mining is not. Following the decision of the German government to phase out subsidies for hardcoal mining by 2018 the domestic production of hard coal in Germany will come to a halt and future demand for hard coal will be covered by imports.

In 2015 thousands of protesters campaigned against a unilateral shift away from coal in regions where the bulk of the German coal industry was located (e.g., the states of Brandenburg and North Rhine Westphalia). ${ }^{106}$ They argued that by exiting the coal industry Germany would gut the economy of these states and cause tens of thousands of job losses. The German mining union, IG BCE, also said hurting the industry would undermine the Energiewende by ensuring that no other countries would follow the German path. Economic concerns for the Brandenburg and North Rhine Westphalia regions were considered politically sensitive because both states' premiers were from Sigmar Gabriel's SPD.

In summer 2016 the German cabinet agreed on a further reform to the German renewable energy act (EEG Erneuerbare-Energien-Gesetz), aiming at reducing the cost of feed-in tariffs (FiT), which slowed down the growth of renewable energies in the German energy mix. The changes should slow the rapid update of renewables and lessen the impact they have had on conventional generation. The major reforms include:

- Changes in FiT structures for wind and solar power towards a competitive bidding;

- Reverse auction bidding for development rights for greenfield projects;

- Annual caps on development of onshore new wind power capacity;

- New bidding processes for solar power installations above $750 \mathrm{KW}$ and caps on biomass capacity.

\subsubsection{Coal Plant Pipeline}

During the 2005 to 2008 period, at least 18 (16,552 MW) of the 23 (20,352 MW) planned coal plants in Germany were to utilise supercritical technology. Of these 23 units, 17 were subsequently cancelled, and all five units which became operational were supercritical. ${ }^{107}$ The following paragraphs outline factors which contributed to the high cancellation rate.

Since 2010, German coal-fired generation has been competitive relative to gas-fired generation due to falling coal prices and $\mathrm{CO}_{2}$ emission allowance costs, combined with increasing natural gas prices. ${ }^{108}$ Consequently, electricity production from coal-fired power plants increased while gas and nuclear power generation contracted. The share of gas in the generation mix decreased by $3.6 \%$ from 2010 to 2013 after a rise of $5.6 \%$ from 2000 to 2010 while the generation in hard coal (lignite)-fired power plants rose by 1.1\% (2.6\%) from 2010 to 2013 after a fall of $6.3 \%(2.7 \%)$ from 2000 to 2010. The fuel switch from gas to coal due to cheap coal-fired power plants has also been explained by the need to provide, at a reasonable cost, a baseload capacity in a system where renewables have been constantly increasing. This strategy has been of great importance in the face of the nuclear sector phase-out after Japan's Fukushima disaster.

Another driver of German coal expansion relies on the potential for significant export revenues. In 2015, Germany reached record levels in its power generation. ${ }^{109}$ However, according to AGEB, improvements in energy efficiency combined with a growing share of renewable generation in the energy mix (30\%, compared to $25.9 \%$ in 2014$)$ is dampening demand. The surplus that exists has therefore been exported to Germany's neighbours (of which

105 Euracoal, “Germany,” 2016.

106 Sören Amelang, "'Time Is Running Out' - Struggle over Future of Brown Coal in Germany Heats up," Clean Energy Wire, 2015, https:// www.cleanenergywire.org/news/time-running-out-struggle-over-future-brown-coal-germany-heats. 107 One unit remains in the planning phase.

108 Agora Energiewende, “The German Energiewende and Its Climate Paradox," 2014.

109Jakub Kucera, “The German Conundrum: Renewables Break Records, Coal Refuses to Go Away,” Energypost, 2016, http:/ / www.energypost.eu/german-conundrum-renewables-break-records-coal-refuses-go-away/. 
Austria and the Netherlands are the largest net importers). Germany then became a net exporter of electricity, breaking records and impeding $\mathrm{CO}_{2}$ emission reductions abroad. As a result, despite an increasing share of renewable energy sources, carbon intensity in Germany's domestic power generation mix has risen, resulting in the 'Energiewende paradox'.

Finally, part of the increase in German coal-fired capacity has also been due to the building of new lignite power plants, which was justified in September 2012 by Germany's environment minister as a climate protection effort to replace several less efficient and old plants. ${ }^{110}$ As outlined above, Germany lignite mines are still profitable without subsidy, providing a major incentive to utilise lignite in power generation.

Table 3 shows that, by the end of 2007, Germany planned to build over 20 GW of coal-fired capacity. Much of this capacity was due online between 2012 and 2015. However, recent changes in market conditions have pushed back some plans to as late as 2020 . Of the $20 \mathrm{GW}$ of planned capacity, at least $16 \mathrm{GW}$ utilised the more efficient supercritical coal-fired boiler technology. At least eight of the 23 plants had pollution control measures. Ultimately, only five units made it to market, totalling $4.9 \mathrm{GW}$ of capacity (over $70 \%$ of the planned capacity was cancelled). The units were built by Trianel, Engie, Vattenfall, ENBW, E.ON, and RWE. All five units utilised efficient supercritical boiler technology, and at least four units contained pollution control measures. As of mid2016, Germany had 1.1 GW of coal-fired generation under construction. Mainova AG owned a small 39 MW power station which was due online in 2016, while Uniper Kraftwerke GMBH was constructing 1.1 GW of power station which was due online in 2018.

Table 3: Summary of Coal-Fired Power Pipeline for Germany, Q4 2007111

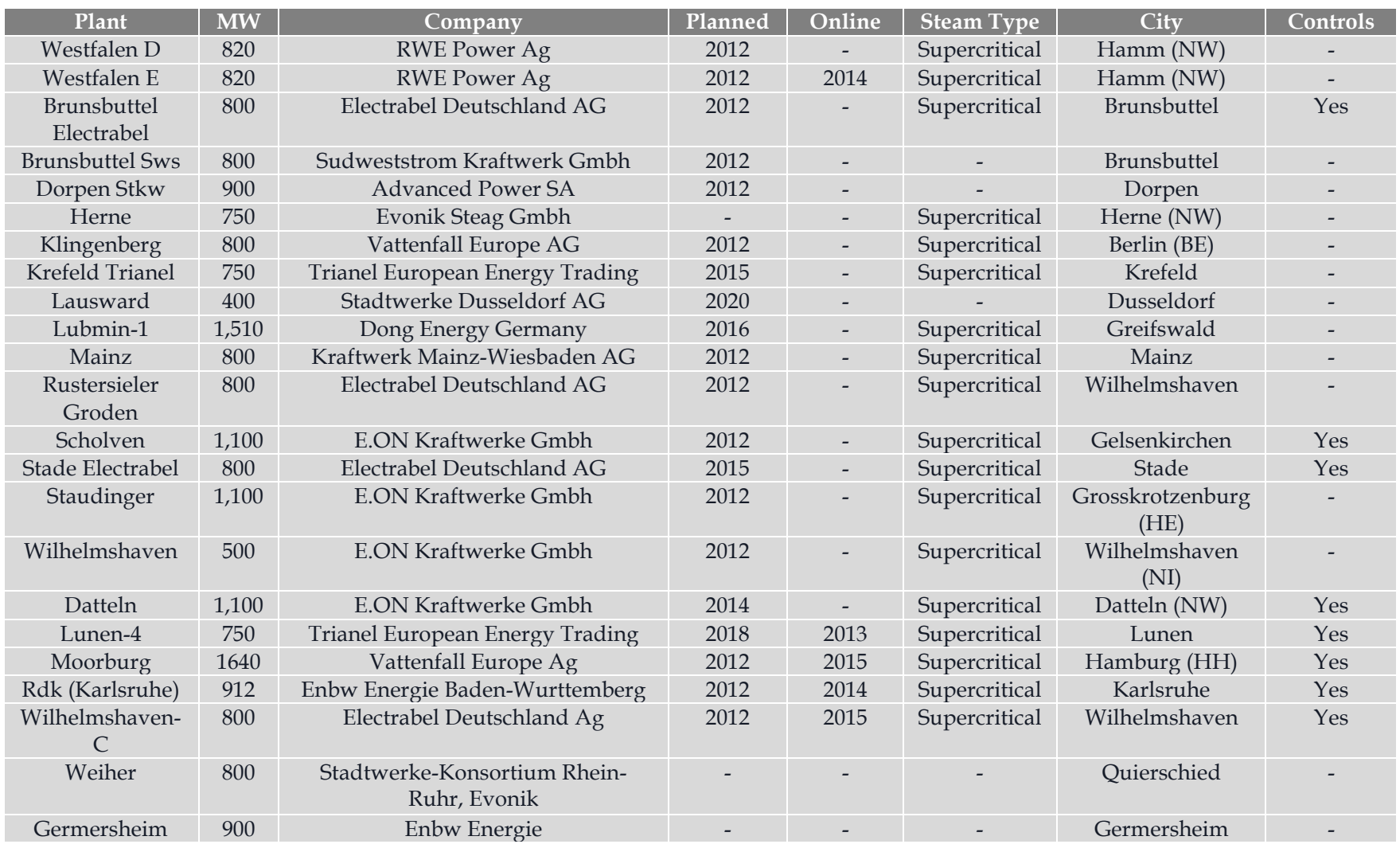

110 Robert Wilson, “Why Germany's Nuclear Phase Out Is Leading to More Coal Burning," The Energy Collective, 2014, http:// www.theenergycollective.com/robertwilson190/328841/why-germanys-nuclear-phase-out-leading-more-coalburning.

111 Platts WEPP Q4 2007 and Q4 2016. 


\subsubsection{Recent Developments and Future Policy}

System adequacy concerns have driven policy decisions to compensate thermal power generators for assets rendered uneconomic, or mandated closures in response to policy action. Beginning in 2013 the German government implemented several one-off agreements with utilities to retain uneconomic capacity within the grid - including new, high efficiency gas-fired power plants. ${ }^{112}$ In July 2015, the German government introduced a series of measures to reduce emissions while enhancing grid stability, including mandating the closure of $2.7 \mathrm{GW}$ coal-fired capacity within plans to create a system reserve. In May 2016, the European Commission cleared state aid payments of $€ 1.6 \mathrm{bn}$ of public financing to compensate for the mothballing and closure of eight lignite plants between 2016-19, 113 representing 13\% of German lignite capacity. ${ }^{114}$ Compensation for stranded assets is based on calculations of foregone future generation revenues, not costs of decommissioning.

No specific measures have yet been implemented to specifically set a roadmap for an exit from coal. Energy Minister Sigmar Gabriel has publicly commented that he would not mandate an exit from coal in Germany, 115 while recognising the importance of delivering the energy transition. There has been debate within the German government during 2016 on the potential for a long-term plan to phase out coal-fired generation, but broader socioeconomic issues (including employment in lignite mining) remains a key concern.

Germany committed itself to shift towards an emission-free economy by $2050 .{ }^{116}$ However, as highlighted by Agora Energiewende, 117 the path towards the envisioned 2050 outcome requires a 2030 power mix consisting of $55 \%$ renewables, $22 \%$ gas, and $19 \%$ coal (lignite and hard coal). As a consequence, lignite generation will have to decrease by $62 \%$ from 2013 to 2030 while hard coal-fired generation will have to drop by $80 \%$ over the same period. Accordingly, the implementation of new plants would sharply contrast with a consistent transformation strategy needed in the German coal sector in order to meet the Energiewende ambitions. As a result, additional generation capacity via the operation of new plants would either prevent the long-term planned emissions cuts or give rise to significant investment impairments putting the related companies at risk.

\subsubsection{Conclusions}

Several factors drove the expansion of planned capacity by the end of 2007. Among them were falling coal prices and $\mathrm{CO}_{2}$ emission allowance costs, increasing natural gas prices, the necessity to afford a baseload capacity, perceived potential for export revenues, as well as the building of new lignite power plants to replace several less efficient and old plants. However, changes in market conditions have delayed some plans to 2020, and ultimately, only five units made it to the market (over $70 \%$ of the planned capacity was scrapped). In May 2016, the European Commission cleared closure of lignite-fired power plants in Germany.

Germany is therefore starting to face the challenge of integrating large quantities of intermittent renewables while reducing its reliance on fossil fuels. It can be seen as a proxy for what lies ahead of other countries deploying renewables at scale. The country has begun increasing its system flexibility through increasing transmission infrastructure, interconnectors with neighbouring countries, deploying residential battery storage, electric vehicle charging stations, demand side management technologies, and the creation of virtual power plants. Yet these solutions have not yet achieved a large enough scale to be able to accommodate the volatility of renewables output.

${ }^{112 C a l d e c o t t}$ and McDaniels, “Stranded Generation Assets: Implications for European Capacity Mechanisms, Energy Markets and Climate Policy."

113 Plants include: Buschhaus (operated by Mibrag), Frimmersdorf P, Frimmersdorf Q, Niederaußem E, Niederaußem F, Neurath C (all operated by RWE), Jänschwalde F and Jänschwalde E (both operated by Vattenfall).

114 European Commission, "State Aid: Commission Clears Closure of Lignite-Fired Power Plants in Germany," Europa, 2016.

115 Ekert, V. "Germany's Gabriel rejects calls to focus on exit from coal”, Reuters,2016.

116Bundesregierung, "Energiekonzept Für Eine Umweltschonende, Zuverlässige Und Bezahlbare Energieversorgung," 2010, https://www.bundesregierung.de/ContentArchiv/DE/Archiv17/_Anlagen/2012/02/energiekonzept-

final.pdf?_blob=publicationFile\&v=5.

117 Agora Energiewende, "The German Energiewende and Its Climate Paradox." 
However, they do have the potential to do so, and can be seen as an area of expertise for which there will be international demand going forward.

\subsection{The Netherlands}

\subsubsection{Power Market Overview}

The power market in the Netherlands is well developed and reached almost $€ 55 \mathrm{bn}$ (10.9\% of GDP) in $2010 .{ }^{118}$ Since 1990, electricity consumption has mostly grown at a stable rate of around $2.6 \%$ per annum to a peak of 119 TWh in 2010. Electricity demand continued to increase until 2010 as the Dutch economy was mostly unaffected by the global financial crisis but fell by 5\% in 2011 (to 114 TWh) and declined even further in the following years. In 2013 and 2014, the Netherlands only generated about 103 TWh p.a. of gross electrical energy ${ }^{119}$ - the lowest since 2007. The industry sector is among the largest consumers of final energy.

Figure 8: Gross Electricity Generation Profile for the Netherlands, 1990-2014120

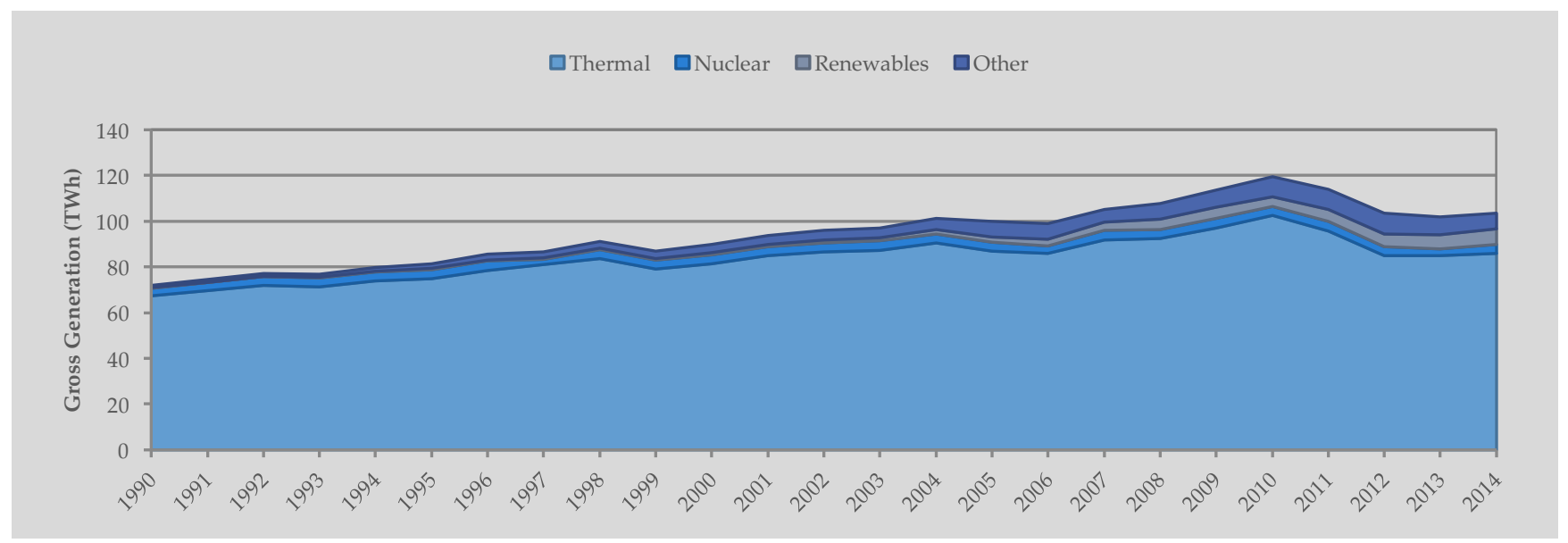

The Netherlands' installed capacity (33 GW in 2014) and fuel mix is predominantly fossil fuel-based (83\% of gross electricity generated) (see Figure 8). Natural gas and coal represent the two largest fuels in power generation. The Netherlands is Europe's second-largest producer of natural gas, after Norway, and much of this indigenous supply is used in domestic power production. In 2014, natural gas represented $52.7 \%$ of gross electricity generation. Solid fuels, such as coal, was ranked second at $28.5 \%$. For the most part, the proportions of natural gas and coal in power generation have remained relatively stable over time (only a small decrease over the last decade): combustible technologies represented $93 \%$ of power generation in 1990 and $83 \%$ in 2014. RES technology, mostly wind, only represented $6.5 \%$ of gross electricity generated in 2014 , while nuclear represented $4.0 \% .121$

\subsubsection{Energy Policy Context}

Similar to all EU member states, the Dutch energy system was subject to the three packages of liberalisation (1998, 2003, and 2009). The three packages set the EU-level objectives to liberalise and decarbonise the EU energy system, without dictating how each member state should achieve these objectives.

118 IEA, “Energy Policies of IEA Countries: The Netherlands 2014 Review” (Paris, 2014).

119 Eurostat, "Database - Eurostat."

120 Ibid.

121 Ibid. 
Regarding liberalisation, the regulatory authorities in the Netherlands have made great progress and facilitated objective decision-making, competition and independence by establishing an independent authority (under the ministry of economic affairs). In terms of market mechanisms, the power market in the Netherlands is among the most open, and liberalisation in the EU and the Dutch power system is a strong advocate for market integration in Europe. The Netherlands will be a key transit country for future electricity supply and will help couple international energy markets, fostering greater market integration and harmonisation of pan-EU electricity markets. To achieve full integration, the single market will require coupling of national European energy markets, which will likely lead to efficiency use of cross-border interconnector capacity, greater utilisation of existing EU capacity, and allow balancing of intermittent RES generation over a wider geographic area. Over the past two decades, the Netherlands has substantially increased its interconnections with both the UK and Norway. The Netherlands is ranked among top EU member states in terms of market integration, ease of entrepreneurship, investment, and innovation. ${ }^{122}$ It also plans to build additional interconnection with Germany, creating a $400 \mathrm{kV}$ Dutch-German transmission line which will provide an addition $1.5 \mathrm{GW}$ of transmission capacity. ${ }^{123}$ Further, the Netherlands plans to increase interconnection with Denmark via under-sea high-voltage interconnectors.

With regards to its other objective - decarbonisation, the Netherlands remains one of the most fossil fuel - and $\mathrm{CO}_{2}$ - intensive economies in the EU. This is despite having partially decoupled GHG emissions from economic growth. GDP grew by around 50\% between 1990 and 2012 while national GHG emissions fell by $8.8 \%$ over the same period. ${ }^{124}$ The Netherlands utilises an environmental taxation system to encourage the sustainable use of resources. However, energy products and fuels (except coal) which are used to generate electricity are exempted from the energy tax. This financial burden on coal-fired generation should (theoretically) reduce coal's competitiveness versus alternative fuel sources. However, greenhouse gas and conventional pollutant emissions from the power sector have been growing due to the large reliance on coal and natural gas, making it more difficult to achieve the Netherlands' ambitious 2020 emission reduction targets for sectors outside of the EU emissions trading scheme. ${ }^{125}$ The deployment of RES has also been relatively low as the current proportion of RES in gross electricity generation is below $4 \%$. The Dutch power system lags behind its national targets for renewable energy sources. ${ }^{126}$ Perhaps the most significant climate related decision to date was the June 2015 ruling by The Hague to legally bind the Netherlands to cut greenhouse gas emissions by $25 \%$ compared to 1990 levels by 2020. As a member of the EU, the Netherlands is already party to a binding target reducing greenhouse gas emissions by at least $40 \%$ by 2030 compared to 1990. But government plans to cut emissions by just $14-17 \%$ compared to 1990 levels by 2020 were deemed unlawful given the scale of the threat posed by climate change. ${ }^{127}$

The Dutch government has recently prepared long-term visions to transition towards sustainable energy supply by 2050. In 2011, the Rutte-I government outlined four key elements to achieve a climate-neutral economy by 2050: carbon-neutral electricity supply, sustainable use of biomass, energy savings, and CCS. ${ }^{128}$ As part of the Energy Agreement for Sustainable Growth (September 2013), the Netherlands plans to scale-up RES energy generation and deployment, and increase its use of biomass. This includes tax breaks to support local, and decentralised energy generation. Further, the Netherlands intends to phase-out inefficient coal-fired power plants and introduce CCS to support the sustainable use of fossil fuels. The construction of additional coal-fired power generation suggests that the Netherland is less likely to meet it ambitious decarbonisation goal.

\footnotetext{
122 IEA, “Energy Policies of IEA Countries: The Netherlands 2014 Review."

123 Ibid.

124 Ibid.

125 Ibid.

126 Ibid.

127 Duncan Robinson and Pilita Clark, "Hague Court Orders Cuts in Dutch Carbon Emissions," Financial Times, June 2015.

128 IEA, “Energy Policies of IEA Countries: The Netherlands 2014 Review."
} 


\subsubsection{Coal Plant Pipeline ${ }^{129}$}

During the EU's boom period of high wholesale prices between 2005 and 2008, the Netherlands planned to install four new coal-fired generating units.

Table 4 shows that a total of 4.47 GW of installed capacity was planned - all were due to go online between 2012 and 2013. At least three of the planned plants were supercritical and were fitted with particle control measures to reduce harmful particle emissions. The installation of these 'clean coal' plants was seen as congruent with the Netherlands' long-term energy and climate policy. Only one of its planned coal-fired units was cancelled - the most polluting plant in Geertruidenberg. The remaining three plants were completed in 2014 and 2015.

\section{Table 4: Summary of Coal-Fired Power Pipeline for the Netherlands, Q4 2007130}

\begin{tabular}{|c|c|c|c|c|c|c|c|c|}
\hline Plant & MWs & Company & Planned & Online & Steam Type & City & Controls \\
\hline Amer & 1,000 & Essent NV & 2013 & - & - & Geertruidenberg & - \\
\hline Centrale Rotterdam & 800 & Electrabel Nederland & 2012 & 2014 & Supercritical & Maasvlakte & Yes \\
\hline Eemshaven & 1,600 & RWE Energy Nederland NV & 2013 & 2015 & Supercritical & Eemshaven & - \\
\hline Maasvlakte & 1,070 & E.ON Benelux BV & 2012 & 2015 & Supercritical & Maasvlakte & Yes \\
\hline
\end{tabular}

As of July 2016, the Netherlands had an additional 2.7 GW of ultra-critical coal-fired capacity under construction. These plants have been designed to use biomass or woodchips as alternative fuels.

The recent construction of coal-fired power plants was in part an attempt to increase future energy security due to declining indigenous natural gas reserves (and production) from its Groningen fields. The Netherlands is expected to become a net importer of natural gas by 2025 .

\subsubsection{Recent Developments and Future Policy}

The Netherlands has committed itself to EU and international climate action. More precisely it confirmed its willingness to participate in the EU 2020 strategy and to decrease $\mathrm{CO}_{2}$ emissions in the transport sector by $17 \%$ by 2030 , and by $60 \%$ by 2050 . The Netherlands also supported the EU GHG emissions reduction of at least $40 \%$ by 2030 , and of more than $80 \%$ by 2050 . It successfully consolidated its energy policy and started to move towards isolating GHG emissions from economic growth. For instance, in 2012, its GHG emissions were 8.8\% lower than in 1990, while GDP had risen by $50 \%$ at the same time. Opening new coal plants would therefore contradict its climate targets and impede the implementation of an energy transition that should be supported by the development and commercialisation of technologies to clean coal, capture and store carbon, save energy, reduce emissions (especially in transport), and foster employment and training. Despite its significant progress, the Netherlands still lags behind its ambitious national target for renewable energy sources. From 2005 to 2013 the share of renewables in final energy consumption rose to $4.5 \%$, well behind the target of $14 \%$ by 2020 . However, this trend is likely to be reversed in the coming years. As of late-2016, the Dutch parliament unexpectedly voted to close all remaining coal-fired power stations to ensure the country meets its Paris climate commitments. While the vote is non-binding, Dutch politicians are seeking quick implementation of the motion. An immediate implementation is seen as the most cost-effective method of meeting Paris targets and would result in the closure of the Netherland's most recently built coal-fired utilities, despite being among the cleanest in Europe. ${ }^{131}$

\subsubsection{Conclusions}

The Netherlands has made great efforts towards market integration but must redouble its efforts on decarbonising its energy system. The Netherlands has an overreliance on 'clean coal' technology and the unrealistic prospect of CCS on coal-fired power generation. Three plants were completed in 2014 and 2015 and only one was cancelled -

129 This section is based on: Ibid.

130 Platts WEPP Q4 2007 and Q4 2016.

131 Arthur Nelsen, “Dutch Parliament Votes to Close down Country's Coal Industry,” The Guardian, September 2016. 
the most polluting plant in Geertruidenberg. Additionally, as of July 2016, the Netherlands had an additional 2.7 GW of coal-fired capacity under construction.

While non-binding, the Dutch parliament has also demonstrated its commitment to achieving its Paris climate targets through its recent vote to close all coal-fired power stations. Over the following years, the Netherlands must decide how it will achieve this low-carbon energy future. At present, the proportion of renewables in the energy system does not facilitate the transition towards a low-carbon economy, and the proportion RES in the nation's fuel mix remains relatively low compared both to other EU member states and its own targets. As the indigenous supply of natural gas is in decline, and the Netherlands lacks domestic coal reserves, the Netherlands could use this opportunity to cease building fossil fuel-fired generating assets and transition towards low-carbon alternative energy sources. Alternatively, the Netherlands can push through legislation to strand coal-fired utilities through early closure, or consider increasing minimum carbon prices, applying more stringent efficiency and GHG standards, or increasing the proportion of high-CAPEX technologies in the Dutch energy system which can phase out coal through merit order.

\subsection{Poland}

\subsubsection{Power Market Overview}

Poland is the sixth largest electricity market in Europe with total production of 159 TWh in 2014. The country remains on the lower end of the scale in terms of electricity production per person per unit of GDP. However, electricity consumption in Poland has grown more rapidly than in any other European country over the past decade, with a 20\% increase between 2003 and 2013.

During the transition to a market economy in 1989, Poland's five state-owned companies were divided into 32 producers, 33 electricity distribution entities and four lignite mines retaining their state enterprise status. With the introduction of the Energy Act (1997) the foundations of a liberalised energy market began taking shape. Although private capital was enabled to invest in the companies, the state retained the majority shareholding. From 2007 onwards, a wave of consolidation took place during which the currently four vertically integrated energy companies were created: PGE, Tauron, Energa and Enea.

Figure 9 presents the Polish gross electricity generation profile.

Figure 9: Gross Electricity Generation Profile for Poland, 1990-2014132

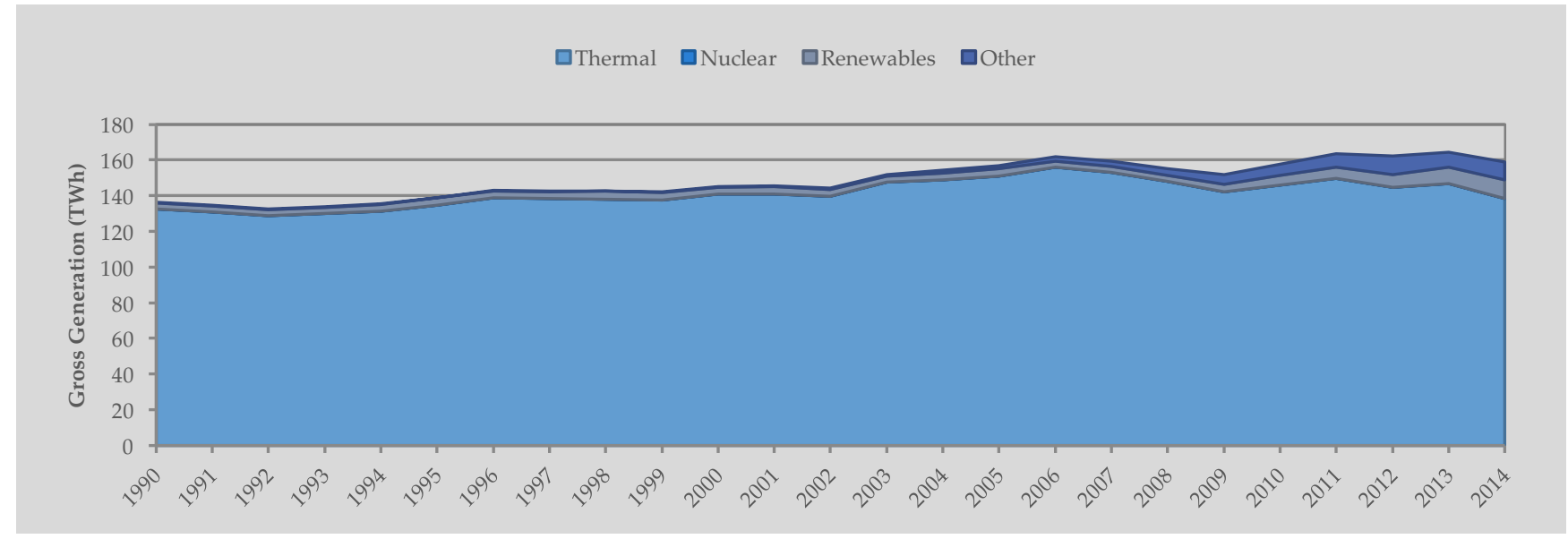

132 Eurostat, “Database - Eurostat." 
There are currently 19 large 'systemic' power plants in Poland running primarily on hard coal or lignite. These stations account for roughly $75 \%$ of total electricity produced in the country. Hard coal accounts for roughly twothirds of thermal power generation, with lignite making up the rest. However, lignite has been increasing its share of total power generation. The largest of these systemic plants include Bełchatów, Opole, Turów, Połaniec, Kozienice, Rybnik, and Dolna Odra. In addition, there are 50 large combined heat and power (CHP) plants operating close to urban areas. CHP plants are also present within industrial clusters (currently 160 such plants are in operation).

Table 5: Electricity Generation Capacity in Poland as of $2014^{133}$

\begin{tabular}{|c|c|c|}
\hline Source & $\begin{array}{c}\text { Capacity } \\
\text { (GW) }\end{array}$ & $\begin{array}{c}\text { Proportion of } \\
\text { Capacity }\end{array}$ \\
\hline Systemic Power Plants & 31.1 & $79 \%$ \\
\hline Lignite & $(9.2)$ & $(23.4 \%)$ \\
\hline Hard coal & $(20.3)$ & $(51.6 \%)$ \\
\hline Natural gas & $(0.9)$ & $(2.4 \%)$ \\
\hline CHP & 1.9 & $4.8 \%$ \\
\hline Hydro & 2.2 & $5.6 \%$ \\
\hline Pumped storage & $(1.3)$ & $(3.4 \%)$ \\
\hline Renewables & 4.2 & $10.6 \%$ \\
\hline Wind & $(3.9)$ & $(9.8 \%)$ \\
\hline Total & $\mathbf{3 9 . 4}$ & $\mathbf{1 0 0} \%$ \\
\hline
\end{tabular}

In 2014, renewables (ex. hydro) accounted for $10.6 \%$ of total electricity generation with biomass co-firing in coal power stations and wind making up the bulk of RES power. These two sources of electricity have also seen the fastest growth in recent years: $40 \%$ and $42 \%$ compound annual growth rate, respectively. This is primarily due to the large wind resources, especially in the north of the country, and the relative ease of using biomass co-firing for compliance with renewables obligations. However, the regulations regarding renewables support is undergoing reform, which will see biomass receiving reduced support going forward (see below).

One of the most pressing issues for the Polish generation fleet, especially the hard coal and lignite power plants, is its age. This can result in unscheduled unit down time making it difficult for the transmission system operator to maintain the desired network frequency and its reserve margin target of $9 \%$ of domestic power plant capacity. Although there has been a rapid increase in power capacity since 2009 the reserve margin has been falling. This is due in part to most of the new additions being wind and in part to the fact that the ageing generation fleet has seen the amount of capacity under maintenance during peak times grow by $9.3 \%$ a year between 2006 and 2013 . Furthermore, several units are scheduled to be decommissioned in the near future due to either age, or concerns over pollutant emissions, or both. Based on plans announced by the largest power producers an estimated 5.4 GW of capacity will go off-line by 2020 . Some of this will be replaced by new capacity, mainly new (high efficiency) coal, although CCGT and wind projects are also being pursued.

Up to the beginning of 2014, power prices in Poland followed very closely those of its neighbouring markets (Scandinavia, Slovakia, Czech Republic, and Germany), at approximately €35/MWh. ${ }^{134}$ In fact, they were typically slightly below, allowing for Poland to be a net exporter of electricity (see Figure 10). However, after introducing an operating reserve mechanism prices have increased and Poland has begun to import electricity, primarily from

133 ARE "Sytuacja w elektroenergetyce", as of 31st December, 2014.

134 http:/ / raportroczny.energa.pl/strona/rynek_energii_elektrycznej_w_polsce 
the German market. Another reason why prices have diverged from regional peers is due to the dynamics between power prices and coal prices.

\section{Figure 10: Volumes of Exchange Power Between Poland and Neighbouring States 135}

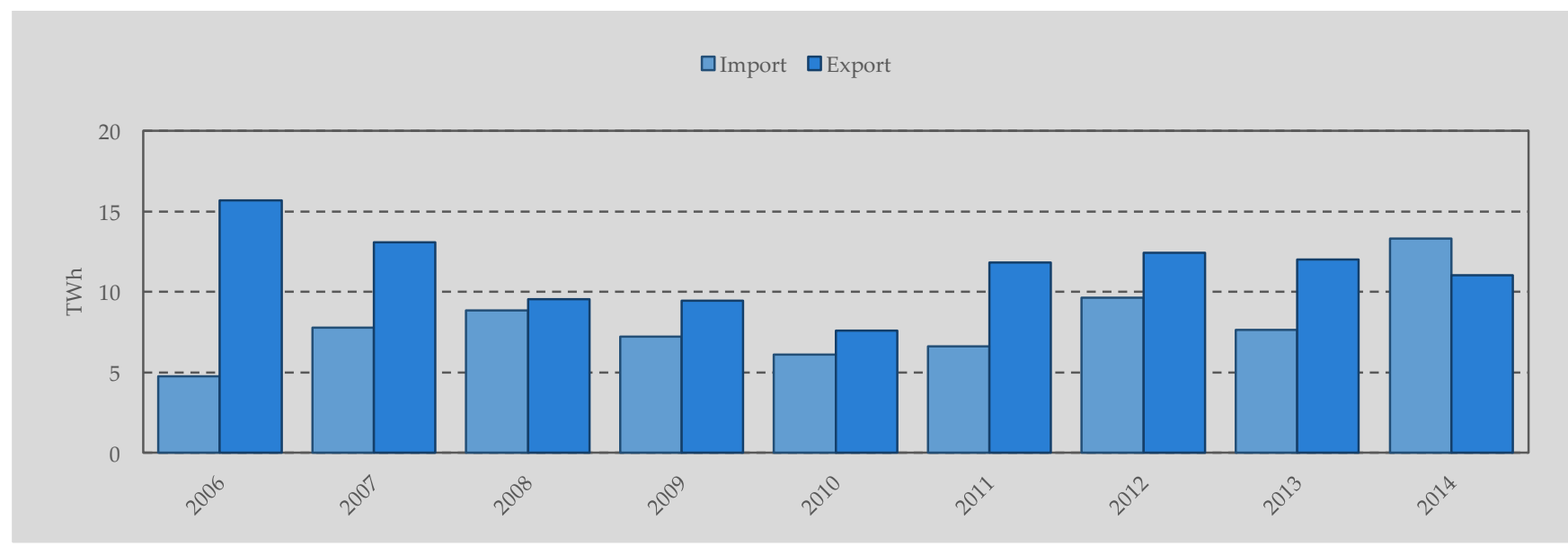

\subsubsection{Energy Policy Context}

According to a report by the Warsaw Institute for Economic Studies, ${ }^{136}$ the coal mining and energy production industry collected five times more subsidies than the renewables industry (excluding old hydro) from 2005 to 2012. In particular, it received over that timeframe about $0.5 \%$ of GDP per year. Poland has actually witnessed a diversification of subsidies accounting for free EU carbon trading certificates, certificates for co-firing biomass, and other EU subsidies. Those data underline how deeply coal-oriented the energy infrastructure is and thus explains the call for the 'rehabilitation of coal' in the EU that was launched by the Polish prime minister, Donald Tusk. ${ }^{137}$

The new objectives in Poland's national energy policy are to improve the security of energy supply and energy efficiency while reducing the cost structures and the economic and environmental impacts. As a result, a Centre of Clean Coal Technologies has been created to define the best ways for Polish coal to turn into an environmentally friendly and socially acceptable fuel in the future. ${ }^{138} \mathrm{It}$ is co-funded by the EU and co-directed by the Central Mining Institute and the Institute of Chemical Coal Processing. The objective is to overcome legal barriers by developing new efficient and low emissions technologies in the power sector, where the majority of power stations are over 25 years old and about $25 \%$ have been operating for more than 30 years. Nowadays the lignite-fired power plants are, for instance, being refitted to satisfy EU environmental regulations.

The Operational Reserve Mechanism (ORM) introduced in Poland in 2014 has lifted both peak and baseload prices. The purpose of this instrument is to counteract the trend in falling wholesale electricity prices, also present in other markets, caused by falling coal prices and increased renewables penetration. PSE (the transmission system operator in Poland) pays those generators that have spare capacity not covered by sales contracts a maximum of PLN 42/MWh (an equivalent of the average fixed cost less depreciation of Polish generators), subject to a reverse

135 http:/ / raportroczny.energa.pl/strona/rynek_energii_elektrycznej_w_polsce

136 Warsaw Institute for Economic Studies, "Subsidising the Past: How Public Aid and Ignoring External Costs Keep Poland's Coal-Based Energy System Alive," 2014, http://www.greenpeace.org/eu-unit/Global/eu-unit/reportsbriefings/2014/20140408 Warsaw Institute for Economic Studies coal financial aid briefing.pdf.

137 Christine Ottery, "What Would the Cost of a New Push for Coal in Poland Be?," EU Energydesk, 2014, http://www.greenpeace.org.uk/newsdesk/energy/data/what-would-cost-new-push-coal-poland-be. 138 Eurocoal, “Poland," Eurocoal, 2016, https:/ / euracoal.eu/info/country-profiles/poland/. 
auction, for their readiness to work for the operator in peak hours (7am-10pm). The size of the ORM is $18 \%$ of the average maximum hourly gross demand for power during individual months of the previous year. This mechanism has stopped the generators from providing electricity for less than their marginal and fixed costs, and hence has helped the 'clean dark spread' to rise. The ORM is the main reserve mechanism in Poland and has a budget of PLN500m, giving it access to around $4.5 \mathrm{GW}$ of power. It is additional to the Cold Reserve which will be introduced for 2016-2017 and has a budget of PLN200m with an additional 830 MW of capacity. 139 The mechanism may be extended to 2019 if deemed necessary.

\subsubsection{Coal Plant Pipeline}

As shown in Table 6, between 2005 and 2008 Poland had planned to build five utility scale coal plants totalling 3,408 MW, at least one of which (the $858 \mathrm{MW}$ expansion to the Belchatow power complex) was to run at supercritical efficiencies. Although Belchatow was the only planned plant slated to run on more polluting lignite coal (three of the remaining four plants were not and no data on fuel type was available for the fifth, Zarnowiec Steag), it was also the only plant scheduled to install pollution control measures (for $\mathrm{SO}_{2}$ ). Of the five originally planned plants, only the expansion to Belchatow was subsequently commissioned.

Table 6: Summary of Coal-Fired Power Pipeline for Poland, Q4 2007140

\begin{tabular}{|c|c|c|c|c|c|c|c|}
\hline Plant & MWs & Company & Planned & Online & Steam Type & City & Controls \\
\hline Blachownia & 910 & PKE Elektrownia Blachownia SA & 2012 & Unknown & - & $\begin{array}{l}\text { Kedzierzyn } \\
\text { Kozle }\end{array}$ & - \\
\hline Halemba & 440 & PKE Elektrownia Halemba SA & 2012 & Car & - & Ruda Slaska 6 & - \\
\hline Siekierki & 400 & Vattenfall Heat Poland SA & 2013 & Cancelled & - & Warszawa & - \\
\hline Zarnowiec Steag & 800 & Polish Power & - & Cancelled & - & Zarnowiec & - \\
\hline Belchatow & 858 & Elektrownia Belchatow II & 2011 & Commissioned & Supercritical & Belchatow & $\mathrm{SO}_{2}$ only \\
\hline
\end{tabular}

After the cancellation of 2.5 GW coal-fired capacity between 2005 and 2008, 1.6 GW of coal-fired power capacity was subsequently built in Poland between 2009 and 2016. Approximately $1.3 \mathrm{GW}$ of this capacity (81\%) is more efficient supercritical coal with a variety of pollution control measures, while the remainder is a series of smaller subcritical plants. Approximately $0.5 \mathrm{GW}$ of this capacity is also able to burn alternative fuels such as biomass.

Table 7 provides the characteristics of the thermal power plants under construction in Poland as of 2015.

Table 7: Thermal Power Plants under Construction in Poland as of $2015^{141}$

\begin{tabular}{|c|c|c|c|c|}
\hline Project name & Fuel & Company & MW & Expected Completion \\
\hline Stalowa Wola & Gas & Tauron / PGNiG & 450 & 2015 \\
\hline Włocławek & Gas & PKN Orlen & 463 & 2015 \\
\hline Kozienice & Hard coal & Enea & 1,075 & 2017 \\
\hline EC Żerań & Gas & PGNiG & 750 & 2018 \\
\hline Puławy & Gas & ZA Puławy / PGE & 400 & 2018 \\
\hline Jaworzno & Hard coal & Tauron & 910 & 2019 \\
\hline Opole & Hard coal & PGE & 1,800 & 2019 \\
\hline Turów & Lignite & PGE & 450 & 2019 \\
\hline Czeczott & Hard coal & Kompania Węglowa & 1,000 & 2019 \\
\hline Gorzów & Gas CHP & PGE & 228 & 2016 \\
\hline Elektrownia wodna na Wiśle & Hydro & Energa & 100 & 2016 \\
\hline Bydgoszcz & Gas CHP & PGE & 437 & 2017 \\
\hline
\end{tabular}

\footnotetext{
139 CIRE, “President of PSE: We Have a Safe Power Reserves for 2016.," 2016.

140 Platts WEPP Q4, 2007 and Q4 2016.

141 Rynek Energii Elektrycznej, “Built and Planned Power Plants,” 2016.
} 


\begin{tabular}{|c|c|c|c|c|}
\hline Płock & Gas & PKN Orlen & 596 & $2017 / 2018$ \\
\hline Lublin & Gas & PGE & 135 & 2018 \\
\hline Łagisza & Gas & PGNiG / Tauron & 413 & 2018 \\
\hline ZE PAK & Gas & ZE PAK & 120 & 2019 \\
\hline Kędzierzyn-Koźle & Gas / Hard coal Zakłady Azotowe Kędzierzyn & 165 & 2019 \\
\hline Dolna Odra & Gas & PGE & 270 & 2024 \\
\hline EJ1 & Nuclear & PGE & 6,000 & 2024 \\
\hline Kozienice & Gas & Enea / PGNiG & 900 & na \\
\hline
\end{tabular}

The coal expansion has relied on several drivers. As intimated above, the subsidies collected by the coal mining and energy production industry, as well as the necessity to improve the security of energy supply and energy efficiency are part of them. Additionally, Poland has important national coal reserves, lacks nuclear power stations and is concerned about depending on Russia for energy (in 2013, 60\% of Poland's gas was imported from Russia). 142 Finally, the reluctance of Poland's policymakers to face the revolt of thousands of coal miners (workforce of 113,000 against 34,000 in the renewables industry in 2012)142 also hinders an energy shift towards renewables.

\subsubsection{Recent Developments and Future Policy}

In August 2015, the Polish ministry of economy released a draft 2050 energy roadmap for consultation. Key takeaways include opposition to further $\mathrm{CO}_{2}$ reduction measures, striving for energy independency by maintaining hard-coal and lignite power generation, energy efficiency measures, and other measures. Furthermore, three different energy scenarios are being reviewed and evaluated: (A) 'Balanced', the most likely based on current trends; (B) 'Nuclear scenario', where nuclear power becomes the dominant fuel in Poland, and (C) 'Gas + RES', conditional on development of shale gas in the country.

Poland's economy is mainly driven by the highly coal-dependent power sector which, in 2013, was responsible for $54 \%$ of Poland's $\mathrm{CO}_{2}$ emissions from fuel combustion. ${ }^{143}$ As such Poland is the least 'emission-efficient' economy in the EU and was ranked, in 2013, as the third highest per capita coal consumer after Australia and South Africa. ${ }^{144} \mathrm{New}$ plants would therefore increase Poland's reliance on fossil fuels and would seriously hinder the $2030 \mathrm{EU}$ climate and energy framework. The latter actually requires EU member states to decrease GHG emissions by at least $40 \%$ by 2030 compared to 1990 levels, raise their share of renewables in energy consumption to at least $27 \%$, and improve energy savings by $27 \%$ in comparison with the business-as-usual case. ${ }^{145}$

Moreover, supporting new coal-fired power plants would come with a huge cost. According to the Warsaw Institute for Economic Studies report, ${ }^{146}$ Poland had already spent around PLN68.345bn (€16.30bn) to subsidise coal power from 1990 to 2012. In particular, Polish citizens had been contributing, via their bills, to two-thirds of the financial subsidies collected by the coal industry, providing support for free emissions allowances, stranded costs of long-term contracts termination, and green certificates for co-firing biomass in coal plants. The study eventually concluded that the external costs related to coal power in Poland are 'nearly as expensive as renewables subsidies'. Moreover a study by the German Fraunhofer Institute ${ }^{147}$ and a separate report by the UK

142 Ottery, "What Would the Cost of a New Push for Coal in Poland Be?"

143 Roberta Pierfederici, "Energy Transition Strategies in High Coal Consuming Countries," IDDRI, 2016, http://www.blogiddri.org/en/2016/03/23/energy-transition-strategies-in-high-coal-consuming-countries-a-case-study-for-china-andpoland/.

144 Eurocoal, "POLAND."

145 European Commission, “2030 Energy Strategy,” Europa, 2016, http://ec.europa.eu/energy/en/topics/energystrategy/2030-energy-strategy.

146 Studies, "Subsidising the Past: How Public Aid and Ignoring External Costs Keep Poland's Coal-Based Energy System Alive."

147 Fraunhofer Institut for Solar Energy Systems ISE, “Levelized Cost of Electricity Renewable Energy Technologies,” 2013, https://www.ise.fraunhofer.de/en/publications/veroeffentlichungen-pdf-dateien-en/studien-und-konzeptpapiere/studylevelized-cost-of-electricity-renewable-energies.pdf. 
government ${ }^{148}$ also stated that the cost related to new domestic coal plants would be higher than those associated with onshore wind.

\subsubsection{Conclusions}

Poland has a liberalised energy market with a similar design to that of many of its European peers. What is unique about the country is its reliance on coal, and heightened concerns over energy security (1.6 GW of coal-fired power capacity was built between 2009 and 2016). Poland has indeed a long cultural and political affiliation with the industry. Under communism, the industry was actually a bellwether of the economy, and to this day remains one of the only industries with strong, well-organised labour unions. ${ }^{149,150}$ Thus, in the minds of Poles, the health of the coal industry seems to be ideologically and politically united with Poland's overall economic wellbeing. Like other countries in Europe, Poland is trying to accommodate its market to falling electricity prices, which are too low to incentivise sufficient new power capacity. In the context of an ageing generation and transmission portfolio, supporting new investment is quickly becoming a political priority. However the orientation of new investments is unclear as Poland's call for EU support for new coal plants demonstrates. ${ }^{151}$

The current situation could be seen as an opportunity for Poland to modernise its electricity system by adopting the latest technological solutions, allowing for active demand-side management, energy storage, and integration of electric vehicles. The government has already indicated its willingness to develop smart grids, smart meters, and improved flexibility technologies. However, it remains to be seen how much emphasis will be placed on transitioning the energy system to a new model, rather than simply replacing old plants with new ones within the same architecture.

\subsection{United Kingdom}

\subsubsection{Power Market Overview}

The UK is one of the largest energy markets in Europe supplying 340 TWh in 2015. ${ }^{152}$ Annual electricity consumption increased every year between 1994 and 2005, but has since fallen by 13\% due to the impacts of the global financial crisis, efficiency improvements, and a continuing transition towards less energy intensive servicebased industries.

Figure 11 shows that, since 1990, gas has replaced slightly over half of coal generation. However, since the start of the last decade both gas and coal have begun to lose market share due to an expansion of renewables. Gross generation from nuclear has remained relatively constant throughout this period. In 2015, the primary fuel used in generation was gas (29\%) followed by all renewables (24\%), then coal (21\%) and nuclear (19\%). However, coal has fallen from a $28 \%$ share of generation just a year earlier.

148 Department of Energy and Climate Change, "Electricity Generation Costs," 2012.

149 Kathiann M. Kowalski, "In Poland, Efforts to Rescue Coal Industry Will Likely Come up Short," Midwest Energy News, 2016, http:/ / midwestenergynews.com/2016/07/12/in-poland-efforts-to-rescue-coal-industry-will-likely-come-up-short/. 150 Krzysztof Dzieciolowski and Maciek Hacaga, "Polish Coal at the Turning Point: Uneasy Past, Challenging Future," Journal of Energy Security, 2015.

151 Megan Darby, "Poland to Back UN Climate Deal - If It Can Burn More Coal," Climate Home, 2016, http://www.climatechangenews.com/2016/09/06/poland-to-back-un-climate-deal-if-it-can-burn-more-coal/. 152Department for Business, Energy \& Industrial Strategy, “UK Energy in Brief 2016," 2016. 
Figure 11: Gross Electricity Generation Profile for the United Kingdom, 1990-2014153

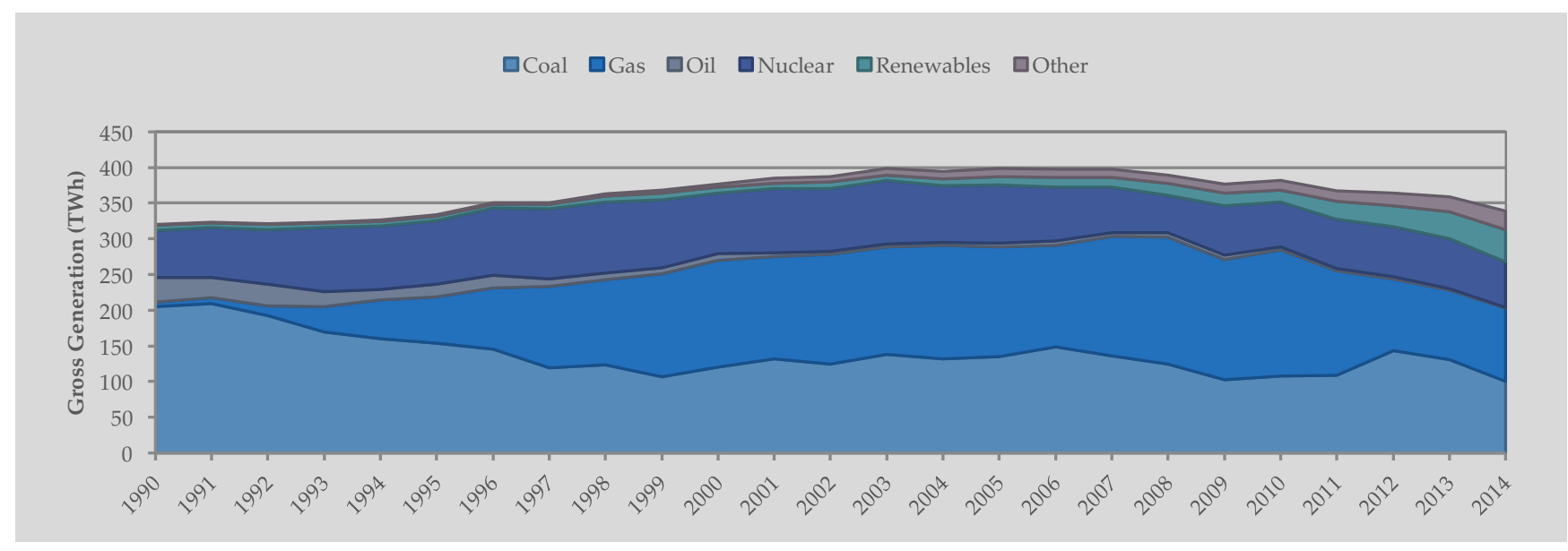

At December 2014, there were $72.2 \mathrm{GW}$ of installed capacity (see

Table 8) of which $52.5 \mathrm{GW}(73 \%)$ was from thermal combustion. ${ }^{154}$ Of this combustion mix, in 2015 , 38\% or 19.9 GW was coal with the remaining $62 \%$ taken up by gas-fired power and biomass. Note that whereas the proportion of coal capacity was around $38 \%$ of all combustion capacity, coal's generation share was only $21 \%$, suggesting low capacity factors. Most new combustion capacity is now gas-fired.

Table 8: Total Installed Capacity in Great Britain (GW)155

\begin{tabular}{|c|c|c|c|}
\hline & 2012 & 2013 & 2014 \\
\hline Combustion (coal gas, oil, biomass) & 62.0 & 55.2 & 52.5 \\
\hline Nuclear & 9.2 & 9.4 & 9.4 \\
\hline Renewables & 5.4 & 6.7 & 7.5 \\
\hline Renewables de-rated for intermittency & 2.3 & 2.8 & 3.1 \\
\hline Pumped Storage & 2.8 & 2.8 & 2.8 \\
\hline Total Capacity & 79.5 & 74.0 & 72.2 \\
\hline
\end{tabular}

Although electricity markets have been privatised since the 1990s, the 'Big Six' energy suppliers (Centrica, EDF, E.ON, Npower, ScottishPower, and SSE) dominate electricity generation and gas supply with a $92.4 \%$ share of domestic customers in 2014, decreased from 99.8\% in 2009.156 Electricity distribution networks in the UK are primarily independent of generation companies, with the exception of the two big Scottish suppliers: ScottishPower and SSE. The UK gas and electricity regulator Ofgem released a report in March of this year in which it 'provisionally' found that 'certain features' of the market result in an adverse effect on competition. ${ }^{157}$

\subsubsection{Energy Policy Context}

Of primary relevance to coal-fired power in the UK are its stringent carbon-related policies (due to the high $\mathrm{CO}_{2}$ intensity of coal generation) and coal specific policies. The UK has set unilateral legally binding targets for

153 Eurostat, "Database - Eurostat."

154 UK Government, “Large Combustion Plant Directive (LCPD): Running Hours during Winter 2014/15 and Capacity for 2015/16," 2016, https://www.gov.uk/government/uploads/system/uploads/attachment_data/file/462364/LCPD.pdf. 155 DECC (Sept. 2015) Large Combustion Plant Directive (LCPD): Running hours during winter 2014/15 and capacity for 2015/16.

156 Cornwall Energy, “Independent Suppliers Reach Record 7.5\% Share of Domestic Market,” 2014.

157 Competition \& Markets Authority, “Energy Market Investigation: Provisional Decision on Remedies,” 2016. 
reducing greenhouse gas emissions from 1990 levels by $50 \%$ by 2027 , and $80 \%$ by 2050. In order to meet these targets, any coal plant built now that lacks CCS would have to be retired well before the end of its feasible operating life. ${ }^{158}$ UK coal plants have also been subject to the EU ETS and the UK also has its own carbon taxes and regulations including: the Climate Change Levy (a tax on the carbon intensity of fuels), the Carbon Price Floor (a tax on the carbon emissions of power stations), and the Emissions Performance Standard (the carbon intensity of new power plants and new boilers on existing plants is limited to $450 \mathrm{~kg} \mathrm{CO}_{2} / \mathrm{MWh}$ ). ${ }^{159}$ Since even so-called 'clean' supercritical coal-fired power stations have carbon intensities around $800 \mathrm{~kg} \mathrm{CO}_{2} / \mathrm{MWh}$, the EPS effectively prohibits the construction or renovation of all coal plants in the UK, unless CCS technology is developed and implemented.

As can be seen from

Figure 11, the steep decline in coal generation over the last few years has been largely replaced by an increase in renewables. Since 2002, the principal renewable energy policy has been the Renewables Obligation, which obliges suppliers to source an annually increasing proportion of their electricity from renewable energy sources. The obligation for the 2016-17 period is 15.4\%. Additional renewables support includes Contracts for Difference (guaranteed electricity prices for renewable energy producers). The UK's National Renewable Energy Action Plan is targeting $31 \%$ of electricity from renewables by 2020 , and much of this increase will likely continue to come at the expense of coal.

Beginning in 2013, the EU's Large Combustion Plant Directive (LCPD) forced older and more polluting coal plants to shut down. The LCPD compels owners of thermal power plants to reduce emissions of particulate matter, $\mathrm{SO}_{2}$ and $\mathrm{NO}_{x}$. In the UK alone, $11.5 \mathrm{GW}$ of coal-fired power capacity will ultimately be shut down under the LCPD. 160 The successor to the LPCD, the Industrial Emissions Directive (IED), will result in even more stringent emissionslimits. Older thermal plants will have to meet tighter environmental standards by 2023, and the UK has pledged to phase out the use of coal to generate electricity by 2025. By this time even the youngest coal-fired plant (Kilroot) will be 44 years old. Since 2012, 11.55 GW of coal-fired power has been closed prematurely due to the mandated pollution limits set out in the LCPD (now superseded by the IED). The largest proportion (by capacity) of the plants that have closed is in the UK. ${ }^{161}$

\subsubsection{Coal Plant Pipeline}

Although the UK had planned to build three subcritical (970 MW total) and four supercritical (6,120 MW total) coal plants in the 2005 to 2008 period, all seven were subsequently cancelled. To date no new coal-fired plants have opened in the UK since Kilroot (520 MW) in 1981, and there are no coal-fired plants under construction or that have received planning permission. Coal's generation share fell from $28 \%$ to $21 \%$ in 2015 , and to only $6 \%$ in spring 2016 due to plant closures, increased use of gas-fired generation, conversions to biomass firing, and increasing RES capacity. ${ }^{162}$ Currently there is $14.5 \mathrm{GW}$ of coal capacity from nine operational generating units, down from 12 operational units and $20.0 \mathrm{GW}$ in 2015. The $4.3 \mathrm{GW}$ of closed coal plants comprised: Rugeley (1.0 GW, closed June 2016), Ferrybridge C (1.0 GW, March 2016), and Longannet (2.3 GW, March 2016). Coal plants are retired on average after about 40 years of service. However, the average age of the coal plants still operating in the UK is 45 years.

\footnotetext{
158 Ben Caldecott, Gerard Dericks, and James Mitchell, "Stranded Assets and Subcritical Coal: The Risk to Companies and Investors," Stranded Assets Programme, SSEE, University of Oxford, 2015, 1-78.

159 'Clean' supercritical coal-fired power stations have carbon intensities around $800 \mathrm{~kg} \mathrm{CO} / \mathrm{MWh}$.

160 The Economist Intellegence Unit, “Coal's Last Gasp in Europe," The Economist, July 2014.

161 Pete Harrison, “UK and Poland Top Dirty Coal List, Closures Loom," Reuters, 2009, http:/ / uk.reuters.com/article/euenergy-coal-idUKLC81083120090213.

162 "Coal Electricity Generation Falls to Record UK Low This Spring," The Guardian, September 29, 2016,

https:// www.theguardian.com/environment/2016/sep/29/coal-electricity-generation-falls-to-record-uk-low-this-spring.
} 
Table 9: Summary of Coal-Fired Power Pipeline for the United Kingdom, Q4 2007163

\begin{tabular}{|c|c|c|c|c|c|c|c|c|c|}
\hline Plant & MWs & Company & Planned & Online & Steam Type & City & Controls \\
\hline Blyth-C & 2400 & RWE & 2014 & - & Supercritical & Bedlington \\
\hline Chapelcross Biopower & 250 & Scottish Biopower & 2009 & - & Subcritical \\
\hline Killoch & 250 & Scottish Biopower & - & - & Annan \\
\hline Kingsnorth & 1600 & E.ON & 2012 & - & Subcritical & Killoch \\
\hline Tilbury & 1600 & RWE & 2013 & - & Supercritical & Rochester \\
\hline Killingholme & 470 & E.ON & - & - & Yes \\
\hline Westfield & 520 & Global Energy and Mining Scotland & - & - & Subcritical & Killingholme \\
\hline
\end{tabular}

\subsubsection{Recent Developments and Future Policy}

The UK plans to close all unabated coal-fired generation by 2025. ${ }^{164}$ However, on June 23, 2016, the UK voted to leave the European Union. The impact of Brexit on energy and climate policy is highly dependent on the future trade negotiations. Of particular relevance to coal would be the LCPD/IED, the EU ETS and possibly its add-on policy, the Carbon Price Floor.

\subsubsection{Conclusions}

Coal-fired power generation in the UK is expected to continue to decline in the medium term, and will likely be phased-out completely by 2025 or earlier due to a combination of competition from renewables, continued stagnation in energy demand, and the advanced age of existing plants.

163 Platts WEPP Q4, 2007 and Q4 2016.

164 International Energy Agency (IEA), “Energy Policies of IEA Countries: The United Kingdom 2012 Review,” 2012, https://www.iea.org/publications/freepublications/publication/UK2012_free.pdf; Department for Business, Energy \& Industrial Strategy, "Coal Generation in Britain. The Pathway to a Low-Carbon Future: Consultation Document," 2016. 


\section{Thermal Coal Economics: Operations and Finance}

This section is divided into two sub-sections. Section 4.1 analyses the operational performance of EU energy utilities between 2000 and 2014 using the most recent available data from Eurostat - a central data archive for the EU. ${ }^{165}$ A thorough analysis of operational performance gives insight into the industry's performance over the period and the potential risks and opportunities facing fossil fuel technology going forward. This section examines the gross electricity generated in the EU against total installed capacity. It also examines the utilisation rates of various technologies. Section 4.2 examines the financial performance of energy utilities through analysis of public financial disclosures for a sample of 14 major European utilities. ${ }^{166}$ Specifically, we examine trends in key financial figures, including revenue, net income and stranded assets during 2000 to 2015. Data for the analysis are taken from a combination of S\&P Capital IQ and S\&P Platt's World Electric Power Plants database.

\subsection{Operational Performance of EU Utilities}

\subsubsection{Gross Generation by Fuel Type}

At the EU-level, there has been a large change in the EU's power generation mix. Figure 12 shows that the gross electricity generated from thermal sources (coal, natural gas and oil) fluctuated around 1,758 TWh until 2007. From $2008-14$, the amount of energy from thermal sources declined to $43 \%$ (1,356 TWh).

Figure 12: Gross Electricity Generation in the EU-28, 2000-2014167,168

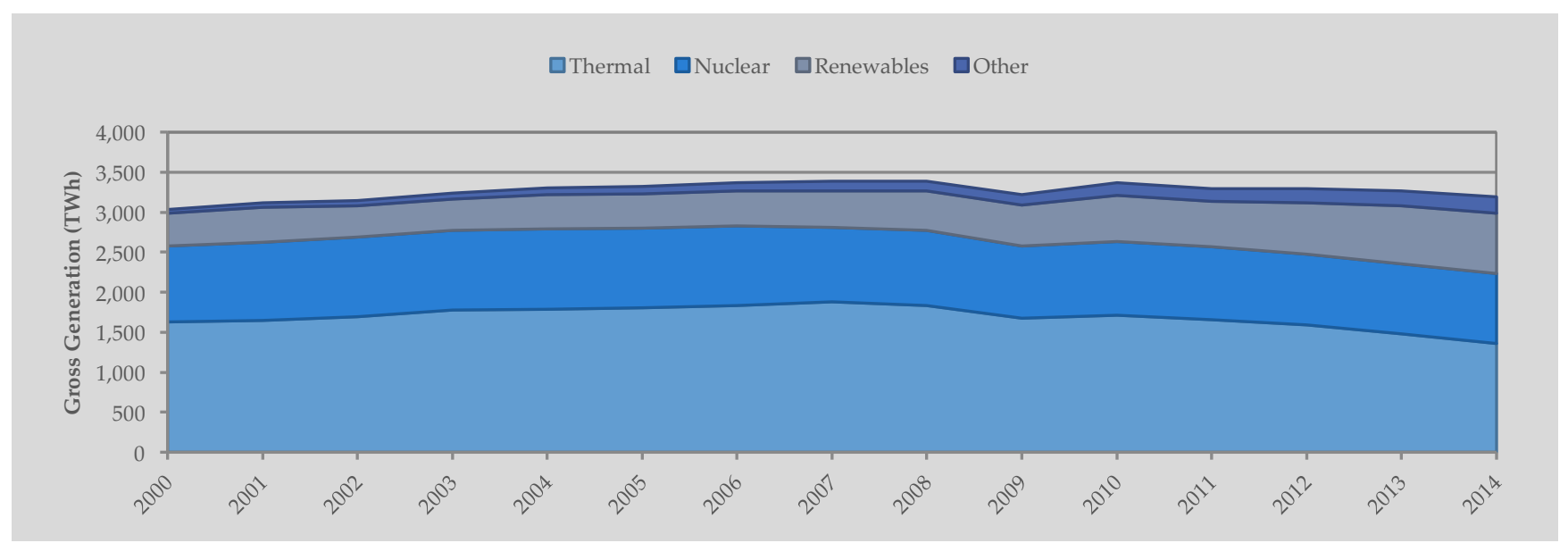

Table 10 shows that technologies which have taken an increasing share of the generating mix during 2000-14 include wind (+231 TWh), biomass (+133 TWh), and solar (+98 TWh). The increasing use of wind and solar is unsurprising due to the merit order effect (see Section 2.2), and policy incentives to support renewables. However, this implies an increasing proportion of intermittent generation technology in the energy system. The increased use of biomass reflects the EU's drive to diversify energy supply and increase coal-to-biomass switching.

165 Note, there is a two year lag regarding data available on Eurostat.

166 The EU's 14 largest, as measured by market capitalisation, European-domiciled international power utility companies with major conventional generation businesses, are (in alphabetical order): CEZ, EDF, EDP, ENEL, EnBW, E.ON, Fortum, GDF Suez, Iberdrola, PGE, RWE, Tauron, Vattenfall, and Verbund.

167 Adapted from Daniel J. Tulloch and Ben Caldecott, “Current and Future Challenges Facing the European Union's Energy System," USAEE Working Paper No. 16-261, 2016, 1-30.

168 Eurostat, "Database - Eurostat." 
The three technologies that have lost the greatest market share in gross generation are coal (-125 TWh), oil (-124 TWh), and nuclear (-69 TWh). The use of oil in generation has been declining steadily over the period unsurprising since oil is a relatively expensive fuel for electricity generation and its role in providing peak power can be replaced by gas-fired generation. Coal has been subject to a range of efficiency and emission legislation which has reduced operating hours, or closed plants entirely. Change in public opinion towards nuclear power, especially fear of catastrophic events following the Fukushima disaster, has resulted in reductions in nuclear capacity. Natural gas remained relatively unaffected over the period. Gas had an increasing role in electricity generation due to the increasing efficiency of natural gas turbines until 2008. Its use in generation has declined since then.

Table 10: Change in Gross Electricity by Primary Fuel 169

\begin{tabular}{ccccc} 
& \multicolumn{2}{c}{ Year } & Net & \\
& 2000 & 2014 & Change & Percentage \\
& $($ TWh $)$ & $($ TWh $)$ & (TWh) & \\
Wind & 22.2 & 253.2 & 230.9 & $1,039 \%$ \\
Biomass & 34.1 & 166.8 & 132.7 & $390 \%$ \\
Solar & 0.1 & 97.8 & 97.7 & $82,068 \%$ \\
Hydro & 386.9 & 406.5 & 19.6 & $5 \%$ \\
Waste & 12.1 & 22.6 & 10.5 & $86 \%$ \\
Other Sources & 1.3 & 4.6 & 3.2 & $242 \%$ \\
Geothermal & 4.8 & 6.2 & 1.4 & $30 \%$ \\
Tide & 0.5 & 0.5 & 0.0 & $-5 \%$ \\
Gas & 513.1 & 490.1 & -23.1 & $-4 \%$ \\
Nuclear & 945.0 & 876.3 & -68.7 & $-7 \%$ \\
Oil & 181.3 & 57.4 & -123.9 & $-68 \%$ \\
Coal & 933.9 & 808.7 & -125.1 & $-13 \%$
\end{tabular}

\subsubsection{Installed Capacity and Net Capacity Factors}

Figure 13 shows that overall installed generating capacity in the EU grew by approximately $48 \%$ from 2000 to 2014. Table 11 shows a breakdown of installed capacity growth in the EU. The growth in fossil fuel capacity has been relatively stable over the period, increasing by 17\% from $381 \mathrm{GW}$ to $445 \mathrm{GW}$. Nuclear has decreased by -10\%; mostly as a result of nuclear shut-downs in Germany. RES capacity increased by $153 \%$ over the period, from 146 GW to 369 GW. This was primarily driven by a steady growth in wind capacity, combined with a rapid growth in solar after 2010. Finally, installed biomass- and waste-fired capacity saw the largest relative increase in capacity of $265 \%$, yet their absolute capacity remained the lowest at $78 \mathrm{GW}$ in 2014 . The increased capacity in thermal technology is concerning, as Table 10 shows that the trend in gross generation is away from thermal technology and towards renewables. This implies that some of this thermal generating capacity may be underutilised in the future.

169 Ibid. 
Figure 13: Installed Electricity Generating Capacity in the EU-28, 2000- 2014170,171

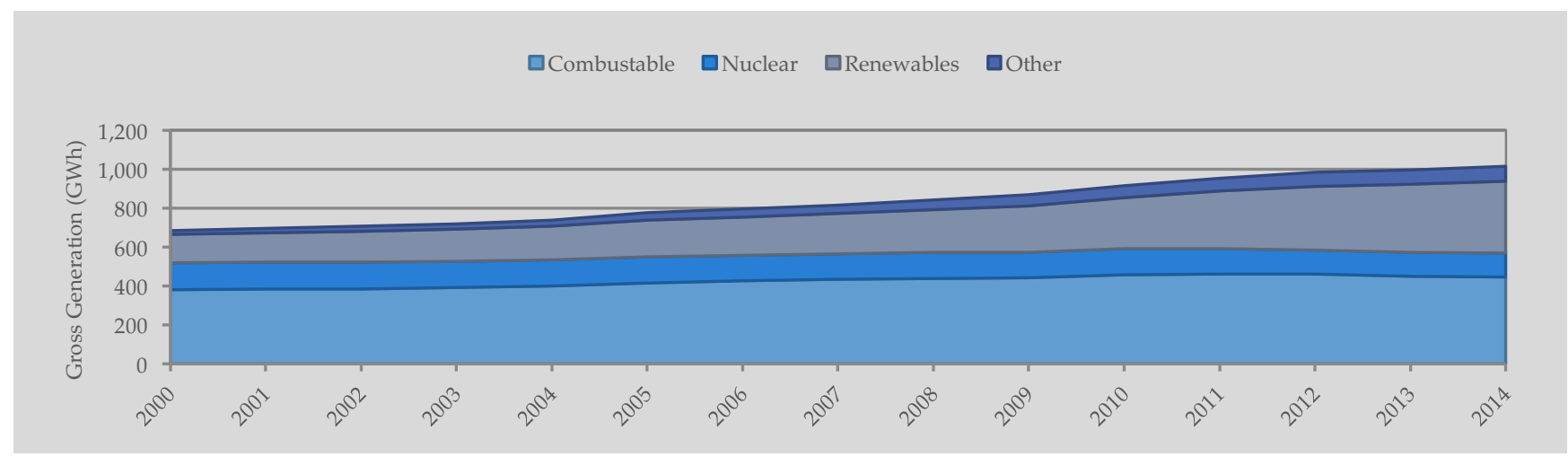

Table 11: Growth in Installed Capacity, 2000-2015172

\begin{tabular}{|c|c|c|c|}
\hline & $\begin{array}{c}\text { Capacity in 2000 } \\
(\text { GW) }\end{array}$ & $\begin{array}{c}\text { Capacity in } 2014 \\
(\text { GW) }\end{array}$ & $\begin{array}{c}\text { Growth } \\
(\%)\end{array}$ \\
\hline Thermal & 381 & 445 & $16.7 \%$ \\
\hline Nuclear & 137 & 124 & $-9.6 \%$ \\
\hline Renewables & 146 & 369 & $152.5 \%$ \\
\hline Other & 21 & 78 & $265.4 \%$ \\
\hline
\end{tabular}

It is worth noting that installed capacity represents 'nameplate capacity': the maximum amount of electricity generated under ideal conditions. Thus, a large amount of hydro and wind capacity does not necessarily mean large utilisation, nor does it mean a stable energy supply. Net capacity factor represents the actual output from a generating unit relative to its potential maximum capacity - a measure of technology utilisation. The net capacity factor is calculated as the ratio of actual output over a period, divided by potential output if it were possible to operate at full (i.e. nameplate) capacity over the same period. Generally, the utilisation of RES technology is typically lower than others as RES only operates in favourable weather conditions. For example, hydroelectric capacity factors in Portugal, which obtained almost a third of its electricity from hydro, was below $56 \% .{ }^{173}$ While modern windfarms can produce electricity $80-98 \%$ of the time, the actual output varies based on wind speed. The realised capacity factor of EU wind installations was approximately $24 \%$ for onshore wind and $41 \%$ for offshore wind in 2013. ${ }^{174}$

Figure 14 presents the net capacity factor for various EU technologies. The most interesting delineation of generating technologies is creating two groups: low-carbon technologies (Plot A) and thermal technologies (Plot B). These two groups also loosely represent CAPEX (Plot A) and OPEX (Plot B) technologies.

170 Adapted from Tulloch and Caldecott, "Current and Future Challenges Facing the European Union's Energy System."

171 Eurostat, "Database - Eurostat."

172 Ibid.

173 J P Deane, B P Ó Gallachóir, and E J McKeogh, “Techno-Economic Review of Existing and New Pumped Hydro Energy

Storage Plant," Renewable and Sustainable Energy Reviews 14, no. 4 (May 2010): 1293-1302,

doi:http://dx.doi.org/10.1016/j.rser.2009.11.015.

174 EWEA, "Wind Energy Statistics and Targets," The European Wind Energy Association, 2013. 


\section{Figure 14: Net Capacity Factors by Generating Technology, EU-28, 2000-2014175}

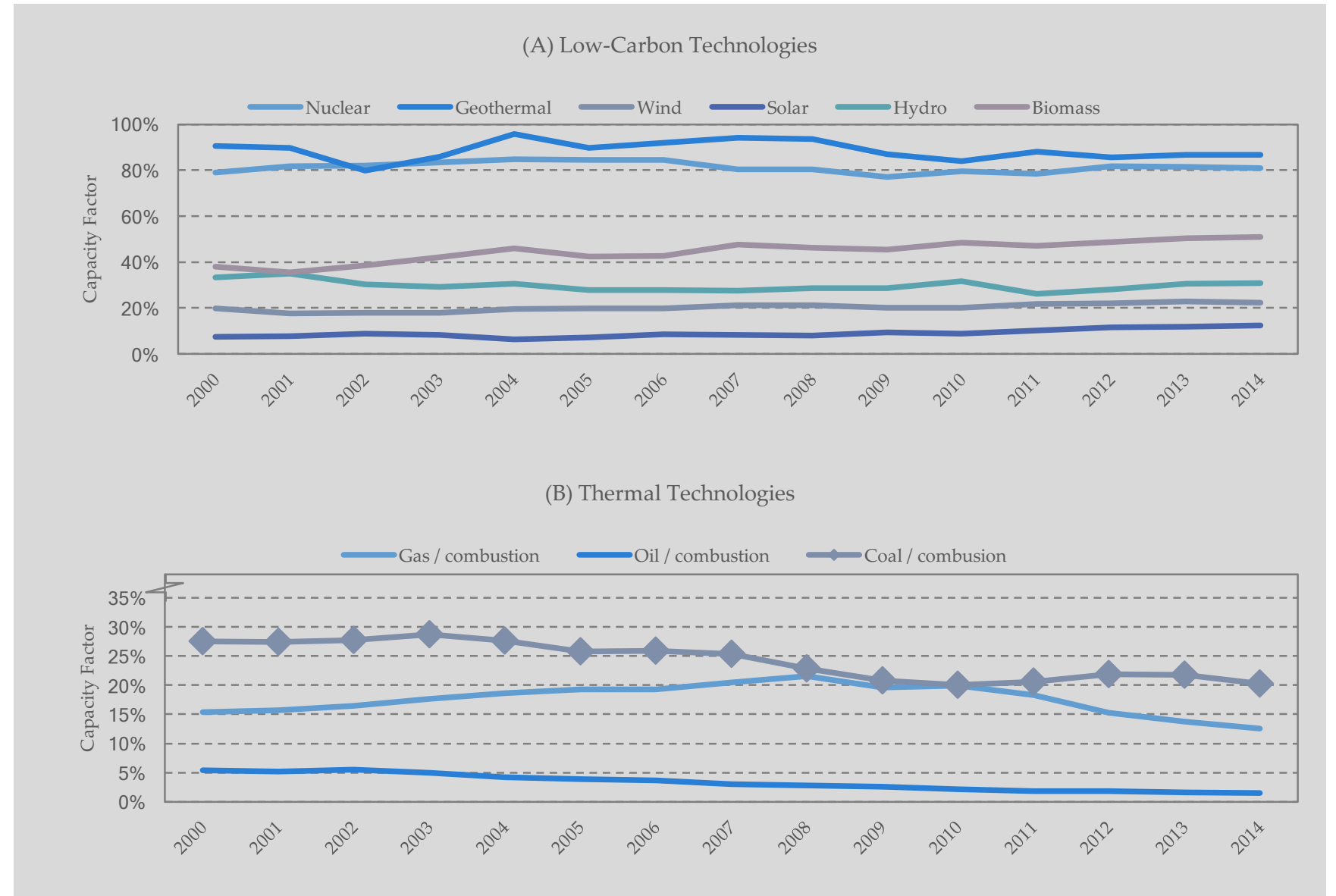

This figure illustrates the net capacity factors over a range of generating technologies in the EU-28. Net capacity factor is calculated as the known gross electricity generated from each technology, divided by the potential output from known installed capacity. Potential output is calculated as $=$ installed capacity $\times(24 h r s \times 365$ days $)$. Gross electricity generated and installed capacities are scaled to the same units. Note, the underlying data does not delineate fossil fuels - instead, provides a grouping called 'combustion technology'. For this reason, it is not possible to determine a true net capacity factor for Plot (B), but we can determine a proxy of gross generation relative to all combustion technology (excluding biomass) to examine relative change in usage.

Figure 14 indicates that utilities with high proportions of low-carbon technologies are likely to see stable utilisation rates in the long term. For Plot (A), the results show that the near-zero marginal cost of low-carbon technologies results in constant dispatch over time with stable net capacity factors - congruent with merit order (see Section 2.2). Plot (A) shows that geothermal technology has the highest utilisation rates of all technologies examined: the mean net capacity factor (utilisation) of geothermal is around $86 \%$ over time. Nuclear technology has large capacities and low-marginal costs, and thus tends to replace coal as the baseload generator in the energy sector. The utilisation of nuclear capacity is also high, with a net capacity factor which fluctuates around $80 \%$. Hydro, wind, and solar had net capacity factors of approximately 29.7\%, 20.3\%, and 9.1\% respectively during 2000-14. Their utilisation rates are sensitive to local weather conditions and are likely to fluctuate; for example, some offshore wind farms in the UK have reached capacity factors of $55 \% .176$ This weather dependency is responsible for low utilisation rates and so more RES capacity is required to produce the same output as non-RES generators. The utilisation of biomass has increased from around $38 \%$ in 2000 to $51 \%$ in 2014 . While efficiency standards may be one factor in their increased use, some coal-fired electricity generators have begun to convert to biomass-fired

175 Eurostat, "Database - Eurostat."

176 http:/ / energynumbers.info/uk-offshore-wind-capacity-factors 
boilers. Drax Group plc reported that its use of wood pellets instead of coal has halved carbon emissions and reduced other air pollutants. ${ }^{177}$ This suggests an opportunity for coal-fired generators to convert to sustainable biomass-fired generators.

Plot (B) shows the utilisation of thermal technologies in the EU-28. Prior to interpreting the data, it is necessary to highlight that Eurostat does not delineate installed capacity for fossil fuel generators; instead, opting to combine all thermal generation under 'combustion capacity'. The following ratios do not represent 'true' net capacity factors, but rather a ratio of gross generation from each fossil fuel to all combustion capacity. Figure 13 shows that thermal (combustion) has remained relatively stable over the period. Given the choice, this would remain the appropriate grouping for several reasons. First, it must be acknowledged that dual- or multi-fuel- power plants can switch fuels within a day if the alternative fuel is available, or modify equipment within weeks or months. ${ }^{178}$ Second, fossil fuels generators have the option of creating combustible, hybrid fuels, such as coal and oil slurries. ${ }^{179}$ Such fuels have been utilised in Europe, and thus their use must be indirectly controlled.

The results show that oil-fired generation typically has very low utilisation rates due to its high costs in comparison to alternative fossil fuels, such as natural gas and coal. The results in Plot (B) of Figure 14 show that the utilisation of oil-fired capacity decreased from around 5\% of combustible capacity to only $1.5 \%$. Between 2000 and 2008 , the use of natural gas increased from 15 to $22 \%$ of combustible capacity, and thereafter declined to only $13 \%$. The rapid decline can be explained by changes in coal use. For EU countries, coal represents a relatively cheap and convenient generating technology, with a long 'trialled and tested' history. As evident from Plot (B), coal typically represents the largest proportion of combustible fuel capacity in electricity generation. Between 2000 and 2007, the use of coal remained relatively constant, fluctuating around $27 \%$, then declined rapidly, reaching $20 \%$ by 2014 . Thus any new-build coal power stations can expect decreasing rather than constant utilisation rates.

\subsection{Financial Performance}

The following sections examine the performance of European energy utilities from a financial perspective. The analysis focuses on a sample of the EU's largest energy utilities, ${ }^{166}$ as measured by market capitalisation. We focus on European-domiciled international power utility companies with major conventional generation businesses. We analyse financial performance between 2000 and 2015. Data for the analysis are a combination of S\&P Capital IQ and S\&P Platt's World Electric Power Plants database. Table 12 presents a list of the sample firms, and both their operating and planned (and under construction) coal-fired capacity. The data shows that total operating coal-fired capacity for the sample was 73.2 GW by the end of 2007. Many of the firms planned to build additional coal-fired capacity; in total $22.1 \mathrm{GW}$ was planned, representing 30.2\% of existing capacity. However, by mid-2016 coal-fired capacity had only increased by $10.3 \%$, to a total of $80.0 \mathrm{GW}$. Seven companies actually reduced their coal capacity, six companies increased their coal capacity, and one remained unchanged. The following section examines the financial performance of these 14 companies.

177 Drax Group plc, “Annual Report and Accounts,” 2015.

178 Patrik Söderholm, "Fossil Fuel Flexibility in West European Power Generation and the Impact of System Load Factors," Energy Economics 23, no. 1 (2001): 77-97, doi:http:/ /dx.doi.org/10.1016/S0140-9883(00)00062-1.

179 Ibid. 
Table 12: Coal Capacity and Market Value for Sample Firms ${ }^{180}$

\begin{tabular}{|c|c|c|c|c|c|c|c|c|}
\hline \multirow{2}{*}{$\begin{array}{l}\text { Unit } \\
\text { (MW) }\end{array}$} & \multicolumn{2}{|c|}{2007} & \multicolumn{2}{|c|}{2016} & \multirow{2}{*}{$\begin{array}{l}\% \text { Change in } \\
\text { Operation } \\
\text { capacity }\end{array}$} & \multicolumn{2}{|c|}{$\begin{array}{c}\text { Market Capitalisation } \\
(€ \text { million) }\end{array}$} & \multirow{2}{*}{$\begin{array}{l}\% \text { Change in } \\
\text { Market } \\
\text { Capitalisation }\end{array}$} \\
\hline & Operating & $\begin{array}{c}\text { Planned \& } \\
\text { Under } \\
\text { Construction }\end{array}$ & Operating & $\begin{array}{l}\text { Planned \& } \\
\text { Under } \\
\text { Construction }\end{array}$ & & Dec 2007 & Dec 2015 & \\
\hline CEZ & 6,510 & 1,980 & 6,224 & $\mathrm{~N} / \mathrm{A}$ & $-4.4 \%$ & 30,135 & 8,782 & $-70.9 \%$ \\
\hline EDF & 9,324 & $\mathrm{~N} / \mathrm{A}$ & 7,920 & $\mathrm{~N} / \mathrm{A}$ & $-15.1 \%$ & 148,465 & 25,227 & $-83.0 \%$ \\
\hline EDP & 1,250 & 800 & 1,250 & N/A & $0.0 \%$ & 16,288 & 12,069 & $-25.9 \%$ \\
\hline ENEL & 6,536 & 750 & 8,193 & N/A & $25.4 \%$ & 50,297 & 36,598 & $-27.2 \%$ \\
\hline EnBW & 2,727 & 912 & 3,175 & N/A & $16.4 \%$ & 14,699 & 5,746 & $-60.9 \%$ \\
\hline E.ON & 14,000 & 7,570 & 4,302 & N/A & $-69.3 \%$ & 93,335 & 17,419 & $-81.3 \%$ \\
\hline Fortum & 1,629 & N/A & 1,309 & N/A & $-19.6 \%$ & 27,486 & 12,366 & $-55.0 \%$ \\
\hline $\begin{array}{l}\text { GDF } \\
\text { Suez }\end{array}$ & N/A & N/A & 2,375 & N/A & & 0 & 39,024 & $\mathrm{~N} / \mathrm{A}$ \\
\hline Iberdrola & 1,225 & $\mathrm{~N} / \mathrm{A}$ & 498 & $\mathrm{~N} / \mathrm{A}$ & $-59.3 \%$ & 51,935 & 41,062 & $-20.9 \%$ \\
\hline PGE & $\mathrm{N} / \mathrm{A}$ & N/A & 10,260 & 878 & & 0 & 5,577 & $\mathrm{~N} / \mathrm{A}$ \\
\hline RWE & 17,004 & 7,240 & 16,121 & 1,100 & $-5.2 \%$ & 53,682 & 7,095 & $-86.8 \%$ \\
\hline Tauron & N/A & $\mathrm{N} / \mathrm{A}$ & 5,300 & 900 & & 0 & 1,177 & $\mathrm{~N} / \mathrm{A}$ \\
\hline Vattenfall & 12,026 & 2,840 & 13,505 & $\mathrm{~N} / \mathrm{A}$ & $12.3 \%$ & 0 & 0 & $\mathrm{~N} / \mathrm{A}$ \\
\hline Verbund & 1,003 & $\mathrm{~N} / \mathrm{A}$ & 598 & $\mathrm{~N} / \mathrm{A}$ & $-40.4 \%$ & 14,757 & 4,120 & $-72.1 \%$ \\
\hline Total: & 73,234 & 22,092 & 81,030 & 2,878 & $10.6 \%$ & 30,135 & 8,782 & $-70.9 \%$ \\
\hline
\end{tabular}

\subsubsection{Market Capitalisation and Book Value of the Sector}

In this section, we provide a comprehensive analysis of the operational and financial performance of coal-fired generation in the European Union. A thorough examination of the performance will help determine the stability and health of EU energy utilities.

The European energy utility sector participated in the pre-2008 economic boom. While broad European market returns have steadily recovered since the GFC, the EU power market has underperformed and experienced persistently low prices. Figure 15 shows that between 2000 and 2007 the market capitalisation of our sample group witnessed a 2.6-fold increase from $€ 149 \mathrm{bn}$ to $€ 501 \mathrm{bn}$. The sector's market capitalisation peaked in 2007 at around half a trillion euros. In 2008, the GFC resulted in a decline in market capitalisation of between $-37 \%$ and $-51 \%$. In response, the yields on some energy stocks have increased over time, some in excess of $10 \%$, making equity an expensive source of capital for utilities. ${ }^{181}$ The energy sector has never truly recovered from the loss, and has continued to decline over the subsequent years to around $€ 216 \mathrm{bn} ;-57 \%$ lower than its peak value.

\footnotetext{
180 S\&P Capital IQ, WEPP Q4 2007 \& Q2 2016.

181 "How to Lose Half a Trillion Euros," The Economist, 2013.
} 
Figure 15: Group Market Capitalisation and Median Market Capitalisation Growth, 2000-2015182

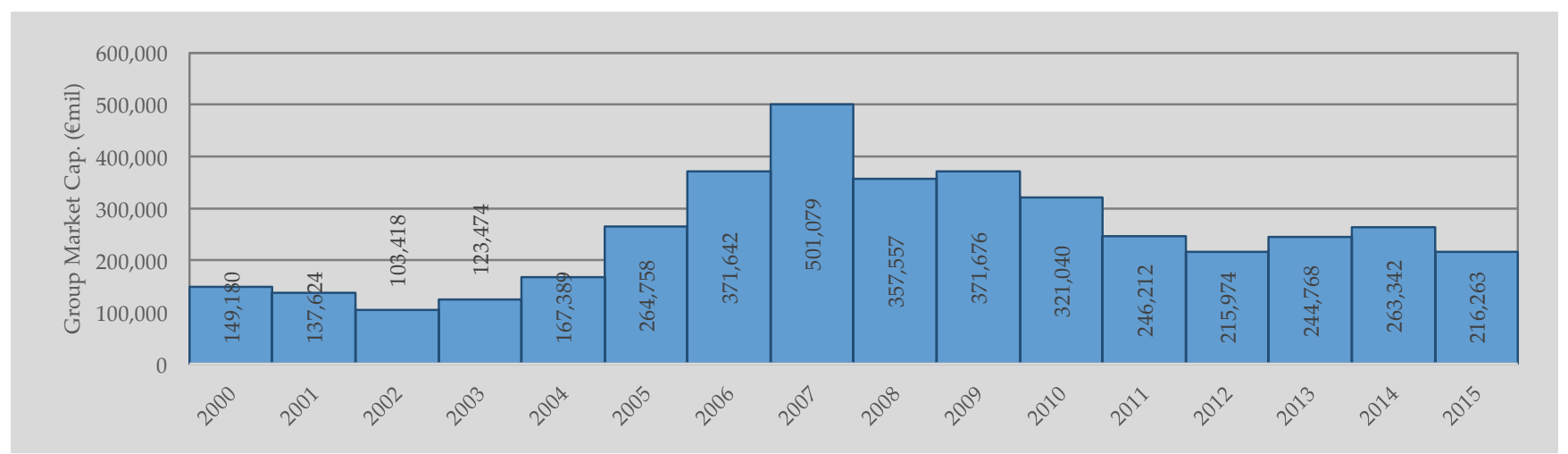

This figure illustrates the sum of annual market capitalisations, in euros, across the 14 sample firms.

The pre-2008 period witnessed policy intervention and company mergers. Indeed, European legislators demonstrated, through the three packages of liberalisation, their willingness to enforce compliance with singlemarket mandates. ${ }^{183}$ Concerns over increased competition due to liberalisation and unbundling of generation from transmission and distribution encouraged utility companies to seek dominant market positions in multiple countries. Further, the removal of national barriers also encouraged a wave of synergistic merger and acquisition activity to either expand across borders to gain economies of scale, or allow domestic suppliers to defend against predatory foreign competitors. ${ }^{184}$ High profits in the early 2000 s gave utility companies strong cash positions leading up to 2008. 185 Simultaneously, a downward revision of organic growth, from 2 to $1.6 \%$, provided an incentive for utilities to fund growth using debt, which had a marginal cost of only $2.4 \%$ after tax. 186

Figure 16 shows that utilities rapidly expanded in size, as measured in total assets. The increasing amounts of debt on the balance sheet imply that the sector is exposed to increasing financial risk. The increase in debt means that utilities magnify both gains and losses. However, the return on capital has trended below the long-term cost of capital, destroying value for shareholders. 187

\footnotetext{
182 S\&P Capital IQ.

183 George Parker, Sarah Laitner, and Thomas Catan, "Lights out? How Europe Is Trying to Fix a Power Failure," Financial Times, 2006.

184 Tulloch and Caldecott, "Current and Future Challenges Facing the European Union's Energy System."

185 Ed Crooks and Mark Mulligan, "Two Hot Trends Coming Together," Financial Times, 2006.

186 "Europe's Coming Merger Boom," The Economist, 2005.

187 FTI-CL Energy, "Towards the Target Model 2.0: Policy Recommendations for a Sustainable EU Power Market Design."
} 
Figure 16: Book Value of Energy Utilities, 2000-2015188

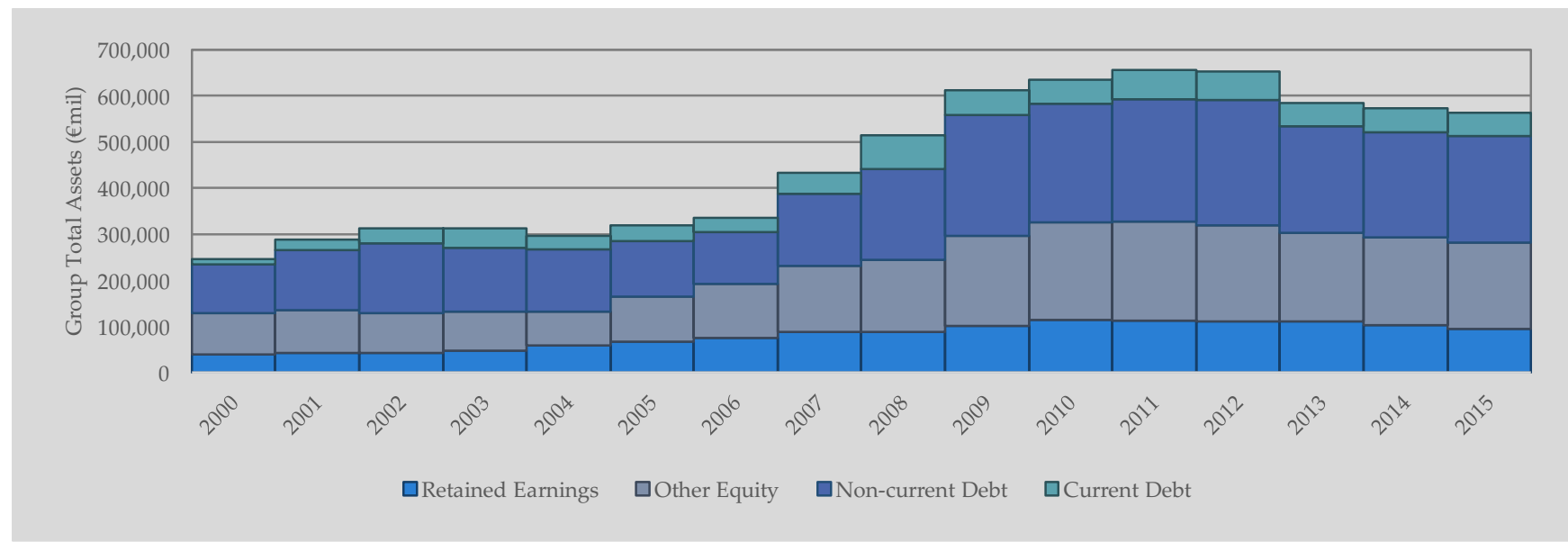

This figure illustrates the group's total assets between 2000 and 2015. To calculate total assets, we aggregate the group's total equity and total debt.

Using data from Moody's, Figure 17 shows that the number of debt contracts issued rapidly increased in the early 2000s. The majority of these debt contracts were considered lower to high investment-grade contracts; no debt was considered 'prime' post-2002 reflecting lower opinions on credit worthiness. During 2002-08, most contracts issued were considered upper medium grade.

However, following the GFC, much of this debt was rapidly revised downwards to lower investment grade. From 2012, in recognition of deteriorating market conditions, some debt was considered speculative. The 14 utilities in our sample were rated better than many other EU power utilities, most of which saw dramatic downward revisions of debt to 'extremely speculative' and 'default imminent' between 2001-07, and again from 2014 onwards. 189

These findings imply that energy utilities will find it increasingly difficult, or expensive, to raise capital through debt or equity in the future, as the costs associated with both forms of capital are increasing. To service such capital commitments, utilities must ensure that their return on capital exceeds their cost of capital. To understand the extent to which this is feasible, the next section analyses the profitability of the industry.

188 S\&P Capital IQ.

189 Tulloch and Caldecott, "Current and Future Challenges Facing the European Union's Energy System." 
Figure 17: Moody's Credit Ratings across Time, 1990-2015190

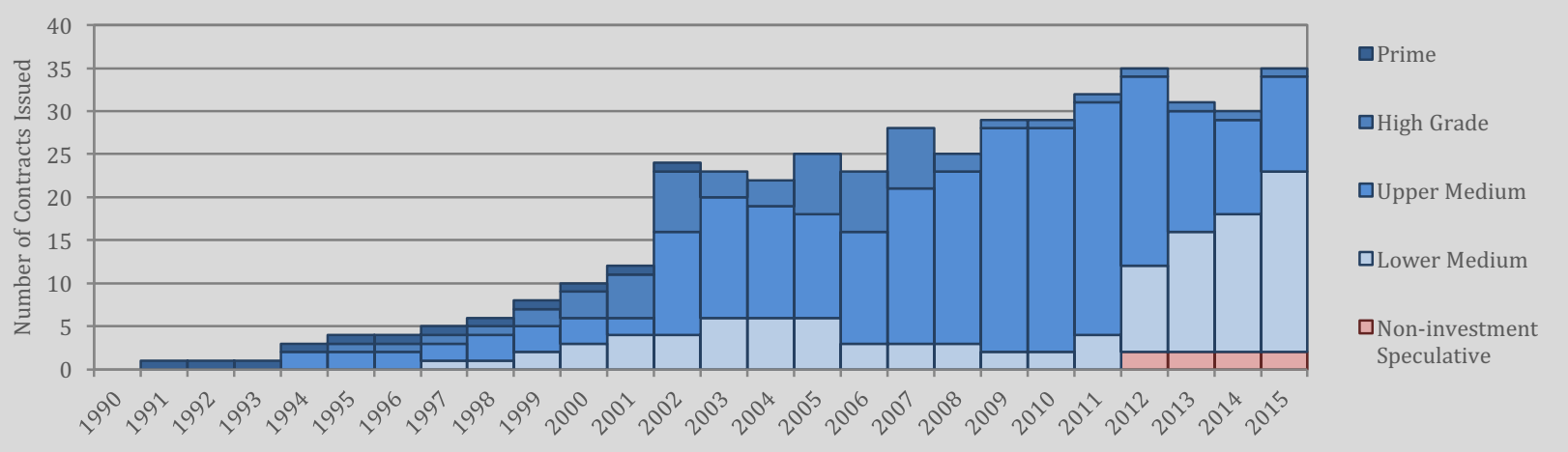

\subsubsection{Group Revenue and Earnings}

As discussed in Section 4.2, the sample's performance has generally improved over time. Between 2000 and 2012, the group's revenue (see Figure 18) increased by 159\% from €215bn in 2000 to $€ 493 \mathrm{bn}$ in 2015; the most rapid rate of increase occurred between 2005 and 2012. While increasing revenue would intuitively suggest greater profitability, this has not been the case because EU utilities have generally seen an increase in the cost of goods sold (COGS) over the period. Thus, operations became relatively expensive, eating into profits.

Figure 18: Group Revenue, 2000-2015191

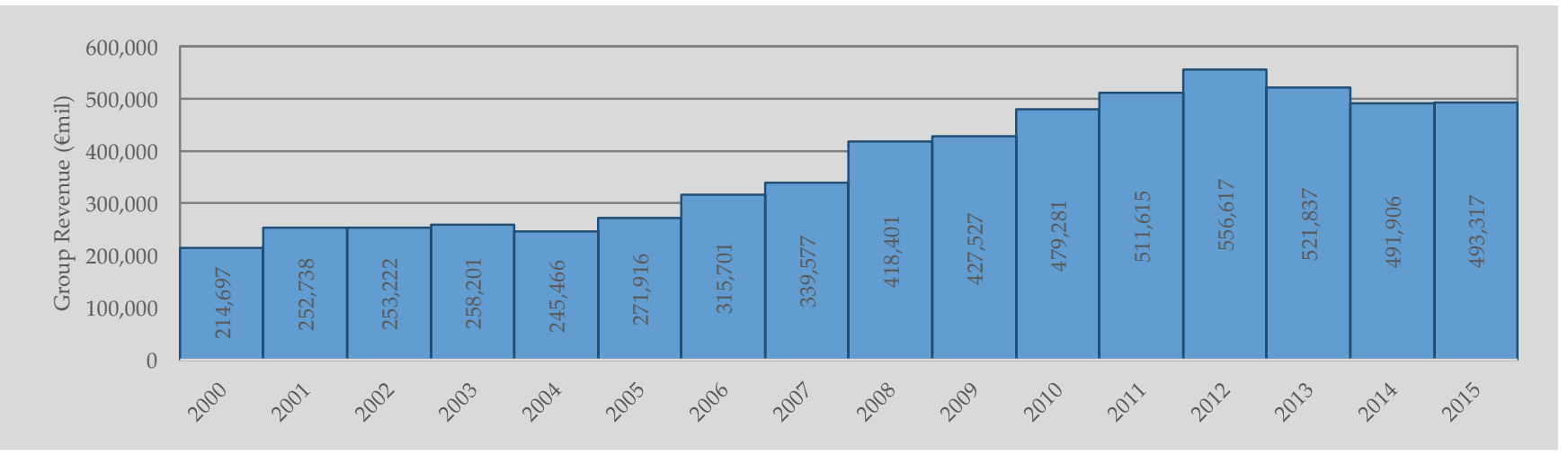

Detailed analysis in Figure 19 reveals a deterioration in the companies' capacity to generate earnings since 2010. The sample has seen aggregate earnings before interest, tax, depreciation and amortisation (EBITDA) fall from $€ 99.7 \mathrm{bn}$ in 2010 to $€ 71.3 \mathrm{bn}$ in 2015. The EBITDA margin (calculated as a proportion of revenues retained as earnings) fell steadily from $51.1 \%$ to $36.6 \%$ between 2010 and 2015. German utilities experienced the largest declines, with RWE, EnBW, and E.ON having margins of $9.8 \%, 7.7 \%$, and 6.1\%, respectively in 2015. Certainly, Germany would benefit from utilising its cheap coal reserves to boost underlying earnings. Across the firms, there are no clear winning technologies which contribute to a higher EBITDA margin.

190 The figure is adapted from Tulloch and Caldecott (2016), with underlying data extracted from Moody's. Data were available for 13 of the 14 sample firms (Tauron lacked data). 191 S\&P Capital IQ. 
Figure 19: Group EBITDA, 2000-2015192

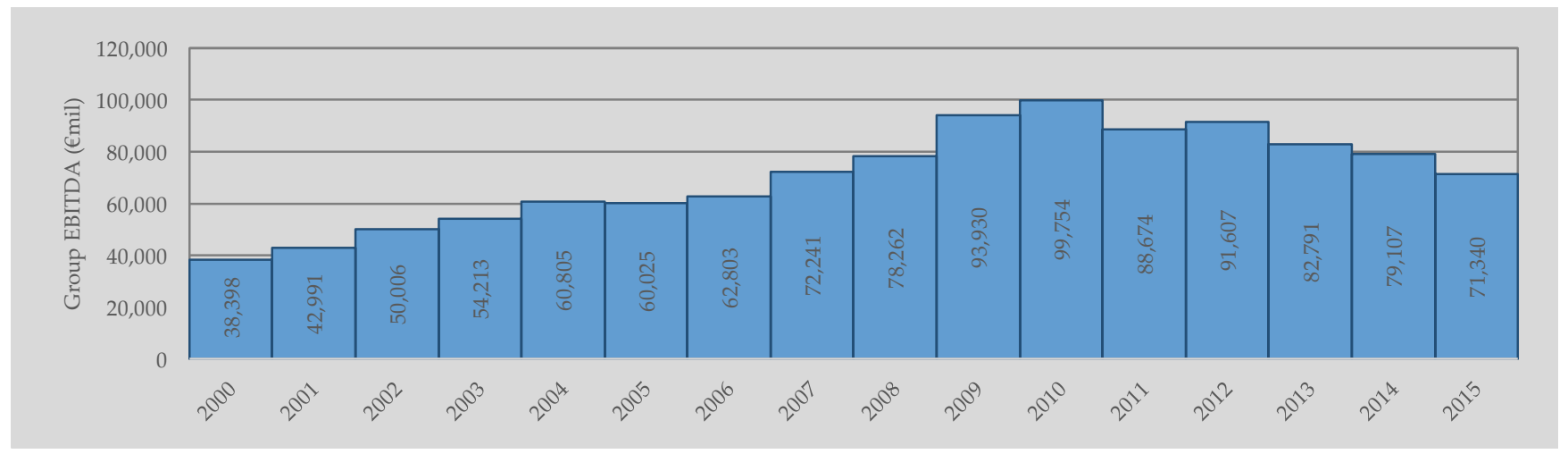

Plot (A) of Figure 20 shows a similar trend. The net income of the sample rapidly increased in the 2003-07 period. While the GFC had an impact on bottom-line profits in 2008, the group's net income in 2009 was the highest over the preceding 15 years - at $€ 36.7 \mathrm{bn}$. After 2009, net income began to decline gradually, eventually becoming a net loss of $-€ 2.7 \mathrm{bn}$ in 2015. From 2011, both the magnitude and frequency of annual losses increased dramatically. In 2015, five of the 14 companies analysed recorded a net loss from operations. ${ }^{193}$

Plot (B) of Figure 20 presents the mean net income at the company-level and the 25th and 75th percentiles - the spread between these lines represents the middle 50\% of observations. ${ }^{194}$ Plot (B) shows that the 2003-08 period saw the range between winning and losing companies begin to widen, with some companies making extraordinary gains. These incumbents, which used to represent $85 \%$ of the industry profit pool, were hit the hardest by falling profitability. Their high degree of exposure to merchant generation - the traditional core of the industry - made them especially vulnerable during the GFC, when energy demand decreased and wholesale electricity prices fell. Many utilities followed a downward trajectory over the following years, although some managed to remain in profit - albeit at a much lower level. Of the sample firms, five were trading at a loss in 2015. ${ }^{193}$ E.ON has traded at a loss for the last two consecutive years and Vattenfall traded at a loss for the last three consecutive years.

The analysis of the group's net income and mean net income implies that the long-term business model of the EU energy utilities is under considerable threat, since many utilities have seen an erosion of profits over time. In the long term, utilities need to adapt to their new operating environment and the most likely solution is a reduction in all the variable costs of operations to boost bottom line profits. Sections 6.2 and 6.3 discuss changes that utilities have implemented to date. In the short term, utilities can impair assets in recognition that the 'good times' are behind them, and that future anticipated cash flows will be significantly lower or potentially unrecoverable.

192 S\&P Capital IQ.

193 E.ON (-€6,999mil), GDF Suez (-€4,617mil), PGE (-€707mil), Tauron (-€421mil), and Vattenfall (-€1,818mil).

194 This measurement, frequently referred to in statistics as the H-spread, is a measure of statistical dispersion. 
Figure 20: Group Net Income, 2000-2015195

(A) Group Net Income

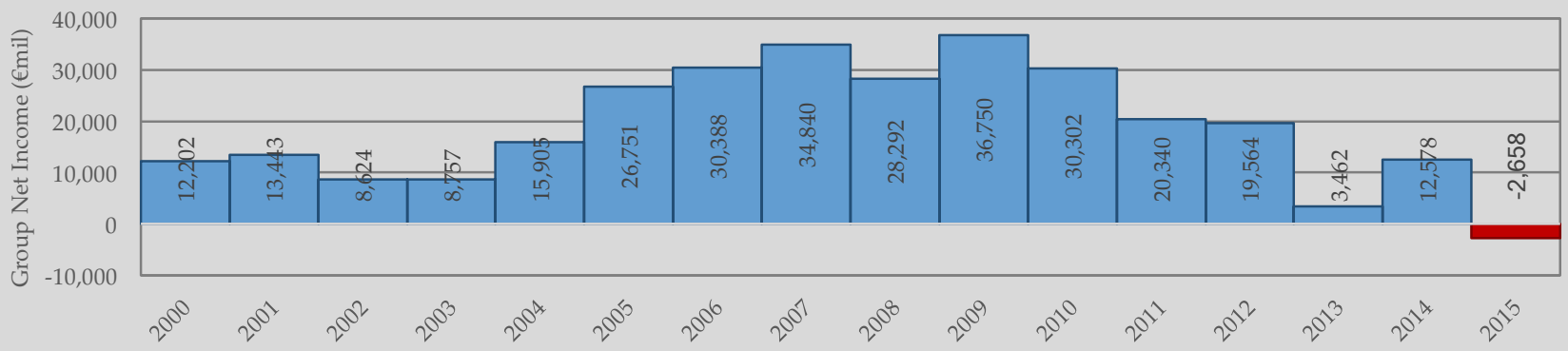

(B) Mean Net Income

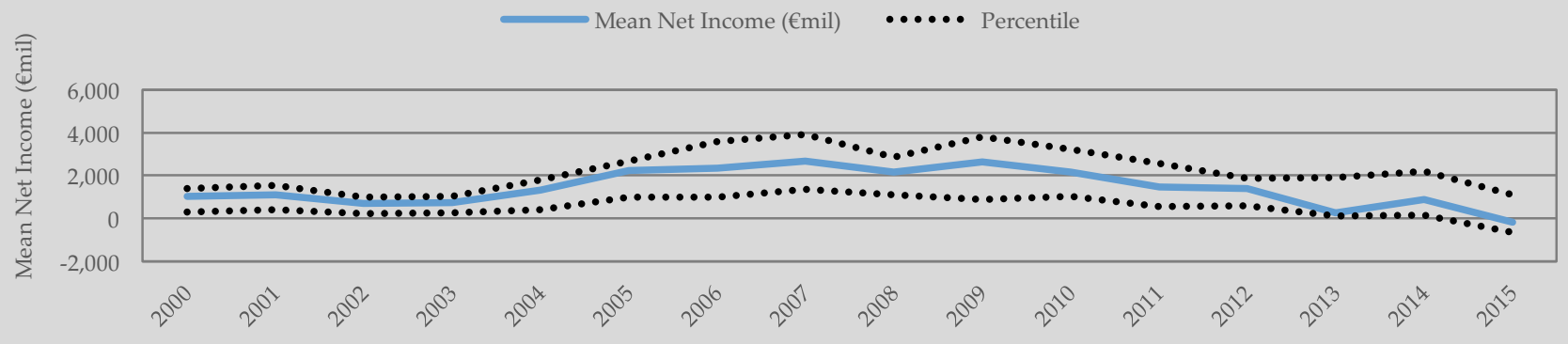

\subsubsection{Group Impairments and Stranded Assets}

We use company disclosure on the value of their net property, plant and equipment (PP\&E) to understand how valuation of real assets has changed over time. PP\&E include assets which are vital to operations but cannot be liquidated easily. PP\&E for utilities are dominated by power generation assets and related infrastructure. Net PP\&E are also used to account for accumulated depreciation expenses over the asset's useful life.

Plot (A) of Figure 21 shows that net PP\&E remained relatively stable until 2005, at around $€ 303 \mathrm{bn}$. Post-2005, there is a rapid expansion of assets and net PP\&E increased to over €544bn in 2012. The greatest rate of investment occurred in the period 2006 to 2009, which is consistent with the expansion of operations and balance sheets. Since 2012 net PP\&E have remained relatively stable, which suggests the sector is no longer expanding. Plot (B) shows the depreciation and amortisation (D\&A) of the group's assets across time. The D\&A co-varies with the net PP\&E, typically fluctuating around 5.9\% over the entire period. However, between 2012 and 2015 there is a sudden reduction in the value of utilities' real assets by $-8.5 \%$ from $€ 544,360 \mathrm{~m}$ to $€ 498,280 \mathrm{~m}$. Fortum, GDF Suez, and E.ON saw the largest fall in the value of real assets, at $-43.0 \%,-34.2 \%$, and $-19.4 \%$ respectively. In contrast, Verbund, Iberdrola, and EDP enjoyed an increase in real assets of $24.6 \%, 15.1 \%$, and $8.9 \%$ respectively. The likely cause for the sudden downward revision of net PP\&E was an unanticipated devaluation or write-down in assets in recognition that generating assets were no longer as productive as previously thought.

195 S\&P Capital IQ. 


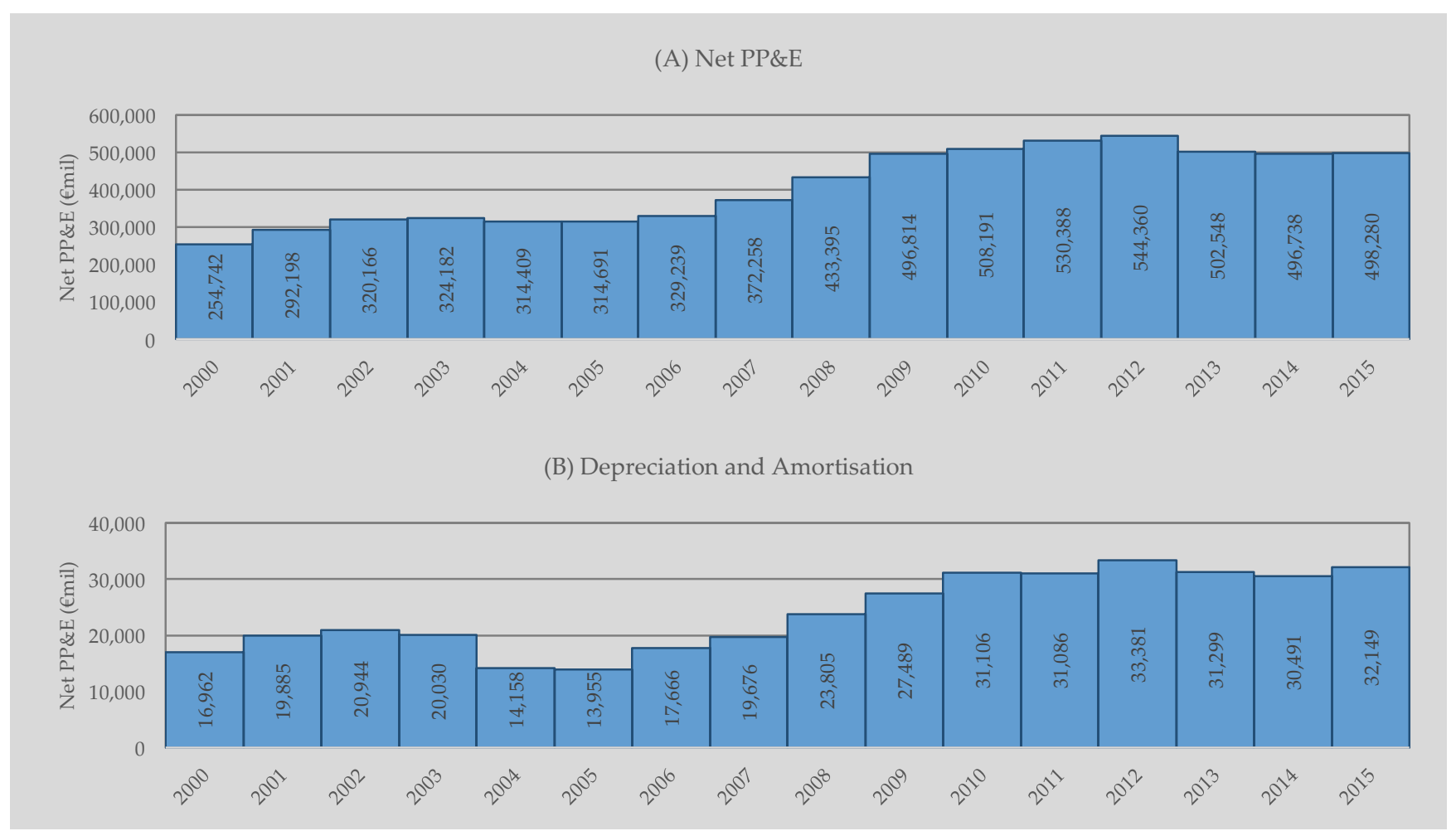

Figure 22 illustrates the group's asset write-down and impairment of goodwill between 2000 and 2015 . The data is presented at an aggregate level, and thus we are unable to delineate the write-down and impairment at the asset level for coal-fired assets. Between 2000 and 2009, the group's asset write-down typically remains low, at around $€ 1.1$ bn per annum. In 2010-12, there is a more than six-fold increase in write-downs, to around €6.9bn per annum. Plot (A) shows that major asset write-downs of €20bn per annum occur from 2013 onwards. Plot (B) also shows a relatively similar pattern for impairment of goodwill. Impairment of goodwill typically remains low between 2000 and 2012, with some unusually large impairments of $-€ 2.4 \mathrm{bn}$ and $-€ 3.5 \mathrm{bn}$ in 2002 and 2008 respectively. Major impairment of goodwill of -€8.4bn and -€7.2bn occurs in 2013 and 2015 respectively. Overall, the write-down in assets was still much larger than the impairment of goodwill.

Both Plots (A) and (B) highlight the utility industry's recognition of the reduced value of their impaired assets, and a fundamental change in the operating environment. Specifically, the carrying value and recoverable amount from the generating asset themselves are perceived to be significantly lower. Put simply, merchant operations and the assets used to generate power are viewed as less profitable in the long term.

196 S\&P Capital IQ. 
Figure 22: Group Asset Write-down and Impairment of Goodwill197

(A) Asset Write-downs

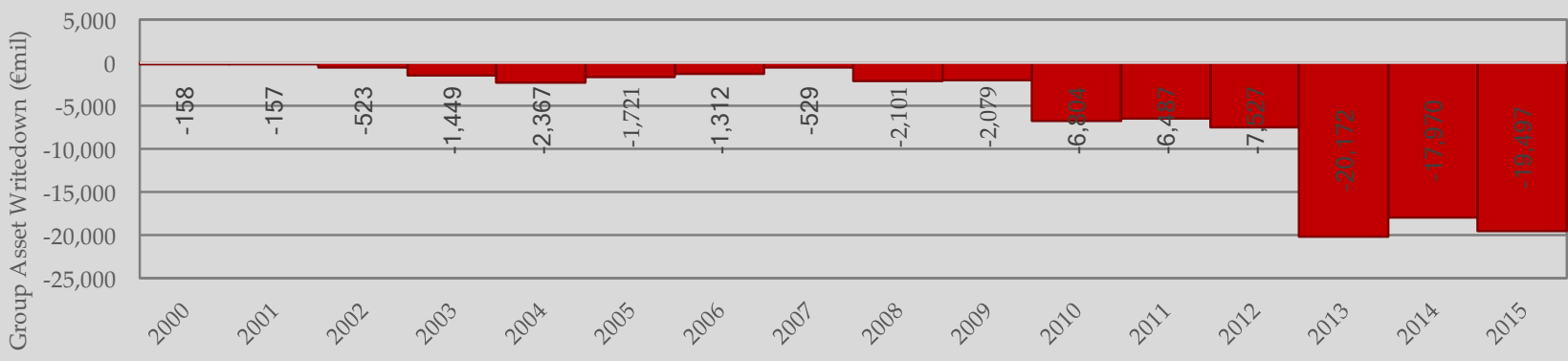

(B) Impairment of Goodwill

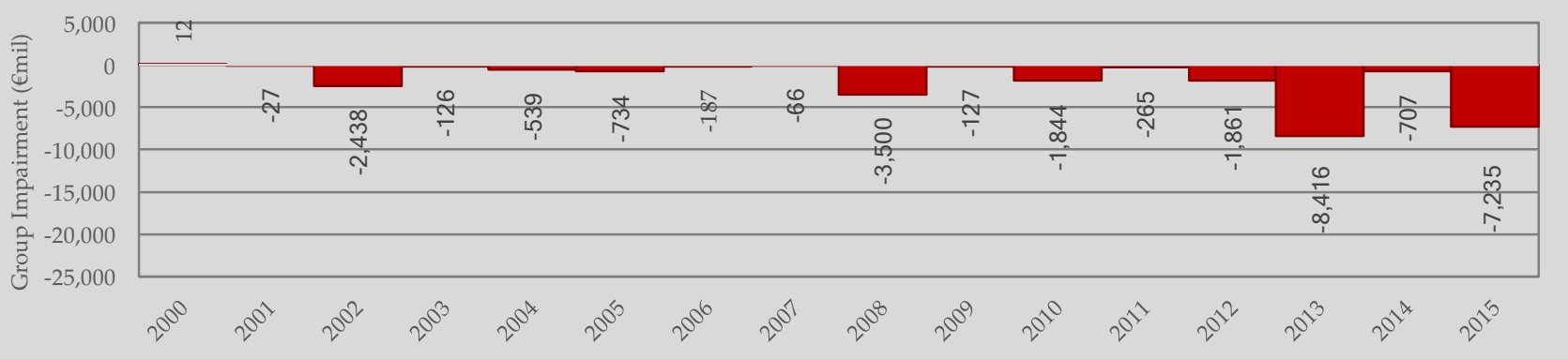

\subsubsection{Impacts}

The conditions for coal-fired power generation in Europe have deteriorated. Full- or high-utilisation rates are becoming rare for conventional generation assets and wholesale power prices have decreased considerably. Some utilities, especially newer and more efficient plants, particularly if they include co-generation, are still in the money and generate profits.

The write-downs on thermal generation in recent years are mostly due to the fact that the market outlook has changed and for many of the plants it is not clear whether they will operate profitably long enough to earn their investment. Furthermore, some older and less efficient plants (some already fully written-off), which were due to be decommissioned already, or early, given the current market environment, have been kept open or been subject to forced mothballing for regulatory reasons (especially in Germany). In some cases decommissioning would have put the stability of the grid at risk.

In many respects the root cause of the relative difficulties of thermal power production compared to low-carbon alternatives is that it operates in different political and economic environments. Thermal power generators do not benefit from priority access to the wholesale market, meaning that full utilisation of fossil fuel assets is not guaranteed. Moreover, the low-marginal cost of low-carbon technology means that it can often out-bid all conventional generation under normal conditions. Lastly, conventional power plants have to comply with numerous additional regulations, e.g. the Industrial Emissions Directive or the EU Emissions Trading Scheme, adding to their cost base.

A likely impact of the factors above is the premature closure or mothballing of thermal, fossil fuel-fired generation assets. Analysts expect further impairments and write-downs of thermal generation assets in the future, which

197 S\&P Capital IQ. 
may well affect the viability of some utilities, though not the big vertically integrated ones. While these asset closures will have a moderate impact on the health of European utilities, they are likely to have a significant impact on their investment strategies. The extent of the plant closures across fuels will also depend on several regional characteristics, such as policies and/or market structures which may retain coal's competitiveness versus alternative thermal generating technologies. At present, coal remains competitive against gas in Germany and Poland, while the Netherlands has deployed a fleet of the 'cleanest' coal-fired power in Europe. Today changes in social norms and increasingly stringent EU regulation present the main challenge to the future of coal plants. 


\section{Asset-level Analysis of Units per Status}

This section analyses the features of units that were operational, retired, planned, cancelled, and under construction. The analysis is organised around three periods of interest (pre-2005, 2005-08, and post-2008). The section examines various types of coal-fired units and their associated capital costs, operational and maintenance costs, size of units, and efficiency of the technology. It therefore investigates the characteristics of both successful and unsuccessful coal-fired plants in the EU.

To conduct our analysis, we combine the Q4 2004, Q4 2007198 and Q2 2016 WEPP databases. The three databases present three snapshots of the utility industry over time, and are selected as they represent structural breaks in our analysis (pre-2005, 2005-08, and post-2008). For the analysis, we merge the three datasets and produce a summary of asset status (operating, planned, retired, under construction, or cancelled).

\subsection{Steam Conditions - Coal-Fired Generating Technologies}

The first part examines the various steam conditions of coal-fired technology. Steam conditions refer to the required temperature and pressure of the boiler used in the production of electric power. The three steam conditions of interest are colloquially referred to as subcritical, supercritical, and ultra-supercritical. Subcritical boilers allow bubbles to form during the water-heating process, producing steam. In contrast, the latter technologies operate above critical pressure (about 3,200 psi), which turns liquid to steam immediately. They consume less fuel, potentially reducing greenhouse gas emissions per unit of energy produced. Table 13 presents the data on the type (whenever provided) and status of each coal-fired technology in the EU, across the three time periods analysed.

Panel (A) shows the domination of subcritical coal-fired generating units across all periods. In addition to being the most numerous units in operation, the subcritical units were also the most numerous being retired. By Q4 of 2007, 15 subcritical units were planned in the EU, and most were expected online between 2009 and 2011. However, by Q4, few of these units had materialised and many were cancelled.

Panels (B) and (C) show that the numbers of supercritical and ultra-supercritical units (respectively) are considerably lower than subcritical units. No more than 30 supercritical generating units were operating at any one time, and 16 ultra-supercritical units entered the market in the Q2 2016 database. The number of ultrasupercritical units under construction is also higher than subcritical units. Overall, there is a clear trend that the $\mathrm{EU}$ is retiring the older subcritical (and possibly high pressure) boiler units and has begun transitioning towards more advanced coal-fired technologies. This would be consistent with the objectives of Poland, which intends to build 'clean coal' technologies. With the changing profile of the EU's coal-fired power fleet, the analysis continues by examining characteristics of the recently built generating units.

\footnotetext{
198 Note, only historical Q4 databases were available for purchase from S\&P Capital IQ WEPP. As the Q4 2008 database would have already included the effects of the GFC and major cancellations, we opt to purchase Q4 2007.
} 
Table 13: Table of Various Coal-Fired Technologies 199

\begin{tabular}{|c|c|c|c|}
\hline Unit (Number of generating units) & \multicolumn{4}{|c|}{ Period } \\
\hline Panel (A) Subcritical & Q4 2004 & Q4 2007 & Q2 2016 \\
\hline Operating & 1,258 & 54 & 112 \\
\hline Retired & 534 & 158 & 442 \\
\hline Planned & 6 & 15 & 4 \\
\hline Cancelled & - & 6 & 16 \\
\hline Under Construction & 3 & 2 & 5 \\
\hline \multicolumn{1}{|c|}{ Panel (B) Supercritical } & \\
\hline Operating & 30 & 2 & 3 \\
\hline Retired & 5 & 1 & 2 \\
\hline Planned & 4 & 37 & 3 \\
\hline Cancelled & - & 10 & 33 \\
\hline Under Construction & 1 & 9 & - \\
\hline Panel (C) Ultra-supercritical & \\
\hline Operating & - & - & 16 \\
\hline Retired & - & - & \\
\hline Planned & - & - & 1 \\
\hline Cancelled & - & - & 10 \\
\hline Under Construction & - & - & 10 \\
\hline
\end{tabular}

\subsection{Asset Characteristics}

\subsubsection{Capital Costs}

First, we examine the cost of building coal-fired units in the EU. The data in Table 13 show a shift towards more efficient, and typically more expensive, supercritical and ultra-supercritical coal-fired generation. We hypothesise that average capital costs (measured per $\mathrm{kW}$ ) will rise as more expensive coal-fired generating units begin construction, and ultimately become operational. A higher capital cost translates to higher sunk costs of generating units, and thus a greater value of potential asset stranding.

We examine the cost of building coal-fired assets in the EU on a per $\mathrm{kW}$ basis, using investment cost data from the IEA for various coal-fired technologies. 200 We delineate the capital investment costs in a $2012 \$ / \mathrm{kW}$ basis for subcritical, supercritical, and ultra-supercritical coal-fired generation. In the few cases of unknown boiler type, we assume capital costs are similar to those of subcritical boilers. We examine the average capital costs across each plant status (Operating, Retired, Planned, Cancelled, and Under Construction) against each dataset (Q4 2004, Q4 2007, and Q2 2016). The mean capital cost will show a shift in capital costs according to plant status, and indicate which type of plants are built or cancelled.

The results in Figure 23 are congruent with those observed in Table 13. The large number of operational and retired subcritical plants during all three periods keeps the capital costs relatively stable, at around $\$ 1,700 / \mathrm{kW}$. The 2007 and 2016 databases are mostly characterised by a greater number of supercritical and ultra-supercritical coal-fired utilities, thus increasing the average capital costs for the planned, under construction, and cancelled series. The large number of retired subcritical plants slightly lowers the average capital cost. Beyond measuring the capital costs on a per $\mathrm{kW}$ basis, we also examine the total build cost of each generating unit.

199 Platts WEPP Database.

200 IEA, “WEO- Investment Costs,” International Energy Agency, 2016. 


\section{Figure 23: Capital Costs per kW of Building Coal-Fired Generation ${ }^{201}$}

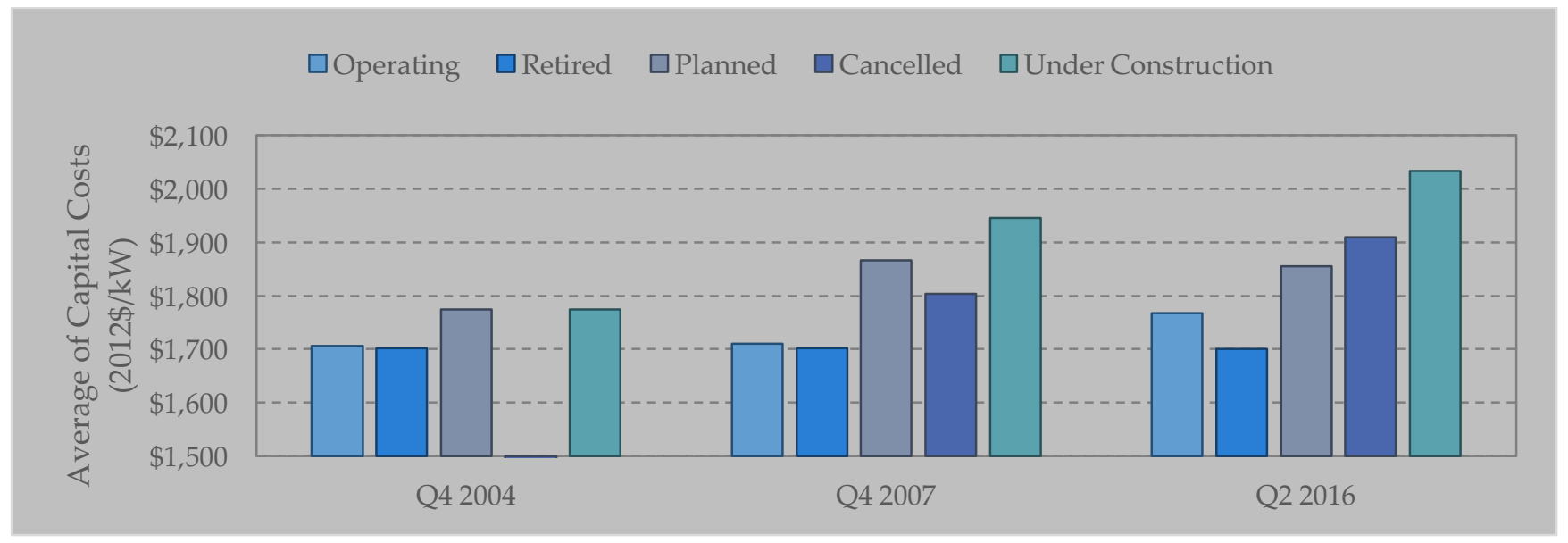

The total build cost is estimated by multiplying the capacity of each generating unit by the average capital cost, based on technology type, and scaled from kWs to MWs. The results are shown in Figure 24 and are fairly similar to those observed previously. Each operating unit typically costs around $\$ 211$ million to build, and the total cost remains consistent across time. Many of the retired units are cheap and small, at around \$134 million per unit. This is consistent with small, old subcritical units being removed from the grid. The total cost for the planned, cancelled and under construction series is typically much higher: between $\$ 414$ million to $\$ 1,382$ million per unit. As these units are mainly supercritical and ultra-supercritical, the costs are expected to be higher. Further, these latter technologies have larger minimum capacities, 202 and are therefore more expensive to build than subcritical units.

\section{Figure 24: Estimated Total Build Cost ${ }^{203}$}

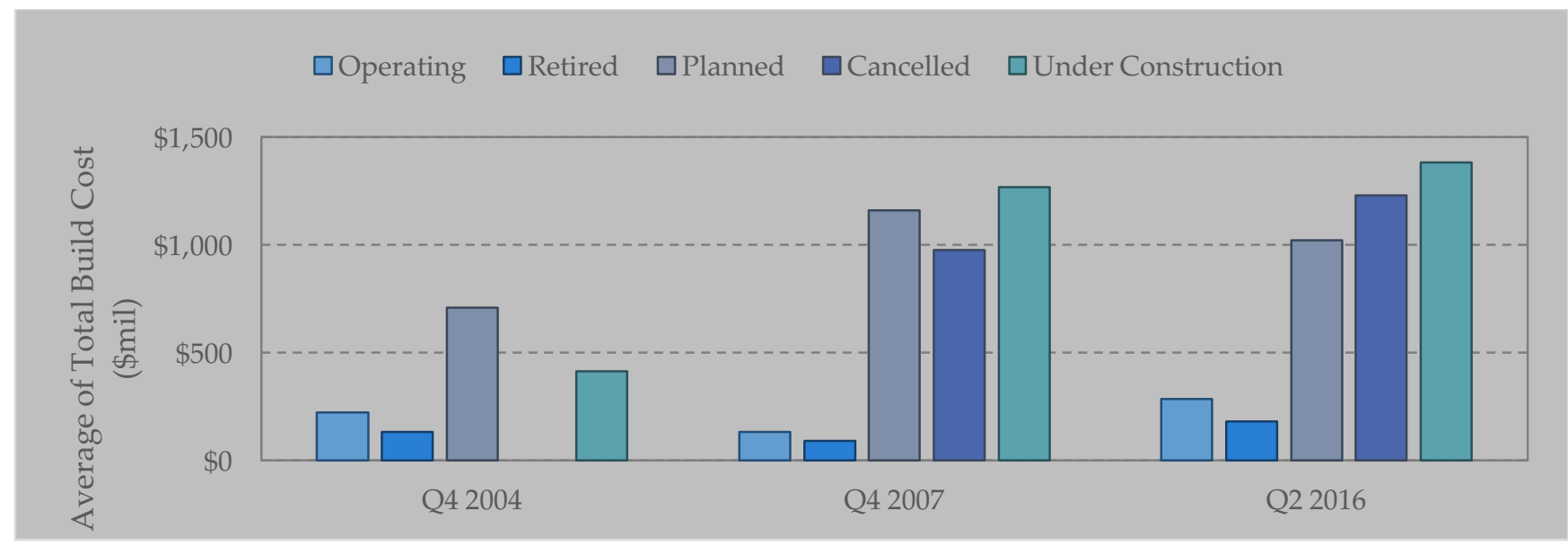

201 Platts WEPP Database.

202 Regardless of operating status, the minimum capacity observed in the WEPP $(2004,2007$, and 2016) databases for subcritical, supercritical, and ultra-supercritical coal-fired generating units was, respectively, 0.035MWs, 21MWs, and 375MWs. The maximum capacity of all three exceeded 1GW.

203 Platts WEPP Database. 
The overall implication of the capital cost analysis is that the cost, on a per $\mathrm{kW}$ basis, and total build cost, is increasing over time. This implies that investors may be at higher risk of asset stranding, as the larger sunk cost suggests higher capital at risk.

\subsubsection{Operating Costs}

The second variable examined is the average operating and maintenance $(\mathrm{O} \& \mathrm{M})$ costs of EU coal-fired units. The estimate of O\&M costs from the IEA (2016) suggests that the average O\&M costs for more advanced boiler technologies, such as ultra-supercritical, are greater than less advanced boiler technology, such as subcritical boilers. A higher O\&M cost places the more expensive technologies at a greater risk of asset stranding, as the nearzero marginal cost of renewables and low-carbon alternatives are often able to outbid all thermal generation in wholesale electricity markets. Importantly, the more expensive coal also risks being outbid by cheaper coal if both satisfy emission standards.

\section{Figure 25: Average Operating and Maintenance Costs for EU Coal-Fired Units (2012\$/kW) 204}

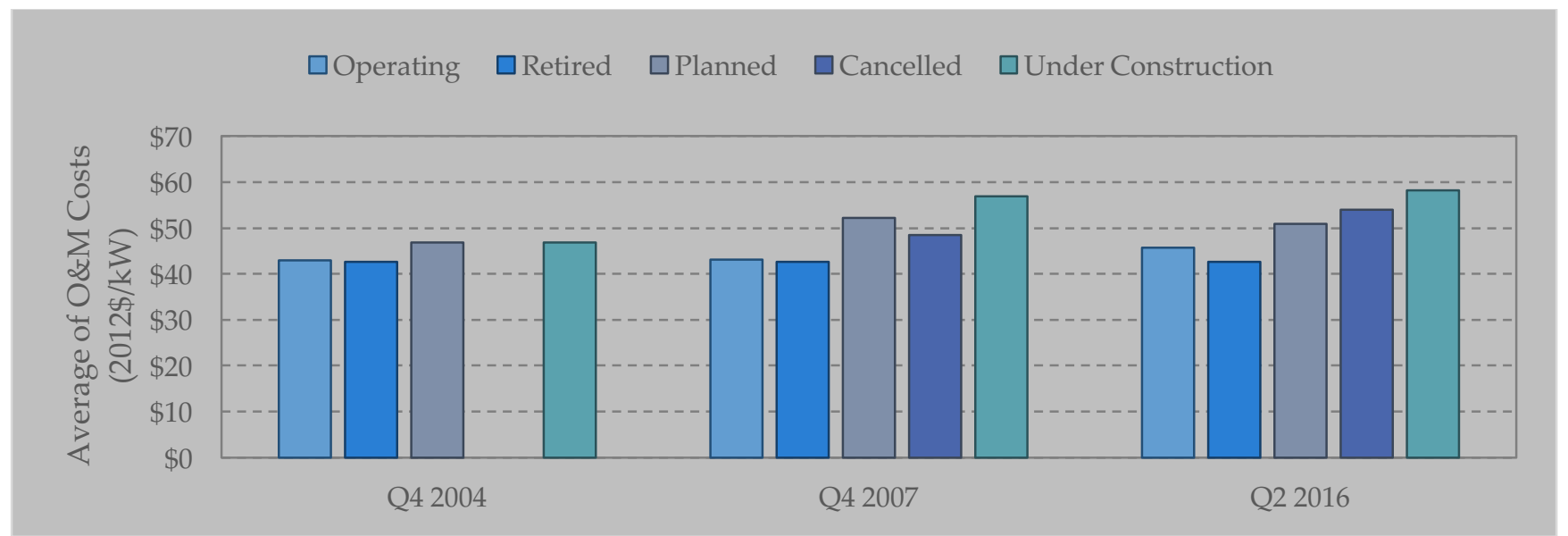

The results in Figure 25 show that the operating and retired coal-fired units typically cost around $\$ 43$ per $\mathrm{kW}$ to run in 2004. The planned capacity and capacity under construction were typically more expensive in each period analysed, at respectively around $\$ 50$ per $\mathrm{kW}$ and $\$ 54$ per $\mathrm{kW}$. The units under construction are actually typically among the most expensive. This is consistent with more supercritical and ultra-supercritical technology entering the market. Accordingly, we find some evidence that the coal-fired units entering the grid are more expensive to operate, and thus are at a higher risk of asset stranding because of their operational costs.

\subsubsection{Size}

Total build cost in Figure 24 shows that the total cost of the planned, cancelled and units under construction was typically higher than the total cost of operational and retired units. We conclude that this was because supercritical and ultra-supercritical units typically have much larger capacities. To ensure this is a correct conclusion, we must also examine the capacities of EU coal-fired units in various states. We use capacity data from WEPP Q4 2004, Q4 2007, and Q2 2016 to examine whether there has been a change in the capacities of EU coal-fired power utilities. We should expect that the planned, cancelled, and units under construction are larger than the operational and retired units, as the former group should consist of the larger, more efficient technologies, while the latter group are mostly subcritical units.

The results in Figure 26 confirm that, from 2007, the average capacity of planned, cancelled and units under construction was greater than 463MWs, while the average capacity of operational and retired units was between 78

204 Ibid. 
and 112MW. The results imply that the EU moved away from the numerous, smaller subcritical plants towards fewer and more advanced generating technologies.

\section{Figure 26: Capacities of EU Coal-Fired Units205}

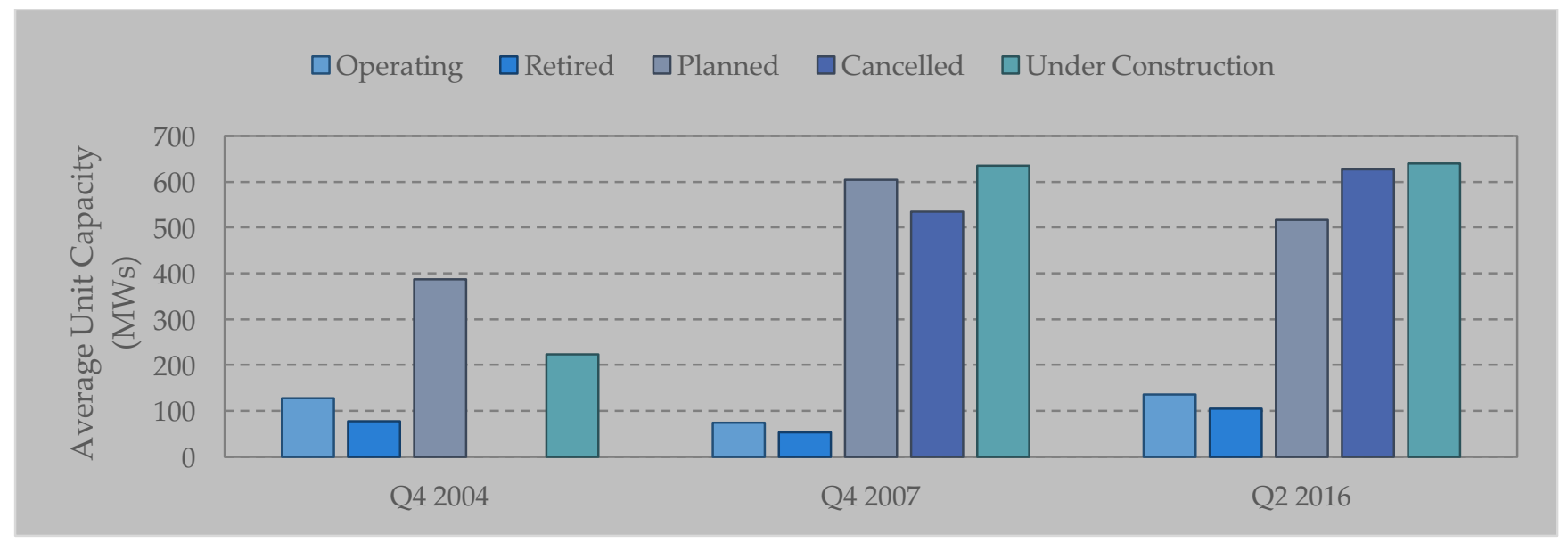

\subsubsection{Efficiency}

Given the fact that the EU is transitioning towards more advanced coal-fired technology, and such technology is expected to be more efficient than the existing subcritical plants, we may expect an associated increase in metrics relating to generating efficiency. Employing IEA data, ${ }^{206}$ we use estimates of efficiency, measured as gross lower heating value of fuel, for various coal-fired generating technologies. The differences in efficiency are not expected to be large, if any, as the range of efficiencies observed is relatively small between technologies: subcritical coal's efficiency is estimated to be $39 \%(9,186 \mathrm{Btu} / \mathrm{kWh})$, while the efficiency of ultra-supercritical is estimated at $46 \%$ $(7,788 \mathrm{Btu} / \mathrm{kWh})$.

\section{Figure 27: Efficiency of EU Coal-Fired Generating Units 207}

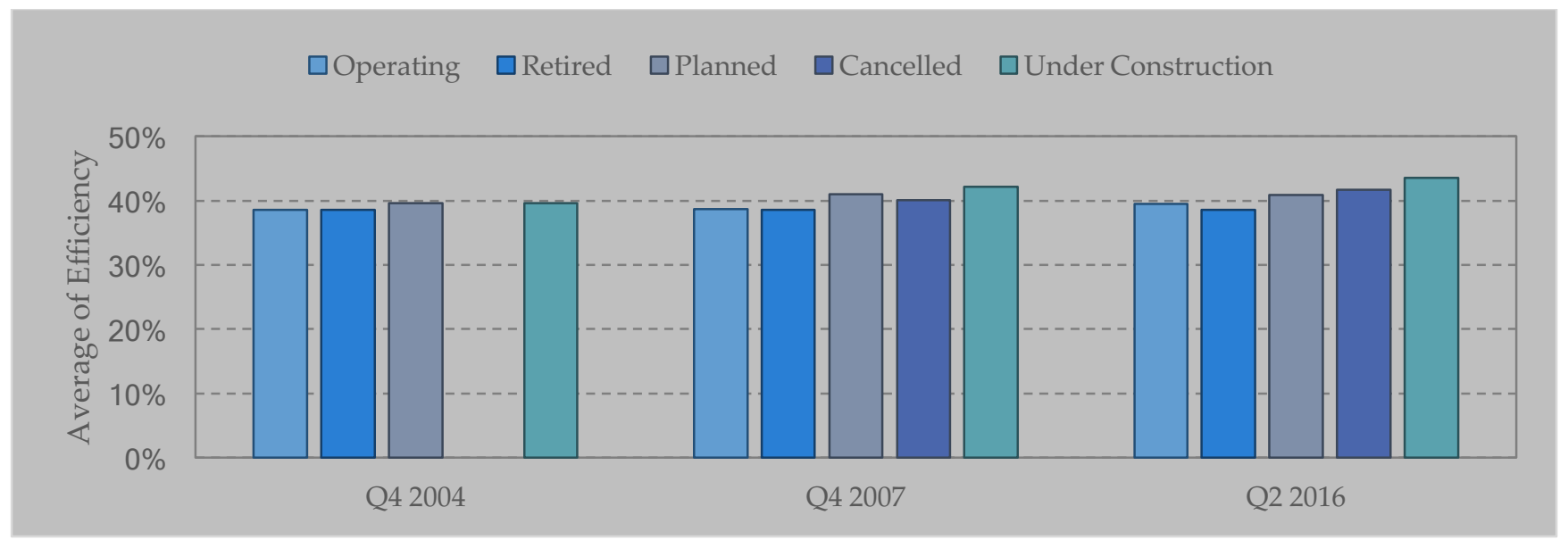

205 Platts WEPP Database.

206 Ibid.

207 Platts WEPP Database. 
Overall, the results in Figure 27 show a small change in measures of efficiency over time. In 2004, there is little change in overall efficiency between the existing and planned units. This is primarily due to the large number of subcritical plants planned during the 2004 period. In the 2007 and 2016 datasets, there is a preference for building the more technologically advanced technologies and, accordingly, the average efficiency factors trend towards the higher values for both planned units and units under construction. The risk of asset stranding due to technological innovation is medium. Although the newly-built coal-fired units are marginally more efficient, they do not differ drastically from the existing coal-fired technology. 


\section{Going Forward: Utilities' Prospects and Responses}

This section provides a brief overview of the short- and medium-term economic prospects of the EU power sector. This section discusses three themes: 1) economic prospects in the short- and medium-term, 2) operational and trading strategies, and 3) new business models and investment strategies.

\subsection{Economic Prospects of Power Generation}

It is important to note that projections of future energy markets are extremely uncertain as the deployment of various power generating technologies is heavily dependent on legislation, market mechanisms, and technological advances. But the consensus for fossil fuel-fired generation is not positive. Low wholesale prices, lower energy demand, and competition from low-carbon alternatives suggest reduced remuneration to conventional power generators. Market fundamentals remain weak, suggesting that the 'perfect storm' in the power market could continue for the foreseeable future. ${ }^{208}$ Accordingly, there is likely to be increased mothballing and decommissioning of these assets as renewables take an increasing share of electricity generation.

\subsubsection{Growth Outlook}

Figure 2 of Section 2.3.1 (page 21) shows that the EU experienced 16 consecutive years of positive energy growth between 1993 and 2008; approximately 1.6\% per annum. EU energy demand peaked in 2008, consuming 3,387 TWhs of electrical energy. Post-GFC, energy demand in the EU has been on a steady decline of $-1.0 \%$ per annum; this trend has also been observed in OECD countries more generally. A survey of the situation post-GFC reports that total energy demand is expected to decline by $-10 \%$ to $-20 \%$ by 2050 . The underlying causes are a combination of decreased demand overall and increased efficiency of energy-intensive appliances as a result of legislative changes. 209

As the proportion of intermittent generation in the system continues to increase over time, baseload generators are likely to play an important role in securing future energy supply by providing ancillary services and support capacity during periods of excess demand or short supply. The use of coal in power generation has remained relatively stable over the past five years and is unlikely to increase. Any new coal capacity today is likely to face early decommissioning due to environmental regulations and the inability to compete against flexible generation in real-time energy markets.

\subsubsection{Resource Landscape}

Coal's affordability compared to natural gas and RES has contributed to its increased use since the GFC. A glut of coal from the US, Australia, and Indonesia has saturated the market and decreased global coal prices. The low price of coal makes it an attractive fuel for power generation in the energy-only market. Currently most coal and lignite operations are 'in the money', i.e. earn their variable cost. The situation is better for newer plants because of their higher fuel efficiency and more prevalent co-generation plants. The short- and medium term outlook (2015-2030) for lignite as well as hard coal is deteriorating and their growth in usage is, for the most part, over. Many proposed coal-fired power plants have been cancelled and the last few years have seen decreasing utilisation of coal in power generation.

Coal use will also be impacted by the potential resurgence of natural gas in the near future. The falling price of oil has begun to narrow the gap between cheap coal and gas prices in recent years. This is due to many long-term gas

\footnotetext{
208 McKinsey\&Company, "Beyond the Storm - Value Growth in the EU Power Sector," 2014.

${ }^{209}$ Erik Delarue et al., "Decarbonizing the European Electric Power Sector by 2050: A Tale of Three Studies," EUI Working Papers, 2011, 1-14.
} 
contracts in Europe being indexed to the price of oil. 210 Natural gas-fired generation is set to take an even greater share of generation from coal. The consumption of coal in the EU is expected to decrease significantly.

\subsubsection{Carbon Markets and Climate Policy}

Even though utilities believe that some European economies (especially Germany and Poland) will continue to depend on coal and lignite, evolving climate targets will lead to a phase-out of all unabated coal (with lignite leaving the picture first). CCS is unlikely to play a significant role as it is too costly to compete with renewables, and some utilities do not expect to utilise their relatively new coal power capacity (including the capacity still under construction) until the end of its useful life. It is likely that the greatest retreat from coal will stem from policy and carbon pricing, which will have a significant effect on wholesale electricity prices.

\subsubsection{Support for RES}

The increasing share of RES in electricity generation in the EU power industry can be attributed to various factors. First, policies to support RES make them attractive investments. These policies are designed to assist the EU to meet its overall emission reduction targets. Some policies, such as feed-in tariffs, also shelter RES technology from competitive forces in the wholesale energy industry. It is likely that these and similar policies will play a major role in the energy sector between now and 2030. Second, the low deployment costs of solar and wind, which are projected to decrease further, reduces the initial capital needed for investment. Between now and 2030, RES technology will become increasingly competitive against conventional thermal generation. The proliferation of renewable generation capacity across EU member states has significantly disrupted wholesale market pricing and trading strategies, as baseload capacity (including fossil fuel generation such as gas and coal) has struggled to compete. Figure 28 shows that, between 2000 and 2014, RES electricity generation increased at the expense of conventional generation. The coefficient of RES and fossil fuel capacity is approximately -0.615 , indicating a $10 \%$ increase in RES capacity and a $-6.15 \%$ decrease in fossil fuel capacity.

\section{Figure 28: Impact of Renewables on Conventional Power Plan Utilisation, 2000-2013211}

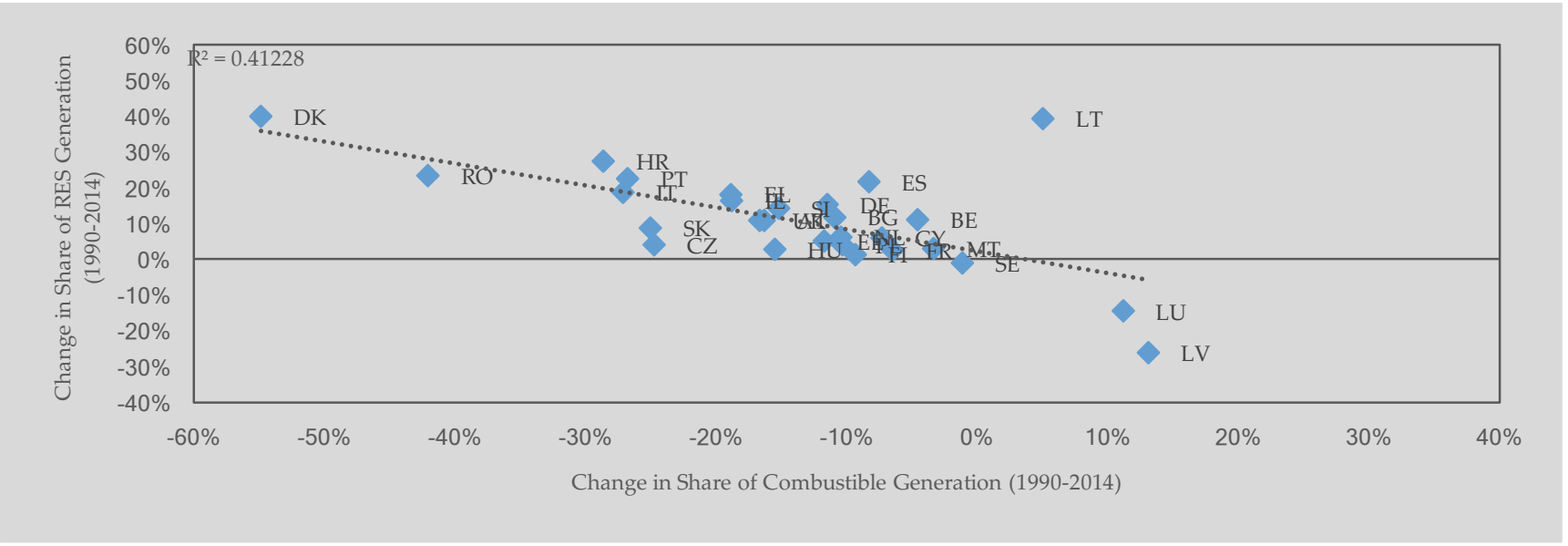

Economic and natural constraints potentially limit RES growth. Examples include low precipitation and restriction on the use of biomass and hydropower beyond current levels. Both these RES technologies are likely to see restricted growth in the short- and medium term as a result of mostly exogenous risks.

210 Ofgem, “Wholesale Energy Markets in 2015” (London, 2015); CEZ Group, “Annual Report 2015,” 2015.

Ofgem, "Wholesale Energy Markets in 2015"; CEZ Group, “Annual Report 2015.”

211 Eurostat, "Database - Eurostat." 


\subsubsection{Policy and Regulation}

The integration of European energy markets over the coming decades is required to ensure efficient cross-border exchanges in electricity and use of existing generating capacity. Although the EU is currently over-capacity (with the exception of the UK which is under-capacity), there are major concerns that energy markets with a large proportion of renewables will be unable to deliver sufficient capacity to meet future energy demand at all times. ${ }^{212}$ The potential lack of adequate capacity in the near future has encouraged member states to intervene by introducing a range of capacity remuneration mechanisms (CRMs) as incentives to investors. Capacity mechanisms can take many forms, but the underlying principal involves making separate payments for available capacity, rather than paying for electricity delivered. ${ }^{213}$ Capacity mechanisms have proliferated across EU member states, with major differences in design and structure (see Figure 29).

\section{Figure 29: Capacity Remuneration Mechanisms in the EU 214}

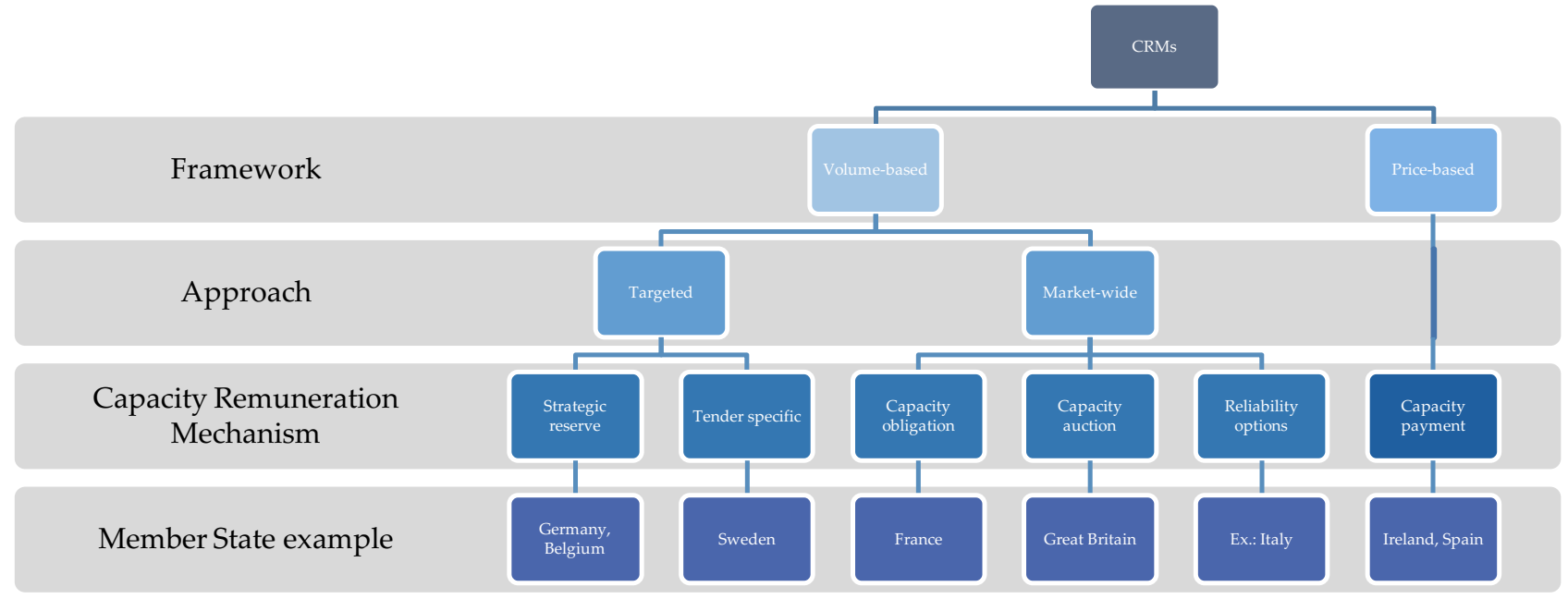

There are several foreseeable problems and challenges when it comes to the implementation of CRMs. First, one of the major barriers to the completion of the EU energy market integration is the fragmentation emerging between member states. The breadth of CRMs may result in national or regional capacity markets which are incompatible. While capacity mechanisms are broadly similar in their objectives, even mechanisms with similar designs (such as the UK's capacity market auctions and the Irish single electricity market's reliability options structure) are contingent upon technical design considerations, which can significantly affect their efficiency. Such a patchwork across Europe will not favour a consistent and integrated market and access to these different markets might differ or even be restricted. These differences in capacity mechanisms across member states have emerged as a primary concern of the European Commission, which launched a sector inquiry into capacity mechanisms under state aid provisions in April 2015.215 Its interim report concluded that while capacity mechanisms have the potential to increase supply security, mechanisms which are 'unnecessary and badly designed can distort competition, hinder electricity flows across borders and lead to consumers overpaying.' 216 No action has been taken yet at the EU level to regulate capacity mechanisms in the context of state aid regulations.

Second, for a capacity market to work, contracts need to be of very long-term nature and this assumes that required capacity can be forecast over many years. There is a risk that such long-term contracts might become stranded if

212 ACER, “Capacity Remuneration Mechanisms and the Internal Market for Electricity of 30 July 2013 - pursuant to Article 11 of Regulation of (EC) No 713/2009" (Agency for the Cooperation of European Regulators, 2013).

213 European Commission, "Launching the Public Consultation Process on a New Energy Market Design" COM(2015) (2015). 214 Adapted from, Tulloch and Caldecott (2016), FTI-CL (2015) and ACER (2013)214

215 European Commission, “Energy and Environment: State Aid to Secure Electricity Supplies,” Europa, 2016.

216 European Commission, "Interim Report of the Sector Inquiry on Capacity Mechanisms," 2016. 
demand is forecast incorrectly. Coal-fired power stations are particularly sensitive to forecasts of future energy demand as they require high-volume turnover and cannot easily scale-back operations in periods of fluctuating energy demand.

Third, the future of the energy system in Europe will depend heavily on how capacity mechanisms are designed. Important questions for the design of a capacity market are, for example, whether existing capacity is taken into account or only new capacity, whether it is a technology-neutral mechanism, and, if so, whether technology neutrality means only generation neutrality or whether transmission, storage, demand response, etc. are also considered. In the case of technology-neutrality, coal-fired generation has a future in energy supply. Yet, utilities are hesitant to invest in additional capacity under current conditions. Further, they are hesitant to invest in coal without the certainty of technology-neutrality. A capacity mechanism would need to address this; hence a capacity market would need to set an incentive for investors to invest in (or keep existing) capacity when and where it is needed.

Finally, depending on the design of the capacity mechanism, the implementation of such mechanism might lead to old existing and inefficient plants staying longer online as originally planned, which would counteract the climate and emission objectives of the EU and its member states. In such a case, existing coal-fired generation would temporarily remain on the energy grid if it resulted in lower committed emissions compared to building new, combustion-fired generating capacity.

Beyond capacity mechanisms, competition policy may also affect the downside risk to energy firms in terms of asset management and operations, especially regarding coal-fired generation infrastructure. For example, Vattenfall's forthcoming sale of its lignite power operations in Germany to Czech utility EPH - including a €1bn premium for re-naturalisation of former lignite mines - has reportedly been stalled at the EU level by concerns of legality under state aid regulations. ${ }^{217}$ Further, Germany's decision to close all nuclear power stations by 2022 has impacted, and will continue to impact, the performance of E.ON and RWE. These German utilities face decommissioning costs of nearly $€ 40 \mathrm{bn}$ (US\$44.2bn). A decision to close coal-fired generation due to its incompatibility with future energy markets would have a major impact on performance in the near term.

\subsection{Operational Strategies}

Because of major structural and market changes, utilities have begun to adapt and implement new operational and trading strategies in response to the new operating environment. They have responded in three main ways by: 1) reducing costs, 2) adapting operations, and 3) mothballing assets. The following paragraphs address each of these and some of the associated challenges.

To reduce the overall cost of operations and increase margins, some companies have reduced labour costs. For example, RWE cut 1,150 jobs in 2015 and plans to cut 2,300 jobs from its conventional power generation business by 2020. Utilities are also working hard to reduce their operating expenditures and are now running capital expenditures (e.g. replacement investments) projects to improve profitability. Most utilities doubt that their current and new assets will operate until the end of their useful life or even long enough to recoup their investment. For many, the net present value of finalising and bringing these assets online to operate them profitably for several years seems higher than cancelling the projects in their current states and absorbing the sunk costs. Hence it is highly efficient (and co-generating) capacity, currently under construction, which will go online, adding to the overcapacities in the European system.

A second solution is for EU utilities to adapt current operations to their new environment, for example by switching fuels to biomass. However, the global supply chain for biofuels does not currently support this (and is unlikely to do so in the medium term). A second solution, specific to coal-fired generators, is to increase flexibility for large generators by introducing a two-shift system, whereby generators do not run in a continuous, baseload manner. The objective of the two-shift system is to reduce start up and shut down times. The increased flexibility

217 Diarmaid Williams, “Vattenfall Lignite Sale Comes under EU State Aid Microscope,” Power Engineering International, 2016. 
of the two-shift system, namely the ability to cycle on and off at lower minimum capacities of $40 \%$, is seen as desirable as it requires minimal changes to hardware. ${ }^{218}$ Such an operating system has already been utilised by Drax, showing its effectiveness in practice. ${ }^{219}$

Wherever possible, utilities can continue to decommission older and less efficient assets, especially when they operate at negative margins. There are two types of mothballing: forced and voluntary. Forced mothballing occurs when regulators do not allow the complete shutdown of some plants to assure grid stability. These are typically older plants, which would otherwise be shut, but are retained to provide some back-up capacity. While most of the recently built, high-efficiency gas fleet has been mothballed, the cost of mothballing coal is usually very high (and even higher for lignite). ${ }^{220}$ Further, coal and lignite are not the best back-up technologies as they require several days', and even weeks', prior notice before they can go back online (depending on the depth of mothballing). Given the current overcapacity in many European markets (e.g. Germany) most utilities do not expect that any of this mothballed back-up capacity will be needed (or become profitable) again in the future. Hence, mothballing coal (in any depth) does not make economic sense, and utilities will continue to lobby for compensation payments wherever they are required to continue to operate these plants or keep the capacity available.

Whether utilities choose to voluntarily mothball their plants depends on the cost. As most lignite and hard coal plants are currently in the money, they should be operated from an economic point of view - thus mothballed coal is unlikely. The costs also depend heavily on the depth of mothballing and the required time for ramping up (e.g. are turbines dismantled). In addition, it depends on the location of the plant and its connection to the grid. Should mothballing be required, the costs of mothballing are in general highest for lignite, then coal. Fixed and capital costs for coal are very high and most of the cost of mothballing would come from ramping-down and then ramping-up again. Lignite capacity is even less likely to be mothballed, as the cost of mothballing is usually much higher than for hard-coal (usually lignite plants have their own mines). The situation for coal and lignite is unlikely to improve, so that - in the absence of policy constraints - any built coal generator would probably operate to the end of its useful life. But such constraints are being introduced across EU member states.

\subsection{New Business Models and Investment Strategies}

This section examines some of the business models and investment strategies available to EU electricity utilities. The first strategy is for wider adoption of RES generating technology, which Europe's major utilities have mostly refrained from undertaking. Figure 30 shows how renewables' penetration in Europe's major utilities has lagged renewables' penetration on the continent as a whole.

Many energy companies have divided their operations into renewables versus non-renewables and are looking to renewables to drive future growth. For example, RWE has created RWE Innogy - containing the renewables portfolio. State-owned Vattenfall plans to sell its loss-making German lignite coalmines and plants to EpH. ${ }^{221}$ The aim is to reduce the company's exposure to fossil fuels. E.ON formed Uniper to assume control of fossil fuel assets, while E.ON focuses on renewables and energy networks. Engie has reformed its business model to sell-off much of its non-renewable energy assets, mostly in exploration and production, and coal-fired power plants. Engie intends to increase investment in renewable energy and decentralised technology.

218 Jaquelin Cochran, Debra Lew, and Nikhil Kumar, "Flexible Coal: Evolution from Baseload to Peaking Plant" (Golden, Colorado, 2013).

219 Drax Group plc, "Annual Report and Accounts."

220 Caldecott and McDaniels, "Stranded Generation Assets: Implications for European Capacity Mechanisms, Energy Markets and Climate Policy."

221 Tino Andresen, Ladka Mortkowitz Bauerova, and Niklas Magnusson, “Sweden Clears Sale of Vattenfall's German Lignite Plants to EPH," Bloomberg, 2016. 
Figure 30: EU Utility Renewables Penetration ${ }^{222}$

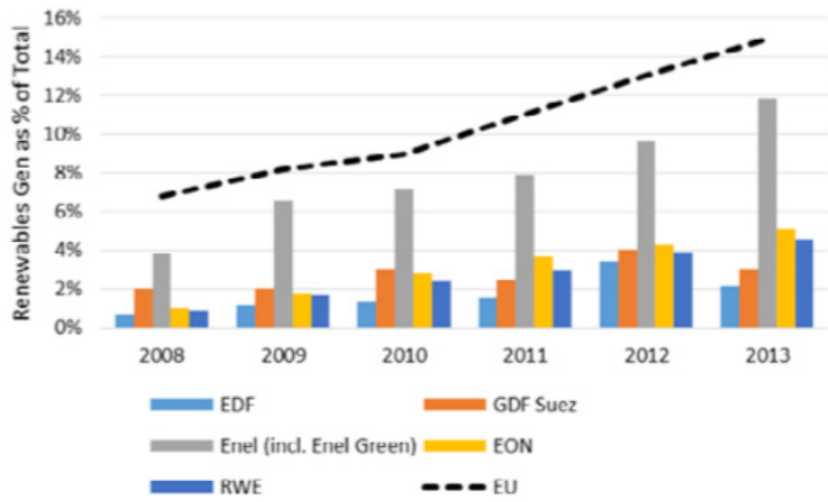

The creation of spin-off firms is designed to maximise income from the strong interest in low-carbon power generation. This also allows companies to seek regulated energy contracts (e.g. contracts-for-difference), as opposed to market-based contracts, to protect themselves against fluctuations in wholesale energy prices and further price declines.223 Arguably, the decision to sell conventional power plants is cheaper than keeping the plants open and winding up operations. ${ }^{224}$ Several large utilities have announced major splits of business units, see Box 1.

\section{Box 1: How to Split a Utility}

Three major European utilities have recently announced splits of their business units: E.ON, RWE, and CEZ.

- E.ON announced its intention in November 2014 to create a new company, called Uniper, which would take over its conventional power plants including gas, coal and nuclear. E.ON itself will refocus on renewables, transmission and distribution, and energy services. Once the split is complete in 2016 these companies will be completely independent; shareholders' shares will be split and they will be able to trade the companies independently.

- RWE announced their intention to spin off their renewables, grids and retail services at the end of 2015, with the intention to complete the operation at the end of 2016. The divisions will be packaged into a separate company which will be listed on the stock market through an initial public offering (IPO); RWE Group will retain 90\% ownership of the new entity. The group's stake may decline over time.

- CEZ, the Czech nuclear and coal utility, announced in the second half of 2015 that the management board will be split into two divisions, with separate targets and responsibilities. One group will focus on renewables, grids and energy services, while the other will maintain the conventional coal and nuclear operations.

Second, utilities can plan fewer conventional capacity investments in the future. In the current uncertain regulatory and market environment capital cost for investment projects increased significantly and as future

222 Matthew Gray, "Coal: Caught in the EU Utility Death Spiral," Carbon Tracker. Http://www. Carbontracker. Org/wpcontent/uploads/2015/06/CTI-EU-Utilities-Report-v6-080615. Pdf, 2015. Underlying data from Bloomberg and Eurostat. ${ }^{223}$ Michael Stothard, "Low European Power Prices Here to Stay, Says Utility CEO," Financial Times, 2016, http:/ / www.ft.com/cms/s/0/4bdf5a4e-1a84-11e6-8fa5-44094f6d9c46.html\#axzz4GBaZBbIv. 224 Andresen, Mortkowitz Bauerova, and Magnusson, "Sweden Clears Sale of Vattenfall's German Lignite Plants to EPH." 
capacity in Europe will most likely come from more capital-intensive forms of generation (wind, solar, nuclear, etc.) the internal rate of return of most capacity-adding projects do not meet hurdle rates.

Third, opportunities are emerging in investment in electricity transmission and distribution. Not only does existing infrastructure need renewal, but the rapid growth of renewables is adding new challenges and opportunities for balancing local grids and delivering electricity to consumers. The emergence of smart grid technologies, smart meters, and local contracting structures also offer new growth opportunities for incumbent utilities. ${ }^{225}$ Moreover, like refining and retailing in oil and gas, transmission and distribution investment offers a natural hedge against volatile commodity prices. This hedging property is driving transmission and distribution asset values in the EU.226

Fourth, power utilities can adapt the services they provide to end consumers. Retail, partnerships, and services are consumer-facing value segments which allow utilities to leverage their wide distribution relationships to generate further value. Even the most basic of value segments, electricity retailing, is becoming increasingly competitive. In the UK, for example, 13 new suppliers have entered the market since 2012 and the market share of major incumbent suppliers is slowly falling. ${ }^{227} \mathrm{New}$ suppliers compete to offer attractive billing and tariff structures, quality of services, and environmentally-sensitive procurement. Commercial partnerships can be formed to leverage wide customer bases and secure market share with loyalty and rewards programmes (e.g. with grocery chains, and banks).

Utilities must increasingly meet the demands of 'prosumers' - end users who both produce and consume electricity. These demands are made more sophisticated by the rise and penetration of new technologies: distributed generation, home automation systems, electric vehicles, home battery storage systems, dispatchable peak loads, and demand response systems. Commercial customers are demanding new service offerings, such as back-up generators to guarantee operations, combined heat-and-power plants, building automation, efficiency programmes, and energy performance contracting. 228,229 While these new value segments offer tremendous potential for growth, utilities will need to compete with both traditional energy service companies and new startup and technology company entrants for market share. ${ }^{230}$ Some utilities are launching venture capital units specifically to support the start-up environment for these technical and service innovations (e.g. Statkraft).231

\footnotetext{
${ }^{225}$ Harris Williams \& Co., "Transmission \& Distribution Infrastructure," 2014; McKinsey\&Company, "Beyond the Storm Value Growth in the EU Power Sector."

${ }^{226}$ EY, “Capital Outlook: Power and Utilities," December (2013).

227 Ofgem, "Wholesale Energy Markets in 2015."

228 IBM, "Transforming the Energy Value Chain," 2012; Cognizant, "Building a Thriving and Extended Utilities Value Chain," no. march (2013).

229 Ibid.

${ }^{230}$ McKinsey\&Company, "Beyond the Storm - Value Growth in the EU Power Sector."

231 Statkraft, "Statkraft Launches Venture Capital Unit to Partner with Dynamic Start-Ups," 2015.
} 


\section{Conclusion}

The principle aim of this report is to conduct a comprehensive analysis into the growth of coal-fired power generation in EU member states between 2005 and 2008. In 2005, total installed capacity in the EU stood at 777 GW and EU utilities were about to embark on a 65-coal-plant construction programme, adding $49 \mathrm{GW}$ of new coal-fired power capacity - about $6.3 \%$ of total EU installed capacity. Ultimately, only $10 \mathrm{GW}(<16.7 \%)$ of the planned capacity came online and most of the remaining coal-fired capacity was cancelled. The majority of proposed coal installations were located in Germany (>20 GW), the United Kingdom (>7 GW), the Netherlands $(>4 \mathrm{GW})$, and Poland (>3 GW).

Our report focuses on four key areas. First, we provide a EU power market overview studying the assumptions that drove the planned expansion of coal-fired generation. We outline stakeholders' assumptions in the pre-2008 period to understand what encouraged the widespread expansion of coal. We then examine how these assumptions changed in the period after 2008 and how they prevented the construction of the vast majority coalfired projects. Second, we pursue country-level case studies to understand local nuances and thus the reason why some member states (Germany, the Netherlands, and Poland) proceeded with building coal-fired generation, while another (the UK) cancelled all coal-fired power projects. Third, we examine the operational and financial performance of the power industry and 14 sample firms to understand the economics of coal-fired power generation over the target period. Finally, we discuss the prospects for coal-fired power generation in the EU over the short- and medium-term, and identify how growth, commodity, carbon, technological, and policy risk factors in the near-future impact investment decisions in the present.

\subsection{Discussion of Results}

\subsubsection{Which Plants Were Built and Why Others Were Cancelled}

Of the 65 coal-fired power plants planned between 2005-08, only 11 made it to market. Much of the built coal-fired power plants occurred in Germany, Poland, and the Netherlands. In Germany and Poland, coal-fired power generation retained competitiveness against gas-fired generation, despite coal being the emission intensive of the two fuels. Further, both countries had ample domestic coal reserves which could contribute to national energy security. Six of the built plants were located directly adjacent to local coal mines. Countries with large indigenous coal reserves, particularly lignite, were more likely to ultimately build coal capacity. The Netherlands is an exception, but has large volumes of coal that pass through its Rotterdam port.

The political environment of all three countries was conducive to building additional coal-fired power assets. The study showed that much of the coal-fired capacity which made it to market was considered 'clean coal'; especially in the Netherlands, which previously positioned itself as a nation which only built 'clean coal'. Moreover, the five new German and three new Dutch plants only burn less polluting bituminous coal. In addition, all the coal plants that were not cancelled utilised more efficient supercritical or ultra-supercritical generation technologies. By contrast, of the 53 coal plants that were cancelled, at least 11 had planned to use subcritical technology. ${ }^{232}$ Among those 11 subcritical plants 3 were in the UK. Poland ended up building only a single coal-fired plant, which burned lignite: a more polluting and $\mathrm{CO}_{2}$-intensive type of coal. With the exception of Westfalen power plant (820 MW) in Germany, all power plants now operating or planned have Flue Gas Desulphurisation (FGD), and even Westfalen was designed so that it can be FGD retrofitted at a later date. Therefore, it appears that plants which were bigger, from larger companies, and which were using less polluting fuel, and more efficient technology with pollution controls were the most likely to be built. Thus, the average capital costs and average operating and maintenance costs rose as more expensive technology came online, implying higher sunk costs, and higher risk of assets becoming stranded.

232 Data on combustion technologies is available for 31 of the 48 cancelled plants. 


\subsubsection{Role of Optimism Bias in Investment Decisions}

In the 2005 to 2008 period, market conditions were conducive to expanding coal-fired generation. The EU experienced increasing GDP growth (which was historically associated with increased energy demand), increase in forecast electricity demand and increase in required capacity. Simultaneously, despite high fuel costs, commodity markets forecast a decline in the cost of coal, natural gas, and oil prices in the following years, suggesting the fuel cost of thermal power generation would be cheaper in the near future. The cumulative impact of these changes may have created conditions of optimism bias, which encouraged many power utilities to propose an expansion of the coal-fired fleet to exploit beneficial market conditions. The expansion of coal was preferable as it was a 'trialled and tested' technology in the EU, and some EU member states had ample coalreserves to exploit. Utilities entered a period of significant sector liberalisation, with positive growth forecasts and relatively cheap debt, which encouraged capacity expansion, as well as a run of mergers and acquisitions among companies wishing to benefit from an ever-increasing market share of electricity generation.

Ultimately, the post-2008 period was defined by a decoupling of GDP and energy demand, lower electricity demand than forecast, and electricity overcapacity due to the expansion of various generating technologies. At the same time, the European electricity market was being challenged by a series of policy interventions addressing the risks of anthropogenic climate change. These policies increased operational and investment risk. Moreover, the expansion of RES capacity, incentivised by a range of policy incentives sheltering RES from risk exposure in the wholesale electricity market (e.g. feed-in-tariff), also impacted market mechanisms and resulted in underutilisation of existing coal-fired capacity. With such a dramatic shift in the operating environment, many of the planned coal-fired projects were cancelled. For some, the net present value of finalising and bringing these assets online to operate them for several years still seemed higher than the net present value of cancelling the projects in their current state and absorbing the sunk costs. Hence, mainly highly efficient (and co-generating) capacity went online, adding to the overcapacities in the European system.

\subsection{Key lessons}

Overall, we are probably close to the end of coal-fired generation in Europe even if the timeline of the phase-out is uncertain. Going forward, analysts expect further premature closures of coal assets as well as some 'forced' mothballing. However, the extent to which this will take place is very country specific and depends on regulations, market mechanisms, and technological advances.

\subsubsection{Coal Capacity Outlook}

The transition away from coal will likely result from policy and carbon pricing, which will have a critical impact on wholesale electricity prices. Between now and 2030, RES technology should become increasingly competitive with conventional thermal generation. While the share of intermittent generation in the system increases over time, baseload generators are likely to play a significant role in securing future energy supply during periods of excess demand or short supply. The use of coal in power generation is unlikely to increase, in particular because of a potential resurgence from natural gas in the near future. Any new coal capacity is expected to face early decommissioning because of both environmental legislation and the failure to compete against flexible generation in real-time energy markets, which will have significant impact on utilities' investment strategies. It is worth noting that the major challenges resulting from this prospect will be of both a social and economic nature.

\subsubsection{Compensation for Stranded Assets}

Compensation for stranded assets is controversial. Some may argue that the bankruptcy of a few utilities will be good for the market as inefficiencies, which may result from bad past decision-making, will be terminated. On the contrary, others may argue that the remaining capacity could lead to instabilities of the power system and therefore lead to the protection of utilities. Politicians may also try to protect some of the utilities, especially small municipally owned utilities. 
Besides the divergence of opinion, a major obstacle to compensation will be the difficulty in determining a fair value of remuneration for the plants which are being shut down, and the uncertainty around the impact of such compensations on investment decisions (e.g. new capacity decisions). As a result, compensation for asset stranding should be the result of a 'surgical' intervention and only affect some participants in the market.

\subsubsection{Policy Interventions}

The use of legislation should be predictable and affect the whole market in a fair fashion, e.g. a carbon tax, high carbon price, or emissions performance standard. The chosen approach should, in particular, allow increasing wholesale prices, reducing the costs of renewable subsidies, which have sheltered RES technology from competitive forces in the wholesale energy industry, and capacity mechanisms.

Whether a capacity mechanism to protect existing capacity is necessary depends on the country. In some countries, the shutdown of a portion of the coal capacity could lead to power grid outages, whereas in others it would simply remove some of the overcapacity existing in the grid. For new capacity, the optimal solution would be a marketbased solution (capacity market) with auctions and cross-border participation. The reason for this conclusion is that investment in power generating capacity needs periods of high power prices or full utilisation to be profitable. Capacity mechanisms address the issue of lower utilisation, at least until technologies such as demand-side management and battery storage begin to compete for capacity payments.

Whatever the mechanisms and tools used, it is critical to ensure that they are implemented consistently. For example, a capacity mechanism aims at keeping coal generation alive, while a carbon price floor aims at reducing coal use (e.g. in favour of gas).

\subsubsection{Optimal Capacity Mechanisms}

There are major concerns that energy markets with a large proportion of renewables will face a lack of adequate energy capacity to meet future energy demand at all times.233 In this context, an optimal capacity mechanism is necessary to incentivise investors to commit capital to invest in (or keep existing) capacity when and where it is needed. However, it raises several challenges. First, guidance should be put forward to harmonise the design of capacity payments across Europe. Second, the design of the capacity mechanism should be carefully examined to consider whether it covers existing capacity or only new capacity, and whether it is a technology neutral mechanism. Moreover, the design should also integrate the climate and emission objectives of the EU and its member states, as well as the risk of the regulator locking in more expensive existing technological solutions.

\subsection{Recommendations}

European utilities completely misjudged the prospects for new coal-fired generation and have since paid a significant price for this mistake. The subsequent write-downs, underperformance, and reductions to balance sheet capacity still weigh down the sector. Had more coal-fired plants reached completion, the negative impacts on the companies would have been even more significant. Utility executives may have anti-coal protestors to thank for successfully campaigning to reduce or stop expansions in some countries such as the UK - a small saving grace.

The implications for utilities and utility investors in jurisdictions where coal expansions are being considered are clear: in a sector experiencing significant technology, policy, and market innovation, optimism biases at a company-level and in terms of both company-level and sector-wide forecasting, are likely to yield significant stranded assets. These have long term implications for companies and their ability to successfully navigate the transition observed in power markets internationally. Utilities and utility investors considering new coal should guard against these optimism biases and consider them carefully.

233 ACER, "Capacity Remuneration Mechanisms and the Internal Market for Electricity of 30 July 2013 - pursuant to Article 11 of Regulation of (EC) No 713/2009." 
In Europe, the end of coal-fired generation is certain, even if the exact timeline of the phase-out is uncertain. Further premature closures of coal assets and 'forced' mothballing will occur. However, the extent to which this will take place is very country specific and depends on regulations, market mechanisms, and technological advances.

Through our analysis, we have identified a range of practical solutions for coal-fired utilities to minimise the risk of stranded coal-fired generation assets in the short- to medium-term. These can be universally applied:

1) Adapt current operations to the new environment by switching fuels (e.g. to biomass), or implementing a two-shift system to increase flexibility for large generators.

2) Analyse which plants within generation fleets can be decommissioned or mothballed and plan fewer conventional capacity investments. The former will give clarity and transparency to the options available to management if power prices continue to decline.

3) Consider and map out conflicts of interest between conventional power division and renewables, T\&D and energy services. If these are difficult to reconcile at a group level consider splitting, spinning off, or creating clearer divisional splits within the company.

4) Explore ways of leveraging the current asset base and proximity to end clients in developing new business models which could bring value to the business and the grid in times of higher price volatility. New demand-side management technologies, electric vehicle deployment, storage, and distributed energy to name a few are not only disruptive to the current energy architecture but also opportune to both incumbents and new market entrants.

5) Undertake an analysis of relevant disclosures to assess exposure to the long-term trends affecting the sector. This would ultimately minimise asset stranding and value destruction.

European policymakers will have to design the best ways to accelerate the phase-out of coal in order to secure power sector decarbonisation. We recommend that they: 234

6) Reform the EU ETS to address the chronic oversupply of carbon credits. Prices on the EU ETS should reflect the negative impact of coal and foster a switch away from using coal in the electricity mix.

7) Introduce emission performance standards.

8) Continue to strengthen the National Emissions Ceiling (NEC) Directive and the IED to align existing emissions with the ones displayed in the best available techniques reference document (BREF). Application of the best available techniques should be enforced to achieve the 7th Environment Action Programme's objectives.

Looking beyond Europe, we also strongly recommend that policymakers internationally:

9) End the public financing of coal projects, prevent the lifetime extension of coal power stations and move financial support towards the development of alternative technologies and energy savings.

10) Conduct structural market transformations to incentivise private investment in low carbon technologies.

11) Build new capacity in low carbon technologies to replace legacy conventional generation assets at the appropriate rate.

12) Recognise that some existing and new-built conventional generating technologies will require early decommissioning in the transition to a low-carbon energy grid.

234 Our set of recommendations is in line with the ones stated in the 2014 WWF report, "Europe's Dirty 30": http://www.wwf.de/fileadmin/fm-wwf/Publikationen-PDF/Studie-Dirty-Thirty-2014.pdf. 


\section{References}

ACER. "Annual Report on the Results of Monitoring the Internal Electricity and Natural Gas Markets in 2012." Brussels: Agency for the Cooperation of Energy Regulators, 2013.

- - - " "Capacity Remuneration Mechanisms and the Internal Market for Electricity of 30 July 2013 - pursuant to Article 11 of Regulation of (EC) No 713/2009." Agency for the Cooperation of European Regulators, 2013.

Agora Energiewende. “The German Energiewende and Its Climate Paradox," 2014.

Ahlstrom, M, E Ela, J Riesz, J O'Sullivan, B F Hobbs, M O'Malley, M Milligan, P Sotkiewicz, and J Caldwell. “The Evolution of the Market: Designing a Market for High Levels of Variable Generation." Power and Energy Magazine, IEEE, 2015. doi:10.1109/MPE.2015.2458755.

Andresen, Tino, Ladka Mortkowitz Bauerova, and Niklas Magnusson. "Sweden Clears Sale of Vattenfall's German Lignite Plants to EPH." Bloomberg, 2016.

Barteczko, Agnieszka. “Conoco the Last Global Oil Firm to Quit Polish Shale Gas.” Reuters, 2015.

Betts, Paul. “Gas Glut That Risks Spoiling Russia's Power Games.” Financial Times, 2009.

“BNEF New Energy Outlook,” 2016. doi:10.1017/CBO9781107415324.004.

BP plc. “BP Statistical Review of World Energy 2016,” 2016.

Bream, Rebecca, and Joshua Chaffin. “European Nuclear Industry in Grips of Revival." Financial Times, 2009.

Bundesregierung. "Energiekonzept Für Eine Umweltschonende, Zuverlässige Und Bezahlbare Energieversorgung," 2010. https://www.bundesregierung.de/ContentArchiv/DE/Archiv17/_Anlagen/2012/02/energiekonzeptfinal.pdf?_blob=publicationFile\&v=5.

Caldecott, Ben, Gerard Dericks, and James Mitchell. "Stranded Assets and Subcritical Coal: The Risk to Companies and Investors." Stranded Assets Programme, SSEE, University of Oxford, 2015, 1-78.

Caldecott, Ben, and Jeremy McDaniels. "Stranded Generation Assets: Implications for European Capacity Mechanisms, Energy Markets and Climate Policy." Stranded Assets Programme, SSEE, University of Oxford, 2014, 1-62.

Carbon Tracker. "Coal Occupying the London Stock Exchange," 2012. http:/ / assets.wwf.org.uk/downloads/coalcapitalbriefing.pdf.

- - - "Unburnable Carbon - Are the World's Financial Markets Carrying a Carbon Bubble?," 2014. http://www.carbontracker.org/wp-content/uploads/2014/09/Unburnable-Carbon-Full-rev2-1.pdf.

CEZ Group. “Annual Report 2015,” 2015.

CIRE. “President of PSE: We Have a Safe Power Reserves for 2016.,” 2016. 
Clark, Pilita. “Europe Sees Surge in Clean Power.” Financial Times, 2012.

- - -. "Renewable Energy Sector Runs the Risk of Overpowering the Market." Financial Times, 2015.

Clark, Pilita, Joshua Chaffin, and Javier Blas. “EU Carbon Prices Crash to Record Low." Financial Times, 2013.

Cochran, Jaquelin, Debra Lew, and Nikhil Kumar. "Flexible Coal: Evolution from Baseload to Peaking Plant." Golden, Colorado, 2013.

Cognizant. "Building a Thriving and Extended Utilities Value Chain," no. march (2013).

Competition \& Markets Authority. “Energy Market Investigation: Provisional Decision on Remedies," 2016.

Cornwall Energy. “Independent Suppliers Reach Record 7.5\% Share of Domestic Market,” 2014.

Crooks, Ed, and Mark Mulligan. “Two Hot Trends Coming Together." Financial Times, 2006.

Darby, Megan. "Poland to Back UN Climate Deal - If It Can Burn More Coal." Climate Home, 2016. http://www.climatechangenews.com/2016/09/06/ poland-to-back-un-climate-deal-if-it-can-burn-morecoal/.

Deane, J P, B P Ó Gallachóir, and E J McKeogh. “Techno-Economic Review of Existing and New Pumped Hydro Energy Storage Plant." Renewable and Sustainable Energy Reviews 14, no. 4 (May 2010): 1293-1302. doi:http://dx.doi.org/10.1016/j.rser.2009.11.015.

Delarue, Erik, Leonardo Meeus, Ronnie Belmans, William D’haeseleer, and Jean Michel Glachant. “Decarbonizing the European Electric Power Sector by 2050: A Tale of Three Studies.” EUI Working Papers, 2011, 1-14.

Department for Business, Energy \& Industrial Strategy. "Coal Generation in Britain. The Pathway to a LowCarbon Future: Consultation Document," 2016.

- - - ."UK Energy in Brief 2016," 2016.

Department of Energy amd Climate Change, UK Gov. “Electricity Generation Costs," 2012. https://www.gov.uk/government/uploads/system/uploads/attachment_data/file/65713/6883electricity-generation-costs.pdf.

Drax Group plc. “Annual Report and Accounts,” 2015.

Dzieciolowski, Krzysztof, and Maciek Hacaga. "Polish Coal at the Turning Point: Eneasy Past, Challenging Future." Journal of Energy Security, 2015.

E.ON. “Annual Report,” 2007.

Eikeland, Per Ove. "The Third Internal Energy Market Package: New Power Relations among Member States, EU Institutions and Non-State Actors?" JCMS: Journal of Common Market Studies 49, no. 2 (2011): 243-63. doi:10.1111/j.1468-5965.2010.02140.x.

Euracoal. “Germany,” 2016. 
Eurocoal. “POLAND." Eurocoal, 2016. https://euracoal.eu/info/country-profiles/poland/.

European Commission. “2030 Energy Strategy.” Europa, 2016. http://ec.europa.eu/energy/en/topics/energystrategy/2030-energy-strategy.

- - -. “Energy and Environment: State Aid to Secure Electricity Supplies." Europa, 2016.

- - - "Energy Economic Developments: Investment Perspectives in Electricity Markets." Report. Vol. 8014. Luxembourg: Publications office of the European Union, 2015. doi:10.2765/48569.

- - -. "Interim Report of the Sector Inquiry on Capacity Mechanisms," 2016.

- - -. "Launching the Public Consultation Process on a New Energy Market Design" COM(2015) (2015).

- - - "State Aid: Commission Clears Closure of Lignite-Fired Power Plants in Germany." Europa, 2016.

European Environment Agency. "Renewable Energy in Europe 2016: Recent Growth and Knock-on Effects." Copenhagen, 2016.

Eurostat. “Database - Eurostat,” 2016.

Evans, Simon. “A Detailed Look at Why UK Homes Are Using Less Energy.” Carbon Brief, June 2014.

EWEA. “Wind Energy Statistics and Targets.” The European Wind Energy Association, 2013.

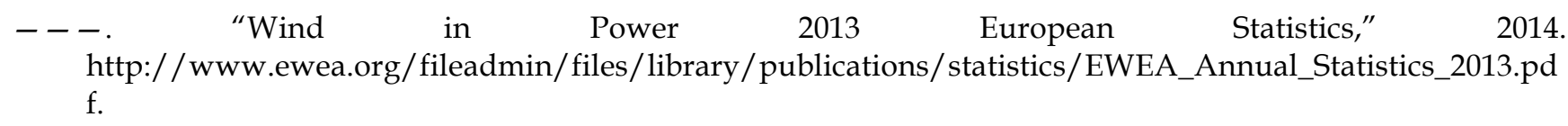

EY. “Capital Outlook: Power and Utilities,” no. December (2013).

Farley, Mike. “Generation Gap and Clean Coal's Vital Role.” Financial Times, 2007.

Fraunhofer Institut for Solar Energy Systems ISE. “Levelized Cost of Electricity Renewable Energy Technologies," 2013. https://www.ise.fraunhofer.de/en/publications/veroeffentlichungen-pdf-dateien-en/studien-undkonzeptpapiere/study-levelized-cost-of-electricity-renewable-energies.pdf.

FTI-CL Energy. "Towards the Target Model 2.0: Policy Recommendations for a Sustainable EU Power Market Design." Paris: FTI-CL Energy, 2015.

Global CCS Institute. "Moving CCS Forward in Europe," 2013.

Gray, Matthew. "Coal: Caught in the EU Utility Death Spiral." Carbon Tracker. Http://www. Carbontracker. Org/wpcontent/uploads/2015/06/CTI-EU-Utilities-Report-v6-080615. Pdf, 2015.

Green, Richard, and Nicholas Vasilakos. "Market Behaviour with Large Amounts of Intermittent Generation." Energy Policy 38, no. 7 (July 2010): 3211-20. doi:http:/ / dx.doi.org/10.1016/j.enpol.2009.07.038.

Harrison, Pete. “UK and Poland Top Dirty Coal List, Closures Loom.” Rueters, 2009. 
Harvey, Fiona. “Carbon Permits Reach Record Prices.” Financial Times, 2006.

- - - . "Power Groups in the Dark over Auction Plan." Financial Times, 2007.

Hirth, Lion. “The Market Value of Variable Renewables," 2013. doi:10.1016/j.eneco.2013.02.004.Previous.

Hollinger, Peggy. “Gazprom Threat Adds to Fear on EU Supply.” Financial Times, 2006.

House of Commons Energy and Climate Change Committee. “The Future of CCS in the UK," 2016.

IBM. “Transforming the Energy Value Chain,” 2012.

IEA. “CO2 Emissions from Fuel Combustion," 2011. https://www.iea.org/media/statistics/CO2highlights.pdf.

- - - .Energy Policies of IEA Countries: The Netherlands 2014 Review.” Paris, 2014.

- - -. "WEO- Investment Costs." International Energy Agency, 2016.

- - -."World Energy Outlook 2013," 2013. http:/ /www.worldenergyoutlook.org/weo2013/.

International Energy Agency (IEA). “Energy Policies of IEA Countries: The United Kingdom 2012 Review," 2012. https://www.iea.org/publications/freepublications/publication/UK2012_free.pdf.

- - -. “Oil Market Report 2006,” 2006.

- - -."World Energy Outlook 2010," 2010.

International Monetary Fund. "World Economic Outlook, October 2008." World Economic and Financial Surveys, 2008.

IRENA. “The Power to Change: Solar and Wind Cost Reduction Potential to 2025.” Bonn, Germany, 2016.

Jamasb, Tooraj, and Michael Pollitt. “Electricity Market Reform in the European Union: Review of Progress toward Liberalization \& Integration." The Energy Journal 26 (2005): 11-41. doi:10.2307/23297005.

Joseph Salvatore. "World Energy Perspective - Cost of Energy Technologies." World Energy Council, 2013. doi:ISBN: 9780946121304.

Kowalski, Kathiann M. "In Poland, Efforts to Rescue Coal Industry Will Likely Come up Short." Midwest Energy News, 2016. http://midwestenergynews.com/2016/07/12/in-poland-efforts-to-rescue-coal-industry-willlikely-come-up-short/.

Kucera, Jakub. “The German Conundrum: Renewables Break Records, Coal Refuses to Go Away." Energypost, 2016. http://www.energypost.eu/german-conundrum-renewables-break-records-coal-refuses-go-away/.

Lupion, Monica, and Howard J. Herzog. "NER300: Lessons Learnt in Attempting to Secure CCS Projects in Europe." International Journal of Greenhouse Gas Control 19, no. 2013 (2013): 19-25. doi:10.1016/j.ijggc.2013.08.009.

McKinsey\&Company. "Beyond the Storm - Value Growth in the EU Power Sector," 2014. 
Meulemeester, Benedict De. “Capacity Payments: Expensive Solution for a Non-Existing Problem.” EnergyPost.eu, 2014.

MiT. “Cancelled and Inactive Projects.” Carbon Capture $\mathcal{E}$ Sequestration $\mathcal{E}$ MiT, n.d.

Morris, Harvey. “Ukraine 'Confident' of Gas Flow to the EU.” Financial Times, 2009.

Narayan, Paresh Kumar, and Arti Prasad. "Electricity Consumption-real GDP Causality Nexus: Evidence from a Bootstrapped Causality Test for 30 OECD Countries." Energy Policy 36, no. 2 (February 2008): 910-18. doi:http://dx.doi.org/10.1016/j.enpol.2007.10.017.

Narayan, Paresh Kumar, and Russell Smyth. “Multivariate Granger Causality between Electricity Consumption, Exports and GDP: Evidence from a Panel of Middle Eastern Countries." Energy Policy 37, no. 1 (2009): 229_ 36. doi:10.1016/j.enpol.2008.08.020.

Nature Energy. “A World in Transition.” Nature Energy 1 (January 2016): 1.

Nelsen, Arthur. “Dutch Parliament Votes to Close down Country's Coal Industry.” The Guardian, September 2016.

Newbery, David. "Missing Money and Missing Markets: Reliability, Capacity Auctions and Interconnectors." Energy Policy, 2015. doi:10.1016/j.enpol.2015.10.028.

Newbery, David M. “Towards a Green Energy Economy? The EU Energy Union's Transition to a Low-Carbon Zero Subsidy Electricity System - Lessons from the UK's Electricity Market Reform." Applied Energy, 2016. doi:10.1016/j.apenergy.2016.01.046.

“Nuclear Pays Its Way.” Financial Times, 2006.

Ofgem. “Wholesale Energy Markets in 2015.” London, 2015.

Ottery, Christine. "What Would the Cost of a New Push for Coal in Poland Be?" EU Energydesk, 2014. http://www.greenpeace.org.uk/newsdesk/energy/data/what-would-cost-new-push-coal-poland-be.

Parker, George; Laitner; Sarah, and Thomas Catan. "Lights out? How Europe Is Trying to Fix a Power Failure.” Financial Times, 2006.

Patel, Tara. “Fracking in Europe.” Bloomberg, 2015.

Pfeifer, Sylvia. “Cost Advantage Fuels Demand for Coal.” Financial Times, 2012.

- - - "Fukushima Fallout: Renaissance in Nuclear Power Generation Now a Long Way off." Financial Times, 2011.

- - - “Utilities Grapple with Renewables Surge.” Financial Times, 2013.

Pfeifer, Sylvia, Pilita Clark, and Ed Crooks. “Critics Try to Stifle Shale Gas Revolution.” Financial Times, 2011.

Rachman, Gideon. “Shale Gas Will Change the World.” Financial Times, 2010.

“Real GDP Growth Rate - Volume.” Eurostat, 2016. 
Riesz, Jenny, and Michael Milligan. "Designing Electricity Markets for a High Penetration of Variable Renewables." Wiley Interdisciplinary Reviews: Energy and Environment 4, no. 3 (2015): 279-89. doi:10.1002/wene.137.

Robert Wilson. “Why Germany's Nuclear Phase Out Is Leading to More Coal Burning." The Energy Collective, 2014. http://www.theenergycollective.com/robertwilson190/328841/why-germanys-nuclear-phase-outleading-more-coal-burning.

Roberta Pierfederici. "Energy Transition Strategies in High Coal Consuming Countries." IDDRI, 2016. http:/ / www.blog-iddri.org/en/2016/03/23/energy-transition-strategies-in-high-coal-consumingcountries-a-case-study-for-china-and-poland/.

Robinson, David. "The Scissors Effect - How Structural Trends and Government Intervention Are Damaging the Major European Electricity Companies and Affecting Consumers." The Oxford Institute for Energy Studies Paper EL, no. 14 (2015): 1-37.

Robinson, Duncan, and Pilita Clark. "Hague Court Orders Cuts in Dutch Carbon Emissions." Financial Times. June 2015.

RWE. “Annual Report.” Essen, 2007.

Rynek Energii Elektrycznej. “Built and Planned Power Plants,” 2016.

Sawin, Janet L., Kristin Seyboth, Freyr Sverrisson, Fabiani Appavou, Adam Brown, Bärbel Epp, Anna Leidreiter, et al. "REN21 2016 Global Status Report," 2016.

Sentance, Andrew. “Services Rescue UK Economy from Worsening Downturn.” The Telegraph, April 2016.

Shiu, Alice, and Pun-Lee Lam. "Electricity Consumption and Economic Growth in China." Energy Policy 32, no. 1 (2004): 47-54. doi:10.1016/S0301-4215(02)00250-1.

Söderholm, Patrik. "Fossil Fuel Flexibility in West European Power Generation and the Impact of System Load Factors." Energy Economics 23, no. 1 (2001): 77-97. doi:http:// dx.doi.org/10.1016/S0140-9883(00)00062-1.

Sören Amelang. “'Time Is Running Out' - Struggle over Future of Brown Coal in Germany Heats up." Clean Energy Wire, 2015. https://www.cleanenergywire.org/news/time-running-out-struggle-over-future-brown-coalgermany-heats.

Statkraft. “Statkraft Launches Venture Capital Unit to Partner with Dynamic Start-Ups,” 2015.

Stevens, Paul. “Shale Gas in the United Kingdom,” 2013.

Stothard, Michael. “Low European Power Prices Here to Stay, Says Utility CEO.” The Financial Times. 2016.

Studies, Warsaw Institute for Economic. "Subsidising the Past: How Public Aid and Ignoring External Costs Keep Poland's Coal-Based Energy System Alive," 2014. http://www.greenpeace.org/eu-unit/Global/euunit/reports-briefings/2014/20140408 Warsaw Institute for Economic Studies coal financial aid briefing.pdf.

The Economist. “Europe's Coming Merger Boom.” The Economist, 2005. 
_ - - . "How to Lose Half a Trillion Euros." The Economist, 2013.

The Economist Intellegence Unit. “Coal's Last Gasp in Europe.” The Economist, July 2014.

The Federal Network Agency. “Report: Monitoring Report 2015,” 2015.

The Guardian. "Coal Electricity Generation Falls to Record UK Low This Spring." The Guardian, September 2016.

Tulloch, Daniel J, Ivan Diaz-Rainey, and I.M. Premachandra. “The Impact of Liberalization and Environmental Policy on the Financial Returns of European Energy Utilities." The Energy Journal 38, no. 2 (2017): 77-106. doi:http://dx.doi.org/10.5547/01956574.38.2.dtul.

Tulloch, Daniel J., and Ben Caldecott. "Current and Future Challenges Facing the European Union's Energy System." USAEE Working Paper No. 16-261, 2016, 1-30.

Tulloch, Daniel James. “The Impact of Risk Factors and Regulatory Change in the Returns of European Energy Utilities." University of Otago, 2016.

UK Governent. “Large Combustion Plant Directive (LCPD): Running Hours during Winter 2014/15 and Capacity for 2015/16," 2016.

Vasagar, Jeevan. “Germany Cautions on Impact of Renewables.” Financial Times, 2014.

Weismann, Gerrit. “Nuclear Phaseout: Germany Faces 'Herculean' Task to Move to Renewables." Financial Times, 2011.

Williams, Diarmaid. "Vattenfall Lignite Sale Comes under EU State Aid Microscope." Power Engineering International, 2016.

Williams, Harris, A Harris Williams, Co White Paper, and Harris Williams. "Transmission \& Distribution Infrastructure," 2014.

Wna. “Plans for New Nuclear Reactors Worldwide." World Nuclear Association, 2013.

WWF. “Europe's Dirty 30:," 2014. http://www.wwf.de/fileadmin/fm-wwf/Publikationen-PDF/Studie-DirtyThirty-2014.pdf. 


\section{SUSTAINABLE FINANCE}

PROGRAMME

Smith School of Enterprise and the Environment

University of Oxford

South Parks Road

Oxford, OX1 30Y

United Kingdom

E enquiries@smithschool.ox.ac.uk

T +44 (0)1865 614942

$F+44(0) 1865614960$

www.smithschool.ox.ac.uk/research/stranded-assets/ 